\title{
V Die Senatsaristokratie zwischen Heermeister und Kaiserhof
}

Die erste Hälfte des 5. Jhs ist weniger die Zeit der römischen Kaiser als die des vir inlustris comes et magister utriusque militiae et patricius ${ }^{1}$. Denn an diesen knüpften sich die Geschicke des Westens maßgeblich. So tritt der Kaiser in den Schatten seiner Heermeister. Die auf uns gekommenen literarischen Quellen tragen dem insofern Rechnung, als sie an der Person des magister militum stets größeres Interesse hatten als an der des Kaisers. Bis ins 19. Jh. fand dies seine Entsprechung in Kunst und Literatur. Hier sei nur an Felix Dahns Stilicho oder Verdis Ezio zu denken. Das vorangegangene Kapitel mag dies ein wenig relativiert haben, doch sollte dies nicht zu einer Verkehrung der Tatsachen führen. Während der Kaiser nach wie vor die Herrschaft innehatte, ,usurpierten' die Heermeister die Regierungsgewalt, so dass unter den Nachfolgern des ,großen` Theodosius ein persönliches Regime des Kaisers, welches Regierung und Herrschaft vereinen konnte, nicht mehr existent war.

Fl. Stilicho (495-408), Fl. Constantius (411-421) und Fl. Aëtius (430 - 454) gelang es über Jahre und Jahrzehnte, die Position des ,starken Manns' hinter - oder besser neben dem Kaiser ${ }^{2} \mathrm{zu}$ behaupten. Einen fast schon unübersichtlichen Umfang hat die Forschungsliteratur mittlerweile angenommen, wobei vor allem mit Lütkenhaus (1998) und Stickler (2002) vorbildliche Arbeiten zu den Heermeistern Constantius und Aëtius vorliegen. Dennoch ist es gerade für die hier vorliegende Darstellung notwendig, abermals den Blick auf die Heermeister zu lenken. Als bedeutendster machtpolitisch relevanter Akteur stellte der magister militum die entscheidende Zentralgestalt auch für die stadtrömische Senatsaristokratie dar. Als vir inlustris fand dieser Aufnahme in den ordo senatorius. Damit war er auch verpflichtet, den Erwartungen der senatorischen Standesgenossen zu entsprechen. So soll im Folgenden der Blick auf das Verhältnis zwischen dem magister militum und der stadtrömischen Senatsaristokratie gerichtet werden und danach gefragt werden, inwiefern der Senat und die senatorischen Häuser Roms mit diesem zusammenarbeiteten und sich für die Pläne der Heermeister politisch einspannen ließen.

\subsection{Stilicho und die politische ,Renaissance‘ des Senats}

Die erste ausführliche Behandlung erfuhr Stilicho durch Mazzarino und NischerFalkenhof, in dessen Werk einleitend zu lesen ist: „Aus allen diesen kleinen Geistern ragt turmhoch die wuchtige Gestalt des magister militum - des Heermeisters - Stili-

1 Die vollständige Titulatur tritt erst bei Fl. Constantius und Aëtius auf (Fast. Merseb. s. a. 435 und vollständig Nov. Val. 17 a. 445); Stilicho hingegen führte nur den Titel comes et magister utriusque militiae praesentalis. Vgl. ENSSLIN (1930) 306-325 und ders. (1931) 467-502.

2 So die treffende Bezeichnung nach STICKLER (2002) 64; ferner KUHOFF (2012) 39-80, hier 65.

Ә OpenAccess. () 2021 Hendrik A. Wagner, publiziert von De Gruyter. (cc) BY-NC-ND Dieses Werk ist lizenziert unter der Creative Commons Attribution-NonCommercial-NoDerivatives 4.0 International Lizenz. 
cho, dem seine Zeit keinen ebenbürtigen Gegenspieler entgegenzustellen hatte. “3. Und in der Tat ist kaum zu leugnen, dass Stilicho für den Zeitraum von 394 bis 408 die Zentralgestalt der weströmischen Geschichte darstellt. Das Regime des Stilicho war aber nicht unangefochten. Nicht nur in Konstantinopel, sondern auch am westlichen Hof, im Heer und unter der stadtrömischen Senatsaristokratie erhoben sich Stimmen, die gegen die Person und die beanspruchte Machtstellung des Heermeisters gerichtet waren. ${ }^{4}$ Anlass hierzu bot vor allem, dass Stilichos Machtfülle ${ }^{5}$ in keiner Relation zu den Befugnissen seines offiziellen Amts stand und sich ebenso wenig durch die bis dato erlangten Würden ${ }^{6}$ rechtfertigen ließ. So lässt sich an zahlreichen Stellen in den Werken Claudians das Bemühen erkennen, die extraordinäre Position Stilichos durch ein rechtlich wie moralisch unanfechtbares Fundament zu stützen. Dies wurde für Claudian zu einer fast zehn Jahre währenden Obsession, die ihn im Bewusstsein der Nachwelt zum unermüdlichen Sprachrohr der stilichonischen Propaganda ${ }^{7}$ werden ließ.

Das schiefe Bild, den spätantiken ,Generalissimus' mit den modernen Vertretern dieser Branche zu vergleichen, ${ }^{8}$ hat dazu geführt, das Regime des Stilicho als eine mit der Zivilverwaltung, und damit auch der Senatsaristokratie, konkurrierende Militärjunta9 aufzufassen. Die Annahme einer streng dichotomen Administration bzw. Reichselite, gespalten in einen zivilen und einen militärischen Sektor, ${ }^{10}$ stellt jedoch eine zu drastische Simplifizierung dar, die den doch um einiges komplexeren Verhält-

\section{NISCHER-FALKENHOF (1947) 19.}

4 Dies legt vor allem die fortwährende Verteidigung der Stellung des Stilicho durch Claudian nahe. Vgl. SCHINDLER (2015) 19-42, bes. 34-41. Zu den späteren Kritikern zählen Hieronymus und aus dem Kreis der Senatsaristokratie Rutilius Namatianus. Vgl. Kap. 6.2.

5 Hierzu vgl. u. a. BÖRM (2013) 45-48; ANDERS (2010) 62f.; STICKLER (2002) 17 f. u. 308; LÜTKENHAUS (1998) 7 f. u. 13f. oder GIZEWSKI (1997) 113-150, bes. 131f. Entscheidend war die Kontrolle über den Kaiser und den Zugang zu ihm, die durch ein besonderes Vertrauensverhältnis aufrechterhalten wurde. Der informelle Titel des parens principum bezeugt öffentlich das besondere verwandtschaftliche und nahe Verhältnis zum Kaiser und der theodosianischen Dynastie. Vgl. ANDERS (2010) 130 f.; MACGEORGE (2002) 200 und ausführlich STRAUB (ND 1972a) 220 - 239; zur informellen Macht vgl. auch SCHLINKERT (1996a) $254 \mathrm{f}$.

6 So hatte Stilicho bis 400 nicht einmal das Konsulat bekleidet und war damit in der Rangfolge formal den amtierenden und gewesenen Konsuln nachgeordnet; so auch dem Fl. Rufinus, der bereits 392 das Konsulat innehatte. Gerade dies mochte es auch erzwungen haben, das Konsulat des Eutropius 399 nicht anzuerkennen, da dieser damit dauerhaft aufgrund der früher erlangten Würde (Amtsalter) und des Patriziustitels (seit 398) in der Rangfolge vor Stilicho gestellt worden wäre. Erst 405 überragte Stilicho mit der zweifachen Konsulwürde alle übrigen Amts- und Würdenträger des Reichs.

7 Vgl. u. a. COOMBE (2018) 30-32; WARE (2012); GRUZELIER (1990) 299-318; SCHMIDT (1976) und i. B. CAMERON (1970); ferner auch CHRISTIANSEN (1969).

8 Vgl. ZIMMERMANN (1997) 165-173, bes. 165-169.

9 So u. a. WOLFRAM (1979) 1-28, hier 13; nachfolgend ders. (1990) 286. Die Konkurrenz zwischen Senatsaristokratie und Militär unterstreicht auch DEMANDT (2013a) 52-84 [1980]. Gegen ein zu schematisches Bild trat zuletzt auch REBENICH (2008) 161 ein.

10 Vgl. KREUTZ (2008) 194; DEMANDT 2(2007) 292f.; MARTIN 2(1990) 181; ausführlicher JONES (1964) 43-46 oder BAYNES (1925) 195-208. 


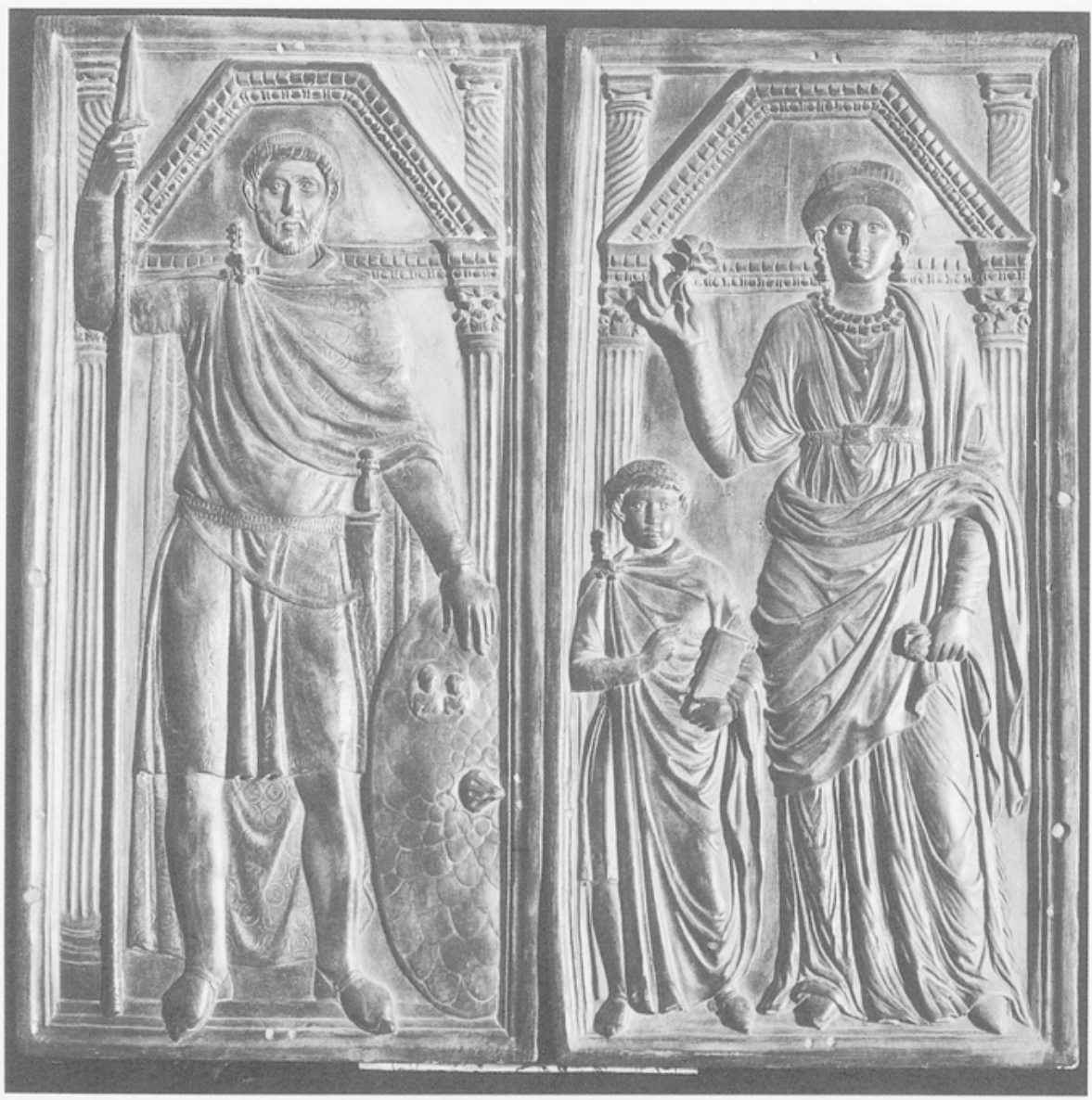

Abb. 3: Diptychon im Domschatz von Monza.

nissen nur unzureichend gerecht wird. Der exzellente Sprachstil und die hohe Gelehrsamkeit, die der claudianischen Dichtung inhärent sind, belegen, dass die Worte, die Stilicho in höchsten Tönen priesen, in erster Linie auf das Wohlgefallen und den Zuspruch der hoch gebildeten Führungseliten, unter welchen die stadtrömische Senatsaristokratie einen besonderen Platz einnahm, abzielten. Mit der Stimme Claudians versuchte Stilicho die stadtrömische Senatsaristokratie für sich zu vereinnahmen. Stilicho war hierbei bestrebt, in seiner Person die militärischen und zivilen Eliten zusammenzuführen. 
Das berühmte Diptychon von Monza (Abb. 3) ${ }^{11}$, welches immer wieder mit dem Namen Stilichos, dessen Gemahlin Serena und des Sohns Eucherius in Verbindung gebracht wurde, ${ }^{12}$ veranschaulicht sehr gut die Verortung des Heermeisteramts zwischen der zivilen und der militärischen Elite. ${ }^{13}$ So finden beide Sphären ihre Entsprechung jeweils auf einer der beiden Elfenbeintafeln des Diptychons, welche zusammen ein „idealtypisches Familienbild“ ${ }^{14}$ wiedergeben. Die linke Tafel (3.1) zeigt einen hohen militärischen Amtsträger, der entweder als magister militum oder comes domesticorum ${ }^{15}$ $\mathrm{zu}$ benennen ist. In einer reich ornamentierten chlamys, die von einer kostbaren Zwiebelknopffibel ${ }^{16}$ an der rechten Schulter über einer gleichermaßen kunstvoll verzierten, mit cingulum militare, bracae und campagi militares kombinierten langärmligen tunica zusammengehalten wird, präsentiert sich ein hoher Militär. Mit der hoch erhobenen Rechten umfasst er den Speer, während seine Linke auf dem angelehnten Schild, auf welchem in einem kleinen Medaillon die Büsten der Augusti ${ }^{17}$ abgebildet sind, ruht. Sein Antlitz gibt mit der schmalen Gesichtsform, der kantigen Wangenpartie, den Stirnfalten und dem kurzen, aber fülligen „Soldatenbart“ einen Mann von fortgeschrittenen Lebensjahren zu erkennen. Die mit einer leichten Welle in die Stirn gekämmte Haartracht entspricht dem Zeitgeschmack der ersten Hälfte des 5. Jhs. und findet sich so auch auf dem Halberstädter Diptychon ${ }^{18}$ wieder. In allen Belangen prä-

11 Abbildung nach KINNEY (2008) Fig. 5. Katalogisiert in DELBRUECK (1929) Nr. 63, Taf. 63 und VOLBACH 2(1952) Nr. 63, Taf. 19.

12 So u. a. MEISCHNER (1996) 389-432, hier 398f.; KIILERICH/TORP (1989) 319; CONTI (1983) Nr. 6; VOLBACH ${ }^{2}(1952)$ 42; DELBRUECK (1929) 242-248; zurückgehend bis auf JULLIAN (1882) 5-35. Das Diptychon von Monza firmiert so auch unter der Bezeichnung „Stilicho-Diptychon“. Vgl. aktuell CHRIST (2015) 173-190; den älteren Forschungsstand referieren CAMERON (2016a) 514-516 und VON RUMMEL (2007) $208 \mathrm{f}$.

13 Bereits VON RUMMEL (2007) 212 spricht von einem ,dualistischen Kontrast zur Ausrüstung der zivilen Eliten“ (i. B. die toga). Vgl. auch ROLLÉ DITZLER (2020) 343: domi et militiae, was aber keineswegs so singulär ist, wie hier ROLLÉ DITZLER meint; vgl. WARLAND (1994) 175-202.

14 Vgl. DECKERS (1996) 137-184, hier 164f. kritisch gegenüber WARLAND (1994) 175-202 mit der Diskussion zahlreicher Vergleichsstücke (u. a. Grabkammer von Silivri Kapı in Istanbul und Glasschnitt nach Cod. Vat. 9136 fol. 217a); nachfolgend WARLAND (2009) 98.

15 Mit diesem Amt lässt sich insbesondere der Schild mit der Abbildung der zwei Augusti verbinden, der so auch in der Not. Dig. or. 15 und occ. 18 den comes domesticorum ausweist. Vgl. WARLAND (1994) 175202, hier. 183. Dies stellt aber nur eine vage Vermutung dar und schließt keinesfalls das Amt des magister militum aus, wie dies WARLAND meint.

16 Typ Keller 6 = KELLER (1971) 52. Vgl. THEUNE-GROSSKOPF (1995) 96f.; DEPPERT-LIPPITZ (1995) 116f.; KIILERICH/TORP (1989) 330-338. Eine solche Fibel befand sich so auch im Grab des Frankenkönig Childerich in Tournai. Entgegen der älteren Forschungsmeinung, die vor allem die zahlreichen Belege im Kontext, germanischer' Grablegen vor Augen hatte, wird es sich bei der Zwiebelknopffibel Typ Keller 6 um eine römische Fabrikation handeln und demzufolge als römisch und nicht ,barbarisch anzusehen sein. Vgl. VON RUMMEL (2007) 210f. und HARDT (2004) $80 \mathrm{f}$.

17 Vgl. KILLERICH/TORP (1989) 353-357.

18 Katalogisiert DELBRUECK (1929) Nr. 2 und VOLBACH ${ }^{2}(1952)$ Nr. 35. Vgl. Kap. 5.2. 
sentiert sich hier ein hoher römischer Offizier, der durchaus Stilicho ${ }^{19}$ darstellen könnte. Barbarismen, wie sie immer wieder im Hinblick auf die Tracht und die Bewaffnung unterstellt wurden, sucht man hier wohl vergebens. ${ }^{20}$

Entsprechend gibt sich auf der rechten Tafel (3.2) ${ }^{21}$ ein hocharistokratischer Hausstand zu erkennen, welchem der Offizier angehörte. Eine edle Dame in gegürteter tunica und langärmliger dalmatica, über welche locker umschwungen eine palla getragen wird, präsentiert sich in anmutiger Pose. Eine Doppelperlenkette und kostbare Ohrringe zeigen den Wohlstand ihres Hauses. Die graziös erhobene rechte Hand hält eine Rose ${ }^{22}$ empor, welche Anmut und Fruchtbarkeit symbolisiert. Die Linke hält ein Tuch, das wie die Blüte ein häufig anzutreffendes Attribut der hochgestellten Frauen darstellt. ${ }^{23}$ Mit der rundlich gedrungenen Kopfform und dem überproportional langen Hals ähnelt das Antlitz der Dame dem der auf der Rothschild-Kameo ${ }^{24}$ abgebildeten Tochter des Stilicho. ${ }^{25}$ Deutlich ausgeprägter zeigt sich bei der Dame auf dem Diptychon von Monza die wulstige Stirntour. Die Ohren bleiben hier frei, während die hintere Haarpartie von einem Haarnetz, welches wohl in Gold zu denken ist, zusammengehalten wird..$^{26}$ Die Haartracht und der Haarschmuck sprechen für eine Dame des Kai-

19 Da eine Beschriftung fehlt, wird die Zuweisung an Stilicho letztlich aber immer nur hypothetisch erfolgen können; so u. a. auch VON RUMMEL (2007) 209f.; WARLAND (1994) oder SHELTON (1982). 20 Vgl. VON RUMMEL (2007) $210 \mathrm{f}$.

21 Die Anordnung der beiden Tafeln wird immer wieder vertauscht; so auch von CHRIST (2015) 173-188, Fig. 12.1; VON RUMMEL (2007) 207 oder VOLBACH 2(1952) Nr. 63, Taf. 19; bereits DELBRUECK (1929) 243 hatte anhand der konvexen Biegung der Längsseiten erkannt, dass die Anordnung der Personen im aufgeklappten Zustand Offizier (Taf. 1.) - Knabe - Dame (Taf. 2) entsprechen müsste; besonders WARLAND (2009) 98 und ders. (1994) 177 betonte wiederholt, dass es für die Beurteilung des Diptychons entscheidend ist, die ursprüngliche Anordnung der Tafeln zu berücksichtigen; dem entspricht KIILERICH/TORP (1989) 321. In der Leserichtung von links nach rechts hat der Offizier den Vorrang vor dem Knaben und der Dame (nach westlicher Tradition); jedoch im zugeklappten Zustand befindet er sich auf der Rückseite. WARLAND (1994) 183 hat durchaus recht, wenn er vermerkt: „Nichts verpflichtet noch den Knaben als Hauptperson des Monzadiptychons anzusehen.“; zur Anordnung, nach welcher im Westen der linken Seite der Vorrang eingeräumt wird, vgl. ENGEMANN (1999) 158-168, bes. 159f.; ausführlich ders. (1998) 109-130 und DELBRUECK (1929) 16.

22 Dieses Attribut ist so z. B. auch der Dame auf dem Dominus-Julius-Mosaik (unteres Register) und der Domina in der Grabmalerei von Silistra beigefügt; für weitere Beispiele, auch hinsichtlich der VenusKonnotation, vgl. WARLAND (1994) 184 u. 190. KIILERICH/TORP (1989) 363 bringen dies expliziert mit Claud. Nupt. Hon. 247 in Verbindung, wonach Serena und ihre Tochter Maria als „zwei Rosen von Pestum an einem Stiel“ gerühmt werden; zu Maria und der Eheverbindung mit Honorius vgl. jetzt auch DOYLE (2019) $124-128$.

23 So z. B. auch auf dem Glasschnitt nach Cod. Vat. 9136 fol. 217a. Vgl. WARLAND (1994) 179f. mit Abb. 2. 24 Sammlung Rothschild, Ville de Paris; katalogisiert DELBRUECK (1933) 206f. mit Abb. 70, Taf. 105 und ders. (1929) Nr. 66.

25 Vgl. MEISCHNER (1993) 613-619.

26 Das Haarnetz mit Gold- und Perlenbesatz bzw. die geschlossene Kappe wird vor allem in der zweiten Hälfte des 5. Jhs. und im 6. Jh. zu einem festen Bestandteil der Staatsfrisur kaiserlicher Damen. Vgl. DELBRUECK (1933) 52. Das Haarnetz wurde so auch, wie dies die Münzbilder zu erkennen geben, von Aelia Flaccilla († 386), Aelia Eudoxia († 404), Aelia Galla Placidia († 450), Aelia Pulcheria († 453), Aelia Eudocia Athenaïs († 460) und Licinia Eudoxia († 462) getragen. Noch Kaiserin Aelia Ariadne († 515), 
serhauses. Der Vergleich mit der Rothschild-Kameo stützt die Annahme, hier Serena zu erkennen. Der Dame zur Rechten beigeordnet steht der Sohn, welcher angeglichen an das militärische Amtskleid seines Vaters chlamys und tunica kombiniert mit bracae und campagi trägt. ${ }^{27}$ Auch hier hält eine Zwiebelknopffibel den langen über die Brust geführten Überwurf zusammen. Jedoch präsentiert sich der Sohn nicht als Militär, sondern als ziviler Amtsträger. Die zum Redegestus erhobene rechte Hand und das in der Linken geführte Schreibtäfelchen kennzeichnen den Knaben wohl als tribunus et notarius. ${ }^{28}$ Somit präsentiert die Rückseite des Diptychons die senatorische Werte, welche dem standesgemäßen aristokratischen Lebensstil und dem zivilen öffentlichen Dienst verpflichtet sind.

Dem gegenübergestellt tritt auf der Vorderseite ein hoher militärischer Amtsträger in Erscheinung, der über seinen familiären Anhang regelrecht zu einem ,Mann zweier Welten' wird. Es ist eben jene außerordentliche Stellung, die maßgeblich von Stilicho dergestalt geprägt wurde, dass der magister militum als Mittler zwischen militärischem und zivil-senatorischem Sektor die für den Zusammenhalt des Reichs und die Bündelung seiner Kräfte entscheidende Schlüsselposition einnahm. Hierbei ,usurpierte‘ Stilicho als magister militum die zentrale Position, die vormals einzig der Kaiser innehatte. ${ }^{29}$ Und so schilderte auch Claudian seinen Stilicho als einen Mann von zwei Naturen: „sonst immer geschieden, einen sich in dir des Jünglings Kräfte und die Würde des

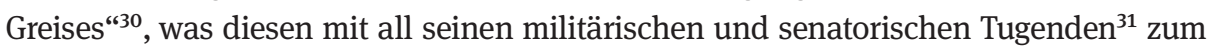
„trefflichsten der Feldherrn und beglücktesten der Väter“32 erhob. Das claudiansche

welche vermutlich auf den Diptychontafeln im Museo Nazionale del Bargello in Florenz und im Kunsthistorischen Museum in Wien dargestellt ist, trägt eine perlenbesetzte Kappe. Falls hier Serena dargestellt sein sollte, stellt das Nichtvorhandensein kaiserlicher Attribute keinen stichhaltigen Beweis gegen die Benennung dar. Vgl. SHELTON (1982) 132-171. Vgl. dazu auch CHRIST (2015) 176.

27 Zur Angleichung des Sohns an den Vater vgl. WARLAND (1994) 182; vergleichbar mit dem Missorium des Aspar in Florenz, welches Vater und Sohn in gleicher konsularischer Tracht (toga contabulata und mappa) zeigt.

28 Da dies als Einstiegsamt den Söhnen aus aristokratischem Hause offenstand; Eucherius 1 bekleidete diese Stellung 396 (PLRE 2, 404. Vgl. Zos. 5,34,7). Zum tribunus et notarius vgl. WARLAND (1994) 181f. 29 Vgl. KREUZ (2008) 219f. wobei hier die Rolle des Militärs zu stark betont wird; zur Usurpation der zentralen Schlüsselstellung vgl. jetzt auch KUHOFF (2012). Ferner vgl. MCEVOY (2013a) 153-186; JANSSEN (2002) 27-39 u. 104-124 und SCHARF (1990) 461-474.

30 Claud. Nupt. Hon. $319 \mathrm{ff} .:$, hic est, hic Stilicho!‘ [...] hoc donat natura tibi. [...] cum sorte remota contingat senio gravitas viresque iuventae, [...]. Hierbei kann gravitas als „Bedeutsamkeit“ bzw. „Einfluss“ im Kreis der Senatsaristokratie verstanden werden, wo gerade die Würde des hohen Alters besondere Achtung genoss; dagegen vires iuventae auf militärisch-agonale Tüchtigkeit verweist. Vgl. DÖPP (1980) 131.

31 Claud. Nupt. Hon. $319 \mathrm{ff} .:$, hic est, hic Stilicho!' führt so auf: auctoritas, gravitas und cura/providentia; Claud. Cos. Stil. 2,6-99: fides und clementia; 2,100-109a: iustitia, patientia, temperies, prudentia, constantia; 2,109b-172: ohne die Laster avaritia, ambitio, luxuria und superbia. Vgl. aktuell zur Anwendung des mos maiorum auf Stilicho in der Panegyrik des Claudian WARE (2012) 220 - 230; zum mos maiorum vgl. SCHOLZ (2011) bes. $89-215$.

32 Claud. Nupt. Hon. 334: [...] optime ductorum, fortunatissimus patrum. Gewiss wird hier zunächst an den Braut-Vater Stilicho zu denken sein; jedoch, wenn er ohne nähere Spezifizierung zum fortunatissime 
Bild, wonach sich in Stilicho zwei widerstrebende Naturen vereint haben sollen, steht in Korrelation zu dem ,Mann zweier Welten' auf dem Monza-Diptychon.

Im Gegensatz zum Kaiser, dessen ,heilige‘ Person prinzipiell den Niederungen der Eifersüchteleien, Intrigen und Machtkämpfe der Führungsgruppen enthoben war, musste sich der magister militum in ihr Zentrum stellen, um von dort aus die Kontrolle zu erlangen. Von größter Wichtigkeit war dabei die Wahrung des Kräftegleichgewichts. Keine Partei, ob nun im Heer, am Hof, in der Reichsverwaltung oder im Senat, durfte zu stark übervorteilt werden, denn dies würde die Akzeptanz zerstören und zwangsläufig oppositionelle Kreise generieren. Für Stilicho, wie auch für seine Nachfolger, war es daher überaus wichtig, nicht nur als ,Warlord' oder ,Generalissimus ${ }^{63}$ in Erscheinung zu treten. Stilicho war darauf angewiesen, in seiner Person militärische Tüchtigkeit, administrative Kompetenz und senatsaristokratische Noblesse zu vereinen.

Der Senat und die stadtrömische Senatsaristokratie spielten für die Politik des Stilicho eine mindestens ebenso wichtige Rolle wie das Heer und der Hof. Mit Stilicho setzt in der Tat eine Renaissance des Senats ein, die diesen so politisch aktiv zeigt wie seit Jahrhunderten nicht mehr. Auch die stadtrömische Senatsaristokratie musste die zwingende Notwendigkeit erkennen, dass die Bewältigung der gewaltigen Probleme, die sich vor Rom und dem Westen auftürmten, eines ,starken Mannes‘ im Amt des Heermeisters bedurfte. Nicht zuletzt ging es auch um die Sicherung ihrer Güter und Reichtümer. Hinzu trat die Verteidigung der Ansprüche Roms, des Senats und der stadtrömischen Senatsaristokratie gegenüber Konstantinopel. Der Konflikt zwischen Ost und West, der im Osten mit den Namen von Rufinus und Eutropius ${ }^{34}$ und im Westen mit Stilichos Namen zu verbinden ist, wurde sicherlich auch von zahlreichen Senatoren in beiden Reichshälften mitgetragen.

Die Ehrwürdigkeit Roms und seines Senats stellte das elementare politische Kapital dar, mit welchem Stilicho die Vorrangstellung des Westens vor Konstantinopel mit Fug und Recht vertreten konnte. Im Gegensatz zu der, Vormundschaft', die keine rechtliche Grundlage besaß, ${ }^{35}$ war das caput mundi und die pars melior humani generis, die die stadtrömische Senatsaristokratie verkörperte, ein ernstzunehmendes politisches Argument. So sind die Werke Claudians voll der laudes Romae. ${ }^{36}$ Natürlich ist Stilicho nach

patrum erklärt wird, schließt dies gleichermaßen auch die patres conscripti ein, denen Stilicho ebenso, wie allen anderen Feldherren, vorangestellt wird.

33 „Warlord“ u. a. WIJNENDAELE (2015) $17 \mathrm{f} . ;$ (2002) 7-9.; MACKAY (2004). „Generalissimus“ u. a. HEATHER (2014) 181; DEMANDT 2(2007) 181; bes. O’FLYNN (1983); bis zurück auf SCHULZE (1809). In Folge ist der militärische Charakter des stilichonischen Regimes immer wieder unverhältnismäßig stark betont worden.

34 PLRE 1, 778-781 (Rufinus 18) und PLRE 2, 440 - 444 (Eutropius 1); die wichtigste - nicht objektive Quelle zum Konflikt stellt Claudians In Rufinum I-III und In Eutropium I-II (Claud. Ruf.) dar. Vgl. u. a. DÖPP (2000) 73-94.

35 Vgl. Kap. 3.1.

36 Vgl. RIEDL (1995) 537-555; KLEIN (1986) 119-144 oder CHRISTIANSEN (1971) 670 - 674. 
Claudian ihr starker „Rächer“ und „Retter“37 und hilft Roma und ihren Senatoren aus unwürdiger Not auf. Doch schmälert dies nicht ihre Bedeutung oder unterstellt sie dem Heermeister. Tatsächlich stellt sich Stilicho in den Dienst Roms und des Senats und wird damit - zumindest in der Panegyrik - zum treuen Diener, ${ }^{38}$ der sich an Größen wie Lucius Iunius Brutus und Camillus ${ }^{39}$ maß.

In der Gildo-Krise 397/398 verhalf Stilicho dem Senat zu einer bedeutenden politischen Funktion. Die entscheidenden Äußerungen hierzu finden sich bei Claudian in seinen Werken De bello Gildonico und De laudibus Stilichonis liber III. Als größte Leistung Stilichos wird hierbei die Wiedereinsetzung Roms und seines Senats in die ihnen angestammten herrschaftlichen Rechte aufgefasst. ${ }^{40}$ Anachronistisch mutet es an, dass sich Kaiser und Heermeister trotz ihrer beachtlichen Machtfülle der Stimme des Senats bedienen mussten und nicht frei nach eigenem Ermessen eine Strafexpedition gegen den rebellischen comes Africae verhängten. Bereits Müller bemerkte, dass mit dem Hinweis auf diese Leistung Stilichos, welche in der Wiedererweckung Roms zum Machtzentrum des Reiches begründet liegt, ein Höhepunkt des Stilicho-Lobs ${ }^{41}$ erreicht wird. Das senatus consultum war nicht nur ein überaus geschickter politischer Schachzug, der sich mit der Stimme Claudians trefflich verkaufen ließ, sondern auch der bestmögliche Ausweg aus dem politischen Dilemma, in welches sich Ost und West hineinmanövriert hatten. Im Grunde wiesen im Winter 397 alle Zeichen auf einen Bruderkrieg hin. ${ }^{42}$ Indem aber der Senat über den Krieg entschied und Gildo als hostis publicus $^{43}$ ächtete, war Honorius von der Verantwortung entbunden. Der Konflikt ließ

37 Gerade in Claud. Eutr. 2,141f. wird Stilicho sogar zum „Rächer des Mars“ gegen den Eunuchen Eutropius und sein schmachvolles Konsulat erhoben. Als „Retter des Reiches“ wird Stilicho besonders deutlich im sog. Soldatenlob in Claud. Nupt. Hon. 300 - 341 stilisiert; ebenso als „Retter der Menschheit“ in Claud. Cos. Stil. 1,142f. oder Claud. Get. 36 - 49. Vgl. SCHINDLER (2009) 140f. Zur Auseinandersetzung zwischen Ost und West vgl. BAYLESS (1972) 9-39.

38 Vgl. MÜLLER (2011) 223-256, hier 239.

39 Zur Diskussion der relevanten Textstellen vgl. FELMY (2001) 88-159.

40 Claud. Cos. Stil. 3,81-86: [...] te duce Romana tandem se vindicat ira. ipsa iubet signis bellaturoque togatus imperat et spectant aquilae decreta senatus. Vgl. MÜLLER (2011) 238.

41 MÜLLER (2011) $238 \mathrm{f}$.

42 Claud. Gild. 390; Oros. 7,36,4f.; Zos. 5,11,1f. und Iord. Rom. 320; zur Ereignisgeschichte und den Hintergründen vgl. JANSSEN (2002) 82-88: hier auch mit einer alternativen Deutung, „daß es Gildos Furcht vor den Hofkabalen seines Bruders war, die ihn wider Willen zum Aufstand trieb, [...]“. Gerade mit Blick auf Konstantinopel und die Illyrien-Frage vgl. HAGL (1999) 43-45; vergleiche aktuell auch MCEVOY (2013a) 156-159 mit Stellungnahme zur älteren Forschungsmeinung.

43 Symm. ep. 4,5; Claud. Cos. Stil.1,325-332 u. 3,89f.; Claud. Gild. 16: [...] quem veniens indixit hiems, ver perculit hostem [...]; ferner CTh. 7,8,7 (a. 400): Praedia ex gildonis hostis publici et satellitum eius bonis sociata domui nostrae ne transeuntes hospitii gratia intrent, decermimus, [...] und CIL 9, 4051 (ILS 795); zur Datierung in den Winter 397 vgl. LEHNER (1984) 12; DÖPP (1980) 113, CAMERON (1970) 105 und allgemein DIESNER (1962) 178-186. Allgemein zu dieser Kompetenz des Senats vgl. jetzt auch ROLLÉ DITZLER (2020) $110 \mathrm{f}$. 
sich so auf einen regionalen „Stellvertreterkrieg“44 begrenzt halten. Die hostis-Erklärung war hierbei das geeignete politische Mittel, um die nahende Auseinandersetzung als interne Strafaktion gegen einen rebellischen Feind Roms zu deklarieren. Konstantinopel musste sich daraufhin von Gildo distanzieren.

Umstritten bleibt, wann genau der PSC Eutropius seinerseits den Senat von Konstantinopel anhielt, Stilicho zum hostis publicus ${ }^{45}$ zu erklären. ${ }^{46}$ Auch der Osten spielte die ,Senats-Karte، aus, jedoch erwies sich dies als deutlich ineffektiver. Während das senatus consultum und die hostis-Erklärung des weströmischen Senats seine Wirkung nicht verfehlte, blieb die Ächtung Stilichos im Westen nahezu wirkungslos. ${ }^{47}$ Stattdessen ehrten die Senatoren Roms ihren Retter, „nachdem Africa durch seine Einsicht und Fürsorge befreit war“ ${ }^{\text {48 }}$, mit einer Statue ${ }^{49}$ auf dem Forum Romanum. Quintus Aurelius Symmachus erwies der civilitas des Stilicho, der nicht wie ein Feldherr gebot, sondern wie ein guter Bürger Roms sich dem Hoheitsrecht des Senats unterstellte, in den höchsten Tönen seine Reverenz. ${ }^{50}$

Mit Symmachus hatte Stilicho einen starken Fürsprecher im Senat, der ihm zugleich die heidnische Senatsaristokratie zuführte. ${ }^{51}$ Doch noch weitere Namen sind anzuführen, die als Unterstützer des Heermeisters infrage kommen. So wird dies auf Fl. Mallius

\footnotetext{
44 JANSSEN (2002) 88; dies noch durch den Zustand verstärkt, dass als Befehlshaber gegen Gildo dessen Bruder Mascezel eingesetzt wurde.

45 Zos. 5,11,2; zur hostis-Erklärung des oströmischen Senats vgl. MCEVOY (2013a) 156-159; WARE (2004) 96-103; MATTHEWS (1975) 272; CAMERON (1970) 173-176; DEMOUGEOT (1951) 172f. Zum Ausmaß des Konflikts zwischen Ost und West vgl. CASTELLO (1979) 155-196.

46 Vgl. HAGL (1999) 44; PASCHOUD (1986) 113-115 mit Anm. 22.; SEECK (1913) 285f. mit Suppl. Bd. 5 (1921) 555.

47 Im Osten hingegen wurden die Besitztümer Stilichos eingezogen; die erhoffte Abfallbewegung von Stilicho blieb im Westen jedoch aus. CAMERON (1970) 102-123 betont hingegen die politisch missliche Situation des Stilicho. Dass dieser nicht den Feldzug gegen Gildo persönlich befehligte und auch nicht für das Jahr 399 das Konsulat beanspruchte, mochte zwar die hostis-Erklärung erzwungen haben; doch die Stellung des Stilicho blieb im Westen auch weiterhin unangefochten.

48 CIL 6, 1730 (ILS 1277): [...] AFRICA CONSILIIS EIVS ET PROVISIONE LIBERATA, EX S(enatus) C(onsulto); zur kompletten Inschrift mit Übersetzung vgl. NISCHER-FALKENHOF 1947, $79 \mathrm{f}$.

49 CIL 6, 1730 (ILS 1277): [...] MAGISTRO EQVITVM PEDITVMQVE, COMITI DOMESTICORVM, TRIBVNO PRAETORIANO ET AB INEVNTE AETATE PER GRADVS CLARISSIMAE MILITIAE AD COLVMEN GLORIAE SEMPITERNAE ET REGIAE ADFINITATIS EVECTO [...].

50 Symm. ep. 4,5 (ad Stiliconem): [...] bonorum motus erupit, consulti igitur in senatu more maiorum neque enim sine legitimo ordine iudicii auctoritas stare potuisset -, ingenti causae devotis sententiis satisfecimus. Vgl. KLEIN 2(1986) 59; WYTZES (1977) 104-106 oder NISCHER-FALKENHOF (1947) 72f. Vgl. hierzu auch Claud. Cos. Stil. 1,325ff. u. 3,86; dazu FELGENTREU (1999) 138f. Weitere 13 Briefe, die an Stilicho adressiert sind, verdeutlichen die Achtung und das Vertrauen, welche Symmachus ihm entgegenbrachte; zum Verhältnis zwischen Symmachus und Stilicho im Spiegel der Briefe vgl. EVERSCHOR (2007) 140 - 149; ferner LÜTKENHAUS (1998) 15 und NÄF (1995) 64. Vgl. auch Claud. Cos. Stil. 2,166-172; hierzu DÖPP (1980) 179. Als besondere Leistung weist Claud. Cos. Stil.1,325-332 die Befragung des Senats aus.
}

51 Vgl. HEINZBERGER (1976) 40. 
Theodorus $^{52}$ und Fl. Macrobius Longinianus ${ }^{53}$ mit hoher Wahrscheinlichkeit zutreffen. Als Protegé des Stilicho ist des Weiteren der CSL Patroinus ${ }^{54}$ bekannt. Die Prozess- und Enteignungswelle nach dem Sturz des Stilicho verdeutlicht, dass dessen Anhängerschaft in Rom noch um einiges größer war. ${ }^{55}$ Als Konsul des Jahres 400 stand Stilicho gewiss nicht isoliert im Kreis der stadtrömischen Senatsaristokratie. Es wird nicht ausschließlich eine haltlose Schmeichelei sein, wenn Claudian verkündet, Stilicho sei der, „den du [Roma] riefst im Jubel des Volks, auf Bitten des Adels, “56 und diesen zu einem neuen Scipio, der „unter das Joch der Römer die Punier wieder beugte“ ${ }^{\text {“57 }}$, stilisierte. So erinnert Claudian an die Befragung des Senats in der Gildo-Krise und stellt es als gegebenen Normalzustand hin, dass fortan der Senat über Krieg und Frieden gebiete. ${ }^{58}$ Doch Claudian weiß noch um mehr. So berichtet er davon, dass Stilicho dem Senat die rechtsprechende Gewalt und das Recht der Begnadigung zurückgegeben haben soll und die Beamten zur Rechenschaft gegenüber dem Gremium verpflichtet habe. ${ }^{59}$ Am ehesten ist hier an die Standesgerichtsbarkeit unter dem iudicium quinquevirale zu denken, die jedoch erst in den Gesetzen des Jahres 423 neu geregelt wurde. ${ }^{60}$ Die Rechenschaftspflicht findet dagegen tatsächlich ihre Entsprechung in einem Erlass vom 13. September 398 (CTh.1,7,3). ${ }^{61}$ Doch wird die Besetzung der principes officii und numerarii - in diesem Fall im officium des comes Africae - gemäß den übrigen officia der comites und duces dem Büro des magister militum unterstellt. Vermutlich bediente sich Stilicho hierbei der Unterstützung des Senats und gestand ihm im Ge-

52 PLRE 1, 900 - 902 (Theodorus 27); PPO 397-399 und Cos. 399; zur Laufbahn vgl. OLSZANIEC (2013) 419-424. Dass Claudian dessen Konsulat besang, spricht dafür, dass Theodorus ein enger Gefolgsmann des Stilicho war.

53 PLRE 2, 686 f.; PVR 400/402 und PPO 406 - 408; beim Massaker von Ticinum 408 zählt dieser zu den vom Heer gelynchten Anhängern des Stilichos (Zos. 5,32,6).

54 PLRE 2, 843 f.; Symm. ep. 7,109 (Einfluss am Hof); Symm. ep. 7,116 (zur Melania-Affäre vgl. Kap. 3.2); in einem weiteren Brief empfiehlt Symm. ep. 7,124 einen Angehörigen der scrinia litterarum als Klient für Patroinus. Als amtierender CSL kam Patroinus 408 während des Massakers von Ticinum ums Leben (Zos. 5,32,6).

55 Zos. 5,34,5 und Oros. 7,38,6.; zum Patronat des Stilicho vgl. KRAUSE (1987) 12f.

56 Claud. Cos. Stil. 3,1: Quem populi plausu, procerum quem voce petebas, aspice, Roma, virum. Vgl. auch Claud. Cos. Stil. 3,49f.: laetatur eques plauditque senator, Votaque patricio certant, plebeia favori. $O$ felix, servata vocat quem Roma parentem! Der equester ordo existierte in der Zeit Claudians nicht mehr; dies soll lediglich verdeutlichen, dass wirklich alle dem Heermeister Beifall zollten, ganz im Gegensatz zu Marius oder Pompeius Magnus, denen entweder die plebs oder der ordo senatorius zujubelten; den Vergleich eröffnet vorher Claud. Cos. Stil. 3,39f. Vgl. FELMY (2001) 238f.; PORTMANN (1988) 88 und CAMERON (1970) $152 \mathrm{f}$.

57 Claud. Cos. Stil. Praef. und Stil. 3,8: [...] sub iuga quae Poenos iterum Romana redegit [...].

58 Claud. Cos. Stil. 3,81-86; hierzu auch LÜTKENHAUS (1998) 15.

59 Claud. Cos. Stil. 3,99-115.

60 Im Jahr 423 wird eine ganze Reihe an Gesetzen erlassen, die sich mit der Standesgesetzgebung befassen und die Position des Senats stärken: CTh. 1,6,11; CTh. 2,1,12; CTh. 4,10,2 und CTh. 9,6,4. Vgl. NÄF (2013) 102; LÜTKENHAUS (1998) 173; GIGLIO (1990) 202-206 und VINCENTI (1992) 67-76.

61 CTh. 1,7,3. Vgl. hierzu SCHARF (2005) 101f.; O’FLYNN (1983) oder CLEMENTE (1968) 175-179. 
genzug das Recht zu, von den Beamten nach abgeleistetem Dienst Rechenschaft einzufordern. ${ }^{62}$

In den Jahren 401/402 und 406 war das Regime Stilichos mit der Abwehr Alarichs und Radagais' vor weit größere Probleme gestellt. ${ }^{63}$ Am Ende stehen nach der Doppelschlacht von Pollentia und Verona und dem Sieg bei Fiesole zwar abermals zwei Ehrenmonumente ${ }^{64}$ für den siegreichen Heermeister auf dem Forum Romanum, auch kann dieser 405 noch einmal das Konsulat bekleiden, doch die Stimmung unter der Senatsaristokratie und im Senat war im Begriff zu kippen. Die Siege des Stilicho erwiesen sich als ,Pyrrhussiege‘, deren Preis zu hoch war. Die Schäden sind zwar kaum genau zu ermessen, doch die zeitnahen Quellen vermitteln einen aussagekräftigen Eindruck davon. Die Vita Melaniae, Palladius und Orosius wären diesbezüglich zu konsultieren. ${ }^{65}$ Sie schildern Verwüstungen apokalyptischen Ausmaßes, ein in Schrecken erstarrtes Volk ${ }^{66}$ und eine an den Rand des Ruins getriebene Senatsaristokratie, dessen weltliche Reichtümer den marodierenden ,Barbarenhorden` zum Opfer fielen. Der durch Raub und Verwüstung entstandene Schaden an den senatorischen Liegenschaften und ihrer beweglichen Habe, der zugegebenermaßen nicht die Senatsaristokratie in ihrer Gesamtheit sogleich in den völligen Ruin stürzte, jedoch sicherlich eine langfristige Beeinträchtigung ihrer Einkünfte bedeutete, forderte nach einem ,Sündenbock $^{6}$. Stilicho selbst hatte sich zur alles überragenden Person im Staat aufgeschwungen und so ist es nur allzu nachvollziehbar, wenn ihn nun die ganze Last der Verantwortung traf, die in früheren Zeiten der Kaiser getragen hätte.

62 Vgl. PORTMANN (1988) 88 und DÖPP (1980) 189; auch Stilicho wird im Jahr 408 aus eigenen Stücken Rechenschaft vor dem Senat ablegen; ebenso Honorius anlässlich seines Konsulats 404 (vgl. Kap. 3.2). $63 \mathrm{Zu}$ den Vorgängen vgl. JANSSEN (2004) 187-196; HEATHER 2(2003) 51-63; ROSEN (2002) 61f.; WOLFRAM (1990) 175f.; LIPPOLD (1972) 149-165; DEMOUGEOT (1951) 356f.; NISCHER-FALKENHOF (1947) 122-132; MAZZARINO (1942) 75f. Die Mehrheit der Forscher setzt den Zug des Radagaisus für die Jahre 405/406 an; dagegen argumentiert BAYNES (1922) 207-220, bes. 218f. für das Jahr 404.

64 CIL 6, 31987 (ILS 799) und CIL 6, 1731 (ILS 1278; nahe der rostra) für den Sieg über Alarich und Radagaisus. Vgl. WITSCHEL (2012) 361 f.; NIQUET (2000) 52; BAUER (1996) 21; BERGMANN (1990) 41- 43 und für Text und Übersetzung JANSSEN (2002) 197 und NISCHER-FALKENHOF (1947) 130.

65 Vgl. Vit. Mel. 14; 18; 19; Pall. Laus. 54. Ferner Oros. 7,37,4-10. Dieser nimmt aber mit seiner spezifischen Intention, die nicht auf asketische Lebensideale oder das nahende, Weltende ${ }^{6}$ abzielt, sondern, wie es der Titel verkündet, eine Historiae adversum Paganos vorlegen wollte, eine Sonderstellung ein. Die Übersiedlung des Hofes nach Rom in den Jahren 403-405 und 407/408 deutet auch auf die schwierige Versorgungslage in Oberitalien (Italia annonaria) hin.

66 Dies schildert auch Claud. Get. 213-266 u. 296-315, wonach sogar die Senatsaristokratie beabsichtigt haben soll aus Italien zu fliehen; dient dies hier einem anderen Zweck als bei den christlichen Autoren, die vor allem die ,Weltflucht' hin zu einem frommen asketischen Leben im Sinn bzw. auch das nahende ,Weltende“ vor Augen hatten. Claudian steigert hierdurch letztlich noch die Bedeutung Stilichos als Beschützer der Verängstigten. Vgl. aktuell HARICH-SCHWARZBAUER (2013) 37-52, bes. 47 ff. Die aus Furcht populär gewordenen Prodigien-Gläubigkeit und der grassierende Aberglaube werden von Claud. Get. 235f. u. 262f. und Oros. 7,37,6 gleichermaßen verurteilt; zur Zeitmentalität vgl. JANSSEN (2002) 149153 mit Diskussion weiterer Quellen. Zur Furcht im Zusammenhang mit dem Zug des Radagaisus vgl. auch Zos. 26,4-7. 
Claudian und Symmachus waren nicht mehr imstande, für Stilicho einzutreten. Entweder durch ihr Ableben oder durch den Rückzug aus der Öffentlichkeit verlieren sich nach 402 bzw. 404 ihre Spuren aus der Geschichte. ${ }^{67}$ Auch Fl. Mallius Theodorus tritt nach seinem Konsulat 399 nicht mehr in einem öffentlichen Amt in Erscheinung. ${ }^{68}$ Damit gingen Stilicho bis spätestens 405 seine wichtigsten Befürworter in senatsaristokratischen Kreisen verloren. Hierbei ist zu berücksichtigen, dass mit dem Abbrechen der claudianischen Panegyrik uns nun keine positive Wertung mehr für Stilichos vorliegt. In der heidnischen, aber auch christlichen Betrachtung, die vor allem die Plünderung Roms 410 erklärbar machen will, ist Stilicho der Hauptschuldige, der ,Verräter und ,Barbarenfreund‘. 69

Als Reaktion auf die finanzielle Schieflage des Staats ist auch eine Tat Stilichos zu sehen, die fälschlich von zahlreichen Gelehrten als „antiheidnische“ Maßnahme ${ }^{70}$ missverstanden wurde. Zosimos ${ }^{71}$ berichtet davon, dass Stilicho die Goldbeschläge der Türen des Jupitertempels auf dem Kapitol entfernen ließ. Der terminus technicus hierfür lautet allerdings ,Kriegsanleihe ${ }^{672}$ und nicht Frevel und war eine Notmaßnahme, die von Römern und Griechen in Krisenzeiten immer schon praktiziert wurde. ${ }^{73}$ Eine Weiterentwicklung mit eindeutig antiheidnischem Charakter findet sich erst in CTh. 16,10,19 vom 15. November $407 .^{74}$ Da aber das Gesetz an erster Stelle die öffentliche Finanzierung der Tempel und der Armee thematisiert, waren hier neben dem Willen zur Bekämpfung des Heidentums offensichtlich ebenso fiskalische Interessen inbegriffen. $\mathrm{Zu}$ oft wird hierbei vergessen, dass durch die Konfiskation von Tempeln, einschließlich ihrer Ein-

$67 \mathrm{Zu}$ Claudian stehen zur Diskussion sowohl ein krankheitsbedingter Tod als auch, dass dieser in Ungnade gefallen sein könnte und aufgrund seiner Nähe zum Heidentum abgeurteilt wurde. Vgl. u. a. CAMERON (1970) 227 u. 472. Hinsichtlich des Symmachus informiert Symm. ep. 4,13; 4,56 und 5,96 über eine Erkrankung, welche sich dieser nach seinem Besuch am Kaiserhof in Mailand im Winter 402 zugezogen hatte. Vgl. MCEVOY (2013a) 172; CAMERON (2011) 339 oder WYTZES (1977) 107.

68 Theodorus 9 (PLRE 2, 1086) der Ende 408 bis Anfang 409 als PPO amtierte, kann womöglich als dessen Sohn identifiziert werden; da dieser aber nach dem Sturz Stilichos unter Olympius in das Amt kam, wird vorausgesetzt werden müssen, dass dieser kein Parteigänger des gestürzten Heermeisters war; womöglich hatte sich auch sein Vater nach 399 von Stilicho distanziert und war in das Lager der Gegner gewechselt. Vgl. FLETCHER (2004) 197; JANSSEN (2002) 254 mit Anm. 80, der sich aber für eine Gleichsetzung ausspricht; MATTHEWS (1975) 279 u. 285.

69 Vgl. Oros. 7,37,1-3 und 7,38,1-6; Hieron. ep. 123,16 und Rut. Nam. 2,41-60. Hierzu vgl. auch Kap. 6.2. 70 BONAMENTE (2011) 82.

71 Zos. 5,38,10-12.

72 In diesen Kontext gehört wohl auch die „Halsbandaffäre“ um Serena, die sich einer kostbaren Kette vom Kultbild der Rhea bemächtigt haben soll. Vgl. Zos. 5,38,5-9.

73 Vgl. Thyk. 1,143: hier eine Anleihe an den Tempelschätzen von Olympia und Delphi durch die Spartaner im Peloponnesischen Krieg; Bell. Afric. 97,1ff.: Julius Caesars Konfiskationen in Africa; Cass. Dio. 42,50,2ff.: Caesar im Bürgerkrieg; ferner Luc. Bell. Civ. 3,141-169: zur „Plünderung“ des Saturntempels in Rom durch Caesar; deutlich negativ konnotiert: „tristi spoliantur templa rapina“; ebenso negativ Herod. 7,3: Maximinus Thrax bemächtigt sich der Tempelschätze Roms. Solche „Kriegsanleihen` waren durchaus eine gängige Praxis, waren aber nicht wenig der Kritik ausgesetzt.

$74 \mathrm{Zu}$ CTh. 16,10,19: templorum detrahantur annonae et rem annonariam iuvent expensis devotissimorum militum profuturae [...]. Vgl. hierzu BONAMENTE (2011) $81 \mathrm{f}$. 
künfte, ihres Grundbesitzes und ihrer Kultgeräte, unter dem Deckmantel einer frommen christlichen Religionspolitik sich für die Staatsgewalt eine Möglichkeit auftat, mittelfristig auf akzeptable Weise wieder an Geld zu kommen. ${ }^{75}$ In diesem Sinn werden in dem hier angeführten Gesetz folglich auch die Gelder zum Unterhalt des Heeres bestimmt. Bemerkenswert ist hierbei der politische Richtungswechsel Stilichos. War dieser vormals noch bemüht gewesen, heidnische und christliche Senatoren gleichermaßen an sich zu binden, ${ }^{76}$ so positionierte sich der Heermeister nun unmissverständlich auf der Seite der Christen gegen das Heidentum. ${ }^{77}$ Es scheint für die schwierige Lage, in welcher sich Stilicho nach 402 befand, symptomatisch zu sein, dass er nicht mehr den Handlungsspielraum besaß, durch behutsames politisches Manövrieren die christliche und heidnische Senatsaristokratie in Konsens mit ihm zu halten.

Als Stilicho Anfang 408 als Bittsteller vor den Senat treten musste, um sich die verhältnismäßig moderate Summe von 4.000 Pfund Gold ${ }^{78}$ bewilligen zu lassen, zeigte sich deutlich die geschwächte Position des Heermeisters. Dies war die Vergütung, die Alarich für seinen Wartestand in Epirus einforderte. Mit Widerworten und offen geäußertem Protest konfrontiert zu sein war für den vermeintlich mächtigsten Mann im

75 Bereits Amm. 12,4,3 berichtet, wie Constantius II. seine Höflinge mit Tempelgütern überschüttet habe; auch ein Gesetz Jovians vom 4. Febr. 364 (CTh. 10,1,8) verfügt, dass Tempel-Grundstücke zum Verkauf dem patrimonium des Kaisers zuzuführen seien; ferner wird in CTh. 16,10,20 vom 30. Aug. 415 noch einmal beschlossen, dass alle fundi, Einkommen von Immobilien (omnia loca) und Zuwendungen der res privata zugeführt werden sollen. Insofern darf auch für CTh. 16,10,19, obgleich keine Angaben gemacht werden, was mit den zu entfernenden Tempelschätzen geschehen sollte, vorausgesetzt werden, dass diese für den Fiskus liquidiert wurden. Vgl. auch BONAMENTE (2011) 81f.; JANSSEN (2002) 200.

76 Ausführlich CASTELLO (1983) 65-96 und DE GIOVANNI (1980) 144-147 und MAZZARINO (1937/1938) $235-262$, bes. $245 \mathrm{f}$.

77 Dies sollte Stilicho möglicherweise wieder in einen Konsens mit dem christlichen Kaiser und dem Hof bringen, die gerade nach dem Einfall des Alarich und Radagaisus wohl restriktivere Maßnahmen gegen das Heidentum forderten. Vgl. JANSSEN (2002) 143-153, 163-165 u. 197-201. Die kompromisslose Haltung des Kaisers und des Hofes in Religionsfragen wird bereits in der „Melania-Affäre“ deutlich; auch Claudian (u. a. Claud. Get. 249-266: „Wolfsprodigium“; vgl. GNILKA (1973) 145-166) tadelt den heidnischen Aberglauben und die ausufernde Wahrsagerei (gemäß Oros. 7,37,6f. und Zos. 5,41,1-3). In diesen Zusammenhang ist wohl auch die Verbrennung der Sibyllinischen Bücher durch Stilicho einzuordnen; Rut. Nam. 2,51-56: Nec tantum Geticis grassatus proditor armis; ante Sibyllinae fata cremavit opis [...]. Zur wachsenden Spannung zwischen ,Heiden“ und Christen Anfang des 5. Jhs., insbesondere in Retrospektive auf die Plünderung Roms 410 vgl. Aug. Serm. 105,13 oder Oros. 7,37,7; hierzu HEINZBERGER (1976) 101f. und LIPPOLD (1972) $160 \mathrm{f}$.; kritisch JANSSEN (2002) $198 \mathrm{f}$.

78 Die Summe entspricht in etwa 288.000 Solidi; nach JANSSEN (2002) 219: 12 Solidi pro Mann und Jahr für zwei Jahre mit einer Mannschaftsstärke von 12.000 Bewaffneten, nach SCHULZ (1993) 30 Solidi pro Mann für ein Jahr mit einer Mannschaftsstärke von etwas weniger als 10.000 Bewaffneten; zum Vergleich konnte sich das Jahreseinkommen nur eines Senators, wie z. B. Pinian (Vit. Mel. 15), auf 120.000 Solidi belaufen; Probus (vermutlich Sohn des Anicius Hermogenianus Olybrius) sollen die Summe von 1.200 Pf. Gold für die prätorischen Spiele aufgewandt haben, Symmachus 2.000 Pf. Gold und ein Maximus (wohl Petronius Maximus) 4.000 Pf. Gold (Olymp. fr. 41,2 (Blockley)). Die geforderte Summe war demnach zumutbar. Vgl. zum senatorischen Besitz auch knapp CAMERON (1994) $139 \mathrm{f}$. 
Westen gewiss eine ungewohnte und nicht zuletzt auch alarmierende Entwicklung der Dinge. Über die Vorgänge in der Senatssitzung informiert Zosimos:

Der Senat versammelte sich im Palast, und als die Frage vorgelegt wurde, ob man Krieg führen solle, oder nicht, votierten die meisten für den Krieg. Stilicho aber, und wenige, die aus Furcht ihm beistimmten, waren entgegengesetzter Meinung und plädierten auf Frieden mit Alarich. ${ }^{79}$

Erst als Stilicho die Sachlage mit etwas mehr Nachdruck darlegte, gab die Mehrheit der Senatoren nach. ${ }^{80}$ Nur ein Senator namens Lampadius ${ }^{81}$ erhob gegen Stilicho die Stimme und fügte hinzu: „Das ist nicht Frieden, sondern eine Übereinkunft der Knechtschaft“ (Non est ista pax, sed pactio servitutis), worauf sich dieser sogleich vor dem Zorn des Heermeisters in eine Kirche geflüchtet haben soll. ${ }^{82}$ Für die Senatoren Roms ging es hierbei wohl weniger um die zu zahlende Summe, sondern um die Aversion einer Politik gegenüber, die sie kaum noch mittragen konnten, geschweige denn weiter subventionieren wollten. ${ }^{83}$ Interessanterweise stehen die von Zosimos wiedergegebenen Worte des Lampadius, die von der „Knechtschaft“ (servitus) sprechen, genau diametral zu dem claudianischen Stilicho-Lob, in welchem der libertas senatus $^{84}$ eine zentrale Bedeutung beigemessen wurde. Stilicho brachte dem Senat nicht mehr die Freiheit, sondern die Knechtschaft und brach mit seinem von Claudian propagierten Idealbild. Auffällig ist hierbei, dass es dem Senat offensichtlich nicht mehr nur genügte, durch Stilicho hofiert zu werden und sein votum ganz nach dem Willen des Heermeisters feierlich abzugeben. Der Heermeister selbst hatte dem Senat ab 398 dieses Selbstbewusstsein eingeflößt.

An dieser Stelle sei noch einmal die Aufmerksamkeit auf den wortgewandten Senator, den Zosimos mit dem Namen Lampadius überliefert, zu lenken. Zu bemerken ist

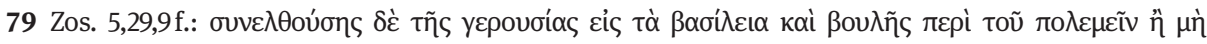

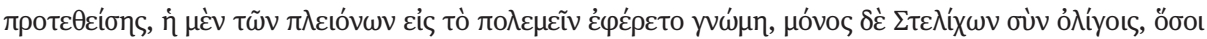

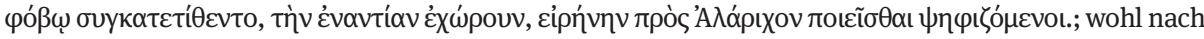
Olymp. fr. 7,2 (Blockley). Hierzu vgl. MCEVOY (2013a) 178-180; FLETCHER (2004) 34f.; JANSSEN (2002) 225f.; MATTHEWS (1975) 279 und ders. (1970a) 81f. u. 86. Eine Besonderheit stellt hierbei auch die Einberufung des Senats im Kaiserpalast (wohl auf dem Palatin) dar sowie die Anwesenheit Stilichos und sicherlich auch des Kaisers, was die Wichtigkeit dieser Angelegenheit unterstreicht.

80 Zos. 5,29,11-13. Vgl. hierzu auch ebd. 5,29,5-8.

81 PLRE 2, 655 (Lampadius 2).

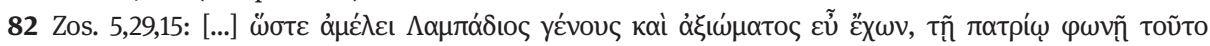
ن் nicht in aller Deutlichkeit, denn sicherlich sollte ein klares votum des Senats - ganz im Sinne Stilichos Honorius, der vermutlich in der Alarich-Frage eher eine ablehnende Haltung einnahm, zum Einlenken bewegen. Vgl. auch NÄF (2013) 96.

83 Hier entgegen JANSSEN (2002) 226, der in erster Linie die „finanziellen Bedenken“ der Senatoren anführt.

84 Vgl. WARE (2012) 100f., 111-118; PORTMANN (1988) 42ff.; speziell zur Begrifflichkeit als Bestandteil der senatorischen Herrscherideologie seit der frühen Kaiserzeit vgl. NERI (1997) 71f. und WIRSZUBSKI (1950) 160 -166. Vgl. hierzu auch Kap. 5.3. 
zunächst, dass Lampadius zwar als „ein Mann, der sowohl durch Geburt als auch Würde ausgezeichnet ist" ${ }^{\text {"85 }}$, vorgestellt wird, man jedoch über seine Amtsposition nichts erfährt. Als Wortführer im Senat wäre zunächst die Stellung des PVR in Betracht zu ziehen. In der Tat käme so auf dem ersten Blick Postumius Lampadius ${ }^{86}$ am ehesten infrage, der zwischen 403 und 408 die Stadtpräfektur innehatte, wenn sich dieser nicht nachfolgend dem Attalus und Alarich als PPO zur Verfügung gestellt hätte ${ }^{87}$. Ein weiterer Lampadius, ${ }^{88}$ der bereits 398 die Stadtpräfektur bekleidet hatte, und überdies wohl der jüngere Bruder des Mallius Theodorus war, ist dagegen ein deutlich aussichtsreicherer Kandidat für eine Identifizierung. ${ }^{89}$ Sollte dies zutreffen, so wäre der im Senat gegen Stilicho auftretende Senator gleich seinem Bruder und Neffen ${ }^{90} \mathrm{zu}$ den Gegnern des Heermeisters übergelaufen.

Eine gewisse Signalwirkung, die den Gegnern Stilichos zusätzlich Auftrieb gab, wird der Senatssitzung im Frühjahr 408 nicht abzusprechen sein. Immerhin stellt sie im Geschichtswerk des Zosimos den Auftakt zum Sturz Stilichos dar. Als exekutives Instrument diente dem Olympius ${ }^{91}$ und den übrigen Verschwörern jedoch das Heer. Am 13. August $408^{92}$ fielen die in Ticinum stationierten Truppen, welche durch Olympius aufgewiegelt worden sein sollen, ${ }^{93}$ über die von Stilicho eingesetzten Beamten her.

85 Zos. 5,29,15.

86 PLRE 2, 656 (Postumius Lampadius 7). Vgl. Kap. 4.1.

87 Dem Lampadius 2 (PLRE 2, 655), der entschieden gegen die Erfüllung der Forderungen Alarichs aufgetreten ist, wird ein solcher Richtungswechsel, der ihn zu einem Freund und Unterstützer Alarichs und des Attalus werden ließ, nicht zugetraut; so dass er für gewöhnlich nicht mit dem PPO des Attalus (PLRE 2, 656 (Postumius Lampadius 7)) gleichgesetzt wird; so bereits PLRE 2, 655: „He is probably distinct from Postumius Lampadius 7, who was PPO under Attalus and therefore presumably friendly to Alaric, ....“; ebenso VON HAEHLING (1978) 315f. Sollte sich aber der Protest des Lampadius vor allem gegen Stilicho und seine Politik gerichtet haben und nicht primär gegen Alarich, so kann eine spätere Zusammenarbeit mit Attalus und Alarich nicht grundsätzlich ausgeschlossen werden.

88 PLRE 2, 654f. (Lampadius 1) und PLRE 1, 493 (Lampadius 3).

89 PLRE 2, 655 (Lampadius 2; „,but may be identical with Lampadius 1“); so auch MACHADO (2013) 55; OLSZANIEC (2013) 422; CAMERON (2011) 733; MATTHEWS (1975) 279 oder CHASTAGNOL (1962) $249 \mathrm{f}$. 90 Ein Theodorus (PLRE 2, 1086 (Theodorus 9)) wird nach dem Sturz des Stilichos als PPO eingesetzt; dieser muss daher eher als Stilicho-Gegner oder Sympathisant des Olympius gelten. Umstritten ist hierbei, ob es sich noch um Mallius Theodorus selbst oder um seinen Sohn handelt, die vermutlich beide von den Befürwortern Stilichos zu dessen Gegnern überliefen; zur Diskussion vgl. KUHOFF (1983) 395 und MATTHEWS (1975) 262, 279 u. 285 die sich gegen eine Gleichsetzung mit Mallius Theodorus aussprechen; dafür VON HAEHLING (1978) 437; MAZZARINO (1942) 374.

91 PLRE 2, $801 \mathrm{f}$. (Olympius 2) und CLAUSS (1980) $174 \mathrm{f}$.

92 Das genaue Datum überliefert Cons. Ital. s. a. 408 (Chron. min. I. 300).

93 Zos. 5,32,1-3; auch der Kaiser soll gegen Stilicho von Olympius vereinnahmt worden sein; die Anschuldigung, Stilicho plane einen Putsch gegen Honorius mit Hilfe Alarichs oder wolle sich die Herrschaft über den Osten für seinen Sohn sichern, wurden in Umlauf gebracht. Vgl. Zos. 5,32,2; Philost. 12,1; Soz. 9,4; Oros. 7,38,1-3; Marcell. Com. s. a. 408 (Chron. min. II. 69). 
Damit bereiteten die meuternden Soldaten der administrativen Gewalt des Heermeisters ein blutiges Ende. ${ }^{94}$

Im Zusammenhang mit den Vorgängen des Sommers 408 lässt sich nichts über eine direkte Beteiligung der stadtrömischen Senatsaristokratie in Erfahrung bringen. Namhafte Personen, die dieser angehörten oder zumindest nahestanden, erscheinen lediglich auf der Liste der Opfer. So nennt Zosimos den Präfekten Italiens Longinianus, den magister officiorum Naemorius, den CSL Patroinus und den QSP Salvius. ${ }^{95}$ Selbst wenn diese durch Simonie ${ }^{96}$ und Willfährigkeit gegenüber dem Heermeister in Amt und Würden gehoben wurden, waren sie dennoch Angehörige des ordo senatorius, die nun ermordet waren. Dies konnte nicht im Interesse der Senatsaristokratie liegen. Schon deshalb wird von einer Mittäterschaft stadtrömisch-senatorischer Kreise an dieser Bluttat eher nicht auszugehen sein. Der Senat wurde vor vollendete Tatsachen gestellt und hatte nur noch die damnatio memoriae über Stilicho zu verhängen und den politischen ,Kollateralschaden', der auch ihre eigenen Reihen schwer traf, nachträglich zu sanktionieren. ${ }^{97}$ Der sich anschließenden Prozess- und Enteignungswelle ${ }^{98}$, die in erster Linie wohl eine schnelle Lösung darstellte, die Staatsfinanzen zu sanieren und die Forderungen der Soldaten zu erfüllen, stand die stadtrömische Senatsaristokratie ab-

94 Die Vorgänge und Verstrickungen in ihren Einzelheiten bleiben weitgehend im Dunkeln, zumal die Überlieferung hier selbst sehr wirr erscheint. Zu Olympius und dem Massaker zu Ticinum am ausführlichsten Zos. 5,32; ferner knapp Olymp. fr. 8 (Blockley); Soz. 9,4,7; Oros. 7,38,5f. und Cons. Ital. s. a. 408 (Chron. min. I. 300). Vgl. hierzu MCEVOY (2013a) 183-185; BÖRM (2013) 50f.; HEATHER 2(2010) 262f.; ausführlich JANSSEN (2002) 241-251; ferner MATTHEWS (1975) 280 -282.

95 Zos. 5,32,6-11; Flavius Macrobius Longinianus (PLRE 2, 686 f.: Longinianus 2), Naemorius (PLRE 2, 770), Patroinus (PLRE 2, 843f.), Salvius 2 (PLRE 2, 974). Die Zugehörigkeit zur stadtrömischen Senatsaristokratie ist nur im Fall des Flavius Macrobius Longinianus sicher belegt; dieser war bereits 401/402 Stadtpräfekt und wird in der Bauinschrift des Baptisteriums von S. Anastasia in Velabro (CIL 6, 41379) als Stifter genannt; auch die stadtrömische Grabinschrift (CLE 311), die mit ihm in Verbindung gebracht wird, scheint seine Abstammung aus der stadtrömischen Senatsaristokratie zu bestätigen. Vgl. NIQUET (2000) 124, Anm. 83 u. 184. Patroinus hatte zumindest gute Kontakte zur stadtrömischen Senatsaristokratie, wie dies die zahlreichen Briefe des Symmachus an ihn oder seinen Bruder Petronius bezeugen (Symm. ep. 7,102-128). Vgl. hierzu FLETCHER (2004) 166.

96 Vgl. Zos. 5,1,2-5 und Eunap. fr. 62 (Blockley). Hierzu vgl. KRAUSE (1987) 12. Claud. Cos. Stil. 2,46ff. und 2,157 ff. rühmt die fides des Stilicho gegenüber seinen Klienten.

97 Vgl. CTh. 7,16,1 (10.12.408). Die Hinrichtung des Stilicho und die Ermordung seiner Gefolgsleute war zunächst ein Gewaltakt, dem eine rechtliche Grundlage fehlte und dessen Rechtmäßigkeit mehr als zweifelhaft erscheinen musste. So war Olympius noch im Nachgang bemüht, durch Verhöre und Folter belastende Aussagen, die den Verrat Stilichos beweisen sollten, herbeizuführen (Zos. 5,35,2-4 u. 5,44,4f.). Die hostis-Erklärung und die erfolgte damnatio memorae - heute noch ersichtlich an der Radierung des Namens in den epigraphischen Zeugnissen (CIL 6, 31987 und 3868 = 31988 = 41381) - bestätigte offiziell die Rechtmäßigkeit dieser Bluttat.

98 Zos. 5,35,2-4 und 5,45,5-7; Anordnungen zur Konfiskation: u. a. CTh. 9,42,20 (29.09.408) und CTh. 9,42,21 (25.10.408) an Theodosius PPO gerichtet. Weitere an Theodorus gerichtete Erlasse schließen Rückgabepetitionen aus: CTh. 7,21,4; 9,40,2 u. 9,42,22 (22.11.408); diese verdeutlichen, wie vehement der Protest gegen die Konfiskation senatorischen Besitzes war. Vgl. hierzu auch FLETCHER (2004) 190-192 und JANSSEN (2002) 255. 
lehnend gegenüber und hintertrieb ihre Ausführung. Deshalb lässt sich wohl gerade in den Jahren 408/409 eine ausgesprochen hohe personelle Fluktuation im Amt des PPO und der beiden Schatzämter feststellen. ${ }^{99}$

Trotz des gemeinsamen Interesses an einem politischen Kurswechsel, der die Ablösung Stilichos natürlich voraussetzte, lehnte die stadtrömische Senatsaristokratie offenbar das neue von Olympius geführte Regime entschieden ab. Eben aus dieser Ablehnung und mangelnden Zusammenarbeit resultierend, war es nicht mehr möglich, nachdem das stilichonische Regime zerschlagen war, wieder eine funktionierende Administration zu etablieren. Durch den Widerstand der senatorischen Amtsträger gegenüber den Prozessen und Konfiskationen wurde ebenfalls die Sanierung der Staatsfinanzen verhindert, wodurch die Zahlungen an die Soldaten ausblieben und diese abermals mit Meuterei, Raub und Mord ${ }^{100}$ antworteten.

Wenn das Verhältnis zwischen dem Heermeister Stilicho und dem Senat und der stadtrömischen Senatsaristokratie beurteilt werden soll, so waren vor allem zwei Maßnahme richtungsweisend. Zum einen definierte Stilicho die Stellung des vir inlustris comes et magister utriusque militiae als alles überragende Zentralstellung der militärischen und zivilen Führung neu und suchte als ,Mann zweier Welten' demonstrativ eine enge Anbindung an die stadtrömische Senatsaristokratie. Zum anderen gab Stilicho dem Senat eine politische Funktion und gestand ihm Befugnisse zu, die den Senatoren Roms noch einmal ein erstaunliches Selbstbewusstsein einflößte. Solang die Interessen einigermaßen deckungsgleich waren, fand Stilicho im Senat und der stadtrömischen Senatsaristokratie eine nützliche Machtstütze, die Handlungsoptionen schuf und die Entscheidungen des Heermeisters legitimieren konnte. Mit Zunahme der Probleme, die nicht mehr schnell und zufriedenstellend gelöst werden konnten, schwand jedoch die Akzeptanz. Infolgedessen musste Stilicho verstärkt Aufmerksamkeit und politische Macht aufwenden, um sich den Senat als Machbasis weiter zu erhalten. Dies aber kostete Zeit und Kräfte, die Stilicho am Ende fehlten, um den Hof und das Heer unter Kontrolle $\mathrm{zu}$ halten.

\footnotetext{
99 Theodorus 9 (Fl. Mallius Theodorus? PLRE 2, 1086) PPO vom 13.09.408 (CTh. 6,28,4) bis 15.01.409 (Const. Sirm. 14); vgl. SEECK (1919) 314 u. 316. Caecilianus 1 (PLRE 2, 244-246) PPO vom 21.01. (CTh. 9,2,5) bis 01.02.409 (CTh. 9,16,12); vgl. SEECK (1919) 316f.Volusianus 1 (Rufius Antonius Agrypnius Volusianus? PLRE 2, 1182f.) CRP am 29.11.408 (CTh. 5,16,31), abgelöst von Heliocrates 1 (PLRE 2, 530). Zum Widerstand gegen die Enteignungswelle vgl. auch Zos. 5,45,5-7.

100 Zos. 5,47; die eingesetzten Befehlshaber Turpilio und Vigilantius verlieren hierbei ihr Leben, Jovius als PPO stieg gleichzeitig zur führenden Person am Hof auf. In Anbetracht des anhaltenden Kontrollverlusts über die oberitalischen Tuppen lässt sich anzweifeln, ob die Ausschreitungen gegen die ,barbarischen foederati und ihre Angehörigen (Zos. 5,35,8) tatsächlich auf Befehl des Hofes - insbesondere des Olympius - geschahen. Wie sich bereits zu Ticinum gezeigt hat, plünderten römische Truppen aus Versorgungs- und Besoldungsdefiziten römische Städte (Zos. 5,35,5). Ein ethnischer Grund, wie der in älterer Literatur angeführte „Anti-Germanismus“, war allenfalls nachgeordneter Natur. Vgl. JANSSEN (2002) 253f. gegen BAYLESS (1976) 70-76, bes. 76; PASCHOUD (1986) 246 mit Anm. 81; DEMOUGEOT (1951) 431; allgemein WAAS ${ }^{2}(1971)$ 37-41.
} 


\subsection{Constantius und die Restauration der römischen Herrschaft}

Nach dem Sturz des Stilicho und der Plünderung Roms erfolgte der Aufstieg des Fl. Constantius. Die Erfolge gegen die Usurpatoren in Gallien und Spanien ${ }^{101}$ verschafften Constantius das nötige politische Kapital, um mit den Großen am Hof erfolgreich konkurrieren zu können. Der magister officiorum Olympius, der 408 die Machtstellung Stilichos an sich gerissen hatte, soll von Constantius brutal beseitigt worden sein. ${ }^{102}$ In diesem Zusammenhang ist von Interesse, welche Haltung der Senat und die stadtrömische Senatsaristokratie gegenüber Fl. Constantius und dem politischen Umsturz am Hof einnahm. Grundsätzlich darf angenommen werden, dass die senatorischen Häuser Roms nur wenig Sympathie für Olympius hegten. Insbesondere nach der Usurpation des Attalus und der Plünderung Roms dürfte das Vertrauen der Senatorenschaft Roms in den ravennatischen Hof und die höfisch-zivilen Entscheidungsträger stark erschüttert gewesen sein. Fl. Constantius, der für die fatalen Ereignisse der Jahre 408 bis 410 keine Verantwortung trug, ${ }^{103}$ konnte vor der stadtrömischen Senatsaristokratie regelrecht als ,unbefleckte Lichtgestalt' in Erscheinung treten.

Nirgends wird dies so deutlich wie in den Werken des Rutilius Claudius Namatianus und des Orosius. Obwohl beide Autoren ihre Werke aus der Rückschau verfassten ${ }^{104}$ und damit bereits die überragende Machtstellung des Constantius klar vor Augen hatten, klingt hier eine Hoffnung an, die sich seit 411 mit der Person des siegreichen Feldherrn

101 Vgl. u. a. BÖRM (2013) 58-60; MCEVOY (2013a) 197-201 und bes. LÜTKENHAUS (1998) 38-72. Die frühe Laufbahn des Fl. Constantius bleibt weitestgehend im Dunkeln; in den Quellen tritt er erstmals im Kampf gegen Konstantin III. in Erscheinung. Eine militärische Laufbahn noch unter Stilicho wird zumeist aber angenommen. Vgl. ferner BÖRM (2013) 58; MCEVOY (2013a) 197; HEATHER 2(2010) 278 und OOST (1966) 238.

102 Olymp. fr. 8,2 (Blockley) und Philost, 12,1: Hiernach wurden Olympius die Ohren abgeschnitten und er wurde zu Tode geprügelt. Vgl. FLETCHER (2004) 45; LÜTKENHAUS (1998) 62-67 und OOST (1968) 238f. Dies, wie auch die Rückkehr des Olympius, ist nicht ganz unumstritten und lässt sich nur an der hier angeführten Stelle in den Fragmenten des Olympiodor belegen. Der nachfolgende Konflikt mit Heraclianus, der aller Wahrscheinlichkeit nach Gefolgsmann des Olympius war, stützt dies jedoch; so u. a. BÖRM (2013) 58 u. 60 und HEATHER 2(2010) 278. Der zeitliche Ablauf ist nicht klar; während BÖRM (2013) 58 die Beseitigung des Olympius mit 410 äußerst früh ansetzt, plädiert LÜTKENHAUS (1998) 62ff. eher für 411/412.

103 Die Stellung des Fl. Constantius am Hof vor 411 ist nicht leicht zu beurteilen. Orosius, der in der Retrospektive von 417 sein Werk verfasste, weist Constantius eine führende Rolle bereits vor dem Gallien-Feldzug von $411 \mathrm{zu}$ (Oros. 7,42,1ff.); andere Quellen verzichten gar auf die Nennung des Fl. Constantius und sprechen nur von den „Feldherren des Honorius“ (so Hyd. Lem. 46 (s. a. 411); Greg. Tur. Franc. 1,57,2f. oder Soz. 9,14,1f.), was wiederum nahelegt, dass Constantius noch nicht die führende Rolle am Hof innehatte, wie dies Orosius annahm. Die Teilung des Oberkommandos mit Ulfila (PLRE 2, 1180; magister equitum) spricht ebenfalls dafür, dass die Machtstellung des Constantius Beschränkungen unterlag. Vgl. BÖRM (2013) 58; MCEVOY (2013a) 197 f.; LÜTKENHAUS (1998) 62 - 64 mit Anm. 41; MATTHEWS (1975) 302 und STEIN (1959) 262.

104 Zur Abfassungszeit vgl. ALONSO-NÚÑEZ (1993) 197-213, bes. 198; ausführlich GOETZ (1980a) $9-12$. 
verbinden ließ. Besonders ins Gewicht fällt das Urteil des gallo-römischen Senators Rutilius Claudius Namatianus, der in De reditu suo den neuen Konsul als Bezwinger der ,Barbaren' und Gründer eines wiedererstarkenden Roms ${ }^{105}$ feierte. So sei Constantius „die einzige Errettung für Latiums Namen“106. Wie auch Orosius ${ }^{107}$ hält Rutilius Namatianus das strahlende Bild, welches Constantius abgibt, der vermeintlichen Niederträchtigkeit und dem Verrat des Stilicho in einer hasserfüllten Invektive ${ }^{108}$ entgegen. Orosius gibt ganz in diesem Sinne zu bemerken:

Damals schließlich begann der Staat zu spüren, welchen Nutzen er von einem Feldherrn hatte, der endlich einmal ein Römer war, und welche Schädigung er bis dahin erlitten hatte, als er lange hindurch barbarischen Heerführern preisgegeben war. ${ }^{109}$

Natürlich ist die Romanitas des Fl. Constantius, der aus dem von ,barbarischen' foederati seit langem beherrschten Militärmilieu in Moesien stammte, ${ }^{110}$ nicht überzustrapazieren. Entscheidend bleibt das durchweg makellos-positive Gegenbild zum ,Semibarbaren' Stilicho. Constantius stand als magister utriusque militiae $e^{111}$ aber so eindeutig in der politischen Nachfolge Stilichos, dass die Forschung nicht müde wird, dies immer wieder zu betonen. ${ }^{112}$ Den Zeitgenossen, insbesondere den senatorischen Kreisen Roms, kann nur schwer entgangen sein, dass sie ihre ganze Hoffnung auf einen ,zweiten Stilicho' richteten. Dem stellten sich Orosius und Rutilius Namatianus entschieden entgegen, indem sie beide Heermeister in einem strengen Schwarz-WeißAntagonismus präsentierten. Nur mit diesem Denken, dass Constantius der ,AntiStilicho' sei, war es für die stadtrömische Senatsaristokratie akzeptabel, sich erneut einem machtvollen Heermeister zu unterstellen.

Nicht alleine die militärischen Erfolge in Gallien und Spanien, ${ }^{113}$ sondern auch die Fortsetzung der bereits von Stilicho vertretenen senatsfreundlichen Politik sicherte Constantius die Unterstützung der stadtrömischen Senatsaristokratie. Ein wichtiges Anliegen des Heermeisters war es, als unentbehrlicher Garant des wiederhergestellten consensus universorum zu gelten. Den Bruch, den die Usurpation des Attalus und

105 Rut. Nam. 1,47-66 Vgl. hierzu Kap. 6.1.

106 Rut. Nam. fr. B,6-10: Conditor ips] novae consul Constantius ur[bis civibus auspi]cium consiliumque dedit, dum post belli]gerum trabeis thoraca secu[ndis effulget] Latii nominis una salus. Zum Text vgl. BARTALUCCI (1975) 3-26; CECCHINI (1974) 401-404 und FERRARI (1973) 15-30; zur renovatio unter Fl. Constantius und dem Lob des Rutilius Namatianus vgl. aktuell BLECKMANN (2007) 106f. und VERBAAL (2006) 157-171 bes. 171.

107 Oros. 7,38,1f.

108 Rut. Nam. 2,41-60.

109 Oros. 7,42,2: Sensit tunc demum respublica et quam utilitatem in Romano tandem duce receperit et quam eatenus perniciem per longa tempora barbaris comitibus subiecta tolerarit.

110 Dies trifft später so auch auf Fl. Aëtius und seinen Vater Gaudentius zu. Vgl. STICKLER (2002) 21.

111 Erstmals belegt in CTh. 7,18,17 vom 29. Februar 412. Vgl. MATTHEWS (1975) 354.

112 U.a. SALISBURY (2015) 88; BÖRM (2013) 63; KUHOFF 2012, 64; HEATHER ²(2010) 278; O’FLYNN (1983) 70.

113 Rut. Nam. 1,47-66. 
Konstantin III. sowohl zwischen dem Senat und dem Hof als auch zwischen der gallischen und der italischen Senatsaristokratie entstehen ließen, galt es zu beheben. Die am 12. Juni 411 erlassene Amnestie ${ }^{114}$ gegenüber den Anhängern des Attalus war ein wichtiger Schritt der Versöhnung, der möglicherweise bereits von Constantius veranlasst wurde. Die Berufung von Johannes, ${ }^{115}$ dem ehemaligen magister officiorum des Attalus, zum PPO für 412/413 setzte zweifellos das richtige Zeichen, dass sich Constantius für die politische Rehabilitierung der stadtrömischen Senatsaristokratie verbürgen würde. Dies wie auch die Vergabe der Stadtpräfektur an die ,altgläubigen` Senatoren Rutilius Claudius Namatianus 414, der zuvor schon 412 magister officiorum war, und Rufius Antonius Agrypnius Volusianus 417/418 waren geeignete Maßnahmen, die gallische und die stadtrömische Senatsaristokratie in Gefolgschaft zu halten. Constantius, dessen Christsein nicht anzuzweifeln ist, führte damit im Gegensatz zu Olympius ${ }^{116}$ den toleranten Kurs Stilichos fort.

Kampflos erfolgte der Machtwechsel am Kaiserhof aber keineswegs. Olympius mochte zwar spätestens Ende $412^{117}$ beseitigt worden sein, doch der comes Africae Heraclianus, einer seiner wichtigsten Gefolgsleute, ${ }^{118}$ der überdies als Henker des Stilicho zweifelhafte Berühmtheit erlangt hatte, kontrollierte nach wie vor die Kornkammer Africa. Im Jahr 412 wurde dieser sogar noch zum Konsul für das Folgejahr designiert. ${ }^{119}$ Vermutlich wurde Heraclianus bewusst als Gegengewicht zu Constantius aufgebaut. Es ist kaum anders zu erklären, als dass Olympius oder sogar der Kaiser selbst, dessen Existenz hierbei zu oft nivelliert wird, Heraclianus zu Hilfe rief. ${ }^{120}$ Als tyrannus ${ }^{121}$ wird

114 CTh. 9,38,11 (12.2.410?); die Datierung wird von DELMAIRE auf den 12. Juni 411 korrigiert vgl. DELMAIRE (1997) 111-126, hier 125 und DELMAIRE (1987) 827-840, hier 838f.

115 PLRE 2, 594 (Ioannes 4) und PLRE 1, 459 (Ioannes 2)? Vgl. LÜTKENHAUS (1998) 65f. und MATTHEWS (1975) 288.

116 Unter dem Einfluss des Olympius kam es in den Jahren nach 408 zu verschärften Maßnahmen gegen ,Heiden` und ,Häretiker'; i. B. der Ausschluss vom Staatsdienst u. a. in CTh. 16,2,31 (=Const. Sirm. 14) und CTh.16,5,43 (= Const. Sirm. 12). Vgl. hierzu auch Zos. 5,46,3; überdies stand Olympius in Kontakt mit Augustinus (Aug. ep. 97), der ein scharfes Eingreifen gegen die Donatisten in Nordafrika forderte. Vgl. hierzu HOGREFE (2009) 41- 43 u. 47 f.; MRATSCHEK (2001) 224-232 und LÜTKENHAUS (1998) 29f.; OVERBECK (1973) $50-52$.

117 Für den 7. Dezember 412 ist Rutilius Claudius Namatianus im Amt des magister officiorum fassbar (Rut. Nam. 1,561f.).

118 Vgl. JANSSEN (2002) 249f., der zu Recht darauf hinweist, dass Heraclianus die wichtige Stellung als comes Africae gewiss nicht nur seiner Dienstbarkeit als Henker des Stilicho verdankte, sondern diese Stellung aufgrund seiner Beteiligung am Sturz des Stilicho und damit als Unterstützer des Olympius und treuer Diener des Kaisers, als welcher er sich präsentierte, erhielt.

119 CTh. 15,14,13 (3.8.413); Oros. 7,42,10; Prosp. Tiro 1250 (s. a. 413).

$120 \mathrm{Zu}$ den Ereignissen und zum Italien-Feldzug des Heraclianus vgl. Oros. 7,42,12-17; Olymp. fr. 23 (Blockley); Prosp. Tiro 1249 (s. a. 412) und Marcell. Com. s. a. 413. Hierin einen Präventivschlag gegen einen befürchteten ,Racheakt des Constantius für die Ermordung des Stilicho zu sehen, trifft die Sache wohl nicht. So vor allem die Erklärung nach OOST (1966) 236-242; nachfolgend auch immer wieder in jüngeren Publikationen zu lesen, so z. B. BÖRM (2013) 60: „[...] als Mörder Stilichos zweifellos ein Todfeind des Constantius [...].“ 
Heraclianus zwar tituliert - so beispielsweise von Hydatius, Olympiodor und Orosius ${ }^{122}$ - jedoch wurde auch seine Loyalität ${ }^{123}$ gegenüber Honorius und der theodosianischen Dynastie stets betont. Damit werden die Fronten, die sich Anfang 413 auftaten, um einiges klarer. Auf der Seite des Constantius werden beträchtliche Teile der stadtrömischen und gallischen Senatsaristokratie und des Offizierkorps gestanden haben. Die Mehrheit in der stadtrömischen Senatsaristokratie und im Senat stand dem comes Africae seit der Usurpation des Attalus sicherlich verhalten, wenn nicht sogar feindlich gegenüber. ${ }^{124}$ Die Hoffnungen des Hofs - insbesondere jener Kreise um Olympius, welche die Kontrolle über den Kaiser im Machtkampf mit Constantius behaupten wollten - richteten sich hingegen auf Heraclianus. Sollte dies zutreffen, so würde sich die Rollenverteilung, welche die Quellen wiedergeben, ins Gegenteil verkehren. Constantius wäre der Rebell, der sich als siegreicher Heerführer gewaltsam an die Macht putschte, und Heraclianus der dem Kaiser und Hof treu ergebene comes. ${ }^{125}$

Mit Constantius siegt letzten Endes auch die stadtrömische Senatsaristokrartie über ihre Feinde. Olympius, dem das Blutbad von Ticinum, die Prozess- und Enteignungswelle ebenso wie die restriktive Haltung des Hofs gegenüber dem Heidentum angelastet

121 So auch PLRE 2, 539f.; ferner immer wieder in Fachaufsätzen und Gesamtdarstellungen zur Spätantike zu lesen: z. B. KUHOFF (2012) 64; HEATHER 2(2010) 300 (wenn auch zurückhaltender); KAMPERS (2008) 105; DEMANDT ²(2007) 181; JANSSEN (2002) 250; SCHMITT (2001) 540 f.; LÜTKENHAUS (1998) 5 (wobei nachfolgend S. 69 ff. deutlich differenzierter); besonders DIESNER (1968) 89-117, hier 105f.; ders. (1964) 30. Vollkommen abwegig erscheint vor allem die Annahme SIRAGOs, wonach Heraclianus angestrebt haben soll, sich durch den Senat von Rom zum Kaiser ausrufen zu lassen; vgl. SIRAGO (1961) 188, Anm. 4. Gegen die Bezeichnung als Usurpator vgl. SZIDAT (2010) 26-29 und SEIBEL (2006) $128 \mathrm{f}$.

122 Hyd. Lem. 51 (s. a. 412): Iovinus et Sebastianus frates intra Galliam et in Africa Heraclianus pari tyrannidis inflantur insania [...]. Ferner Olymp. fr. 23 (Blockley). Im sog. Tyrannen-Katalog des Orosius (Oros. 7,42,10) wird Heraclianus zwar aufgeführt, jedoch zusammen mit Gerontius und Alarich, die keineswegs als Usurpatoren zu verstehen sind; wobei die Unterscheidung zwischen Usurpatoren und abtrünnigen Feldherren sehr wohl gemacht wird. Vgl. Oros. 7,42,15: Hunc omnem catalogum, ut dixi, vel manifestorum tyrannorum vel inoboedientium ducum [...]. Indirekt wurde so auch Stilicho zu einem tyrannus stilisiert, der für seinen Sohn Eucherius die Herrschaft über den Osten erlangen wollte (Oros. 7,38,1); ferner auch Gainas (Marcell. Com. s. a. 400); zum veränderten Gebrauch der Begrifflichkeit vgl. SEIBEL (2006) 28f. u. 33.

123 Soz. 9,8,7f. und Zos. 6,11; 6,12,1: hier im Konflikt mit dem Usurpator Attalus 409/410; so auch HEATHER 2(2010) 300; SEIBEL (2006) 34; JANSSEN (2002) 250; LÜTKENHAUS (1998) 35 u. 67. Dies umfasst nicht nur den bewaffneten Widerstand gegen Attalus und die Blockade gegen Rom, sondern auch Hilfszahlungen an Ravenna (Zos. 6,10,2 und Soz. 9,8).

124 Zum schwierigen Verhältnis zwischen Heraclianus und den stadtrömischen Senatoren; auch hinsichtlich der angeblichen Bereicherung an den aus Rom geflohenen Aristokraten (Hieron. ep. 130,7) vgl. KOTULA (1977) 257-266, hier 262f. Das in Olymp. fr. 23 (Blockley) angeführte Vermögen des Heraclianus, welches sich auf 4.000 Pf. Gold belief, fällt aber eher bescheiden aus.

125 Bereits ELBERN (1984) 121 betont, dass es Heraclianus nicht um die Absetzung des Kaisers ging, sondern um die offengelegten Machtambitionen des Constantius, denen es entgegenzutreten galt; ihm folgend SEIBEL (2006) 130f.; prinzipiell auch LÜTKENHAUS (1998) 67, der ihn als gefährlichsten Gegner des Constantius bezeichnet, und eben nicht des Kaisers; dagegen SIRAGO (1961) 189. 
wurde, war beseitigt. Heraclianus, ungehorsam gegenüber dem Senat, zweimal Rom die zustehenden Kornlieferungen vorenthaltend, ${ }^{126}$ hatte durch Niederlage und Tod seine Strafe erhalten. Überdies konnte sich die Senatsaristokratie durch die gewährte Unterstützung den Heermeister verpflichten, so dass sie sowohl eine bevorzugte Behandlung als auch machtpolitisch relevante Zugeständnisse erwarten durfte. Dem kam Constantius bereits 414 nach, als er sein erstes Konsulat antrat und opulente Spiele ${ }^{127}$ ausrichten ließ. Die Kosten dafür wurden aus dem Privatbesitz des Heraclianus, der Constantius zugefallen war, bestritten. ${ }^{128}$ Damit wurde noch einmal unterstrichen, dass der Sieg des Constantius über Heraclianus ein Sieg für Rom war.

Das Diptychon aus dem Domschatz von Halberstadt (Abb. 4) ${ }^{129}$, welches zumeist mit dem Namen des Fl. Constantius in Verbindung gebracht wird, vermittelt einen guten Eindruck davon, mit welchem Bild sich der magister militum vor Rom präsentierte. Gewiss ist die Zuweisung des Diptychons und seine Datierung ${ }^{130}$ in Ermangelung einer Inschrift ${ }^{131}$ schwer abzusichern und muss hypothetisch bleiben. Dennoch legen seine ikonographischen Besonderheiten nahe, es mit Fl. Constantius in Verbindung zu brin-

126 Oros. 7,42,12; erfolgt muss dies unmittelbar mit Beginn der schiffbaren Jahreszeit, im Frühjahr 413, sein (zuvor schon 409). Vgl. LÜTKENHAUS (1998) 68.

127 Olymp. fr. 23 (Blockley); das Konsulat wird zwar in Ravenna angetreten; die Anwesenheit des Hofs in Rom ist aber für den 30. August 414 (CTh. 16,5,55) belegt. Vgl. SEECK (1919) 328. Gerade die Summe von insgesamt 2.000 Pf. Gold aus dem konfiszierten Vermögen des Heraclianus, die Constantius für die Ausrichtung seine konsularischen Spiele angewiesen bekam, entspricht den Kosten einer Spielgebung in der Metropole Rom (Olymp. fr. 41,2 (Blockley)). In Ravenna werden sich die Kosten schon allein aufgrund der geringeren Bevölkerungszahl und der wohl bescheideneren Ausmaße des Circus auf eine kleinere Summe belaufen haben. Bis heute ließ sich überdies der Standort des Circus in Ravenna archäologisch nicht fassen und auch ein sicherer Beleg für die Spielgebung in den literarischen Quellen kann nicht angeführt werden (Sid. carm. 23,307- 427 und Cassiod. Chron. a. 519).Vgl. aktuell PUK (2014) 167 f.; ferner HEUCKE (1994) 384ff.; DEICHMANN (1989) 223 und HUMPHREY (1986) 632f.

128 Olymp. fr. 23 (Blockley).

129 Foto: Falk Wenzel, Kulturstiftung Sachsen-Anhalt; Inv.-Nr. DS045. Vgl. DELBRUECK (1929) 87-93, Nr. 2 und VOLBACH ${ }^{2}$ (1952) 32f., Nr. 35.

130 Die Zuweisung erfolgte in Ermangelung einer Inschrift anhand stilistischer Kriterien und eines schlüssigen Ausschlussverfahrens durch DELBRUECK (1929) 91f.; ihm folgen u. a. OLOVSDOTTER (2011) 99-124; dies. (2008) 164-165; dies. (2005) 114-120; BÜHL (2001) 193-206; ENGEMANN (1999) 158-168; MEISCHNER (1996) 400 - 404; KÖNIG (1981) 299-360, hier 328 u. 331 und VOLBACH 2(1952) 32. Dagegen wies CAMERON das Diptychon dem östlichen Konsul Constans (PLRE 2, 311 (Constans 3)) von $414 \mathrm{zu}$; u. a. begründet durch die Darstellung östlicher ,Barbaren“ im unteren Bildfeld. Vgl. CAMERON (1998) 385-403, bes. 385; hiergegen argumentierten VON RUMMEL (2007) 245-249; BÜHL (2001) und ENGEMANN (1999). KIILERICH/TORP (1989) 343f. mit Anm. 122 nennt neben Fl. Constantius auch Heraclianus als möglichen Konsul des Diptychons. Vgl. erneut CAMERON (2015) 259 - 262; aktuell auch ROLLÉ DITZLER (2020) 344-346.

131 Auf dem rückseitigen Deckel des sog. Antiphonas, wo vormals die rechte Tafel angebracht war, sind Fragmente einer Inschrift zu sehen: [.]I[.] // C[I]AE // NA. Diese Inschrift wird von FUHRMANN zwar nicht dem Diptychon selbst zugewiesen, wird von ihm aber in ottonische Zeit datiert, so dass an eine Überführung des Diptychons aus Konstantinopel im 13. Jh. (1204 Eroberung; 1205 Rückkehr Konrad von Krosigks) nicht zu denken ist; gegen CAMERON (1998); vgl. FUHRMANN (2009) 10-12. Auch CAMERON (2015) 258-262 berücksichtigt dies nicht. 


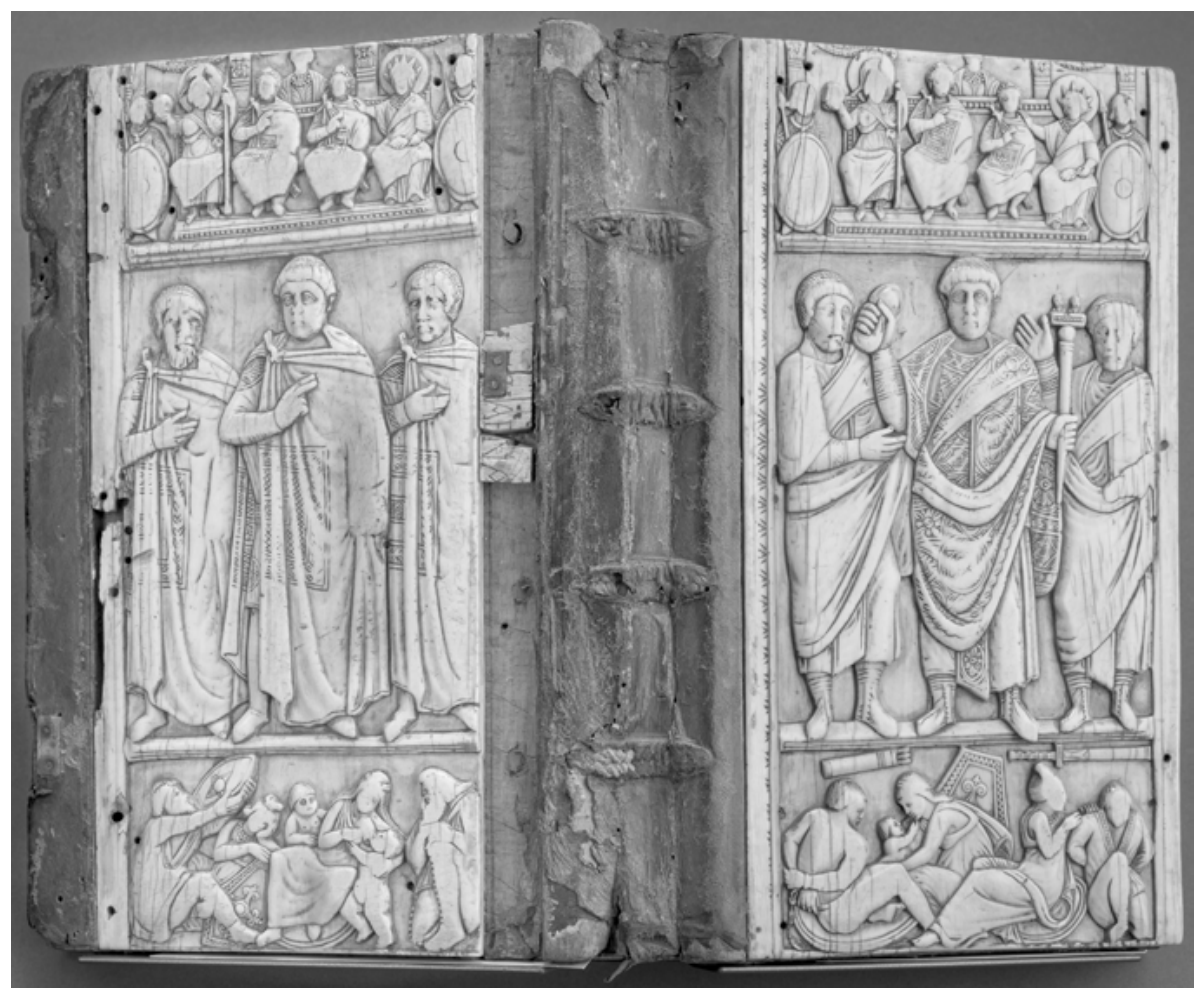

Abb. 4: Antiphonar mit Konsulardiptychon Constantius III.

gen. So deutet die Darstellung besiegter ,Barbaren“ (submissio) ${ }^{132}$ im unteren Bildfeld auf einen Militär, ${ }^{133}$ dem die Würde des consul ordinarius verliehen wurde, hin. Das Repräsentationsbild des Kaiserkollegs (Honorius und Theodosius II.) ${ }^{134}$ im oberen Register verdeutlichen das besondere Nahverhältnis des Konsuls zum Kaiserhaus. Als hoher Militär, der siegreich gegen die ,Barbaren` ins Feld zog, das Konsulat verliehen bekam

132 Hierzu ausführlich VON RUMMEL (2007) 245-249; ENGEMANN (1999) 162f.; mit Recht wird hier besonders die topische Darstellung der ,Barbaren“ betont, die keine konkrete Ethnizität zu erkennen gibt und sich nicht auf einem tatsächlich errungenen Sieg beziehen muss; entgegen CAMERON (1998) 391 (östlich: Perser, Skythen oder Sarmaten); KÖNIG (1981) 328 u. 331 (Vandalen) und VOLBACH ${ }^{2}(1952)$ 32 (Vandalen) nach DELBRUECK (1929) 91 (Vandalen in iranischer Tracht). Die ,exotische“ Tracht der Besiegten könnte so auch auf den Sieg über Heraclianus und seine nordafrikanischen Truppen 413 anspielen.

133 Dies bekräftigte erneut OLOVSDOTTER (2011) 116; auch CAMERON (1998) 386f. und ders. (2015) $160 \mathrm{f}$. betont die Besonderheit der submissio im unteren Register und verbindet diese mit einem militärischen Amtsträger/Auftraggeber; so bereits auch DELBRUECK (1929) 92.

134 So bereits DELBRUECK (1929) 91f.; dem folgt auch CAMERON (1998) 385-389. 
und ein Nahverhältnis zum Kaiserhaus anstrebte, kommt im Westen ${ }^{135}$ für diesen Zeitraum prinzipiell nur Flavius Constantius infrage. Da Theodosius II. hier deutlich kleiner dargestellt ist, ${ }^{136}$ sollten wohl am ehesten die Jahre 414 und 417 in Betracht gezogen werden. ${ }^{137}$

Der Geehrte auf dem Halberstädter Diptychon ist ausschließlich im zivilen Habitus zu sehen. Die Tafel A, die Hauptseite (hier rechts), zeigt den Konsul im kunstvoll bestickten Triumphalkostüm der toga palmata, in der Rechten die mappa und in der Linken ein Zepter, bekrönt mit den Büsten der Kaiser Honorius und Theodosius II. ${ }^{138}$ Auf der Tafel B (links) präsentiert sich der Konsul in der chlamys, die rechte Hand zum Redegestus erhoben. Die Begleiter, die den Konsul rechts und links flankieren, sind jeweils an die Tracht ihres Dienstherrn angeglichen und tragen ebenso die toga contabulata bzw. die chlamys. Bei dem Gefolge des Konsuls handelt es sich um hochrangige Vertreter der Senatsaristokratie. Die rechte Person neben dem Konsul ist hier durch die mappa in seiner Linken und das einfache Trabeakostüm ebenfalls als Konsul ${ }^{139}$ anzusprechen. Es handelt sich hier somit weniger um Amtsdiener als vielmehr um ein hochrangiges senatorisches Geleit, welches dem Konsul gegeben wird und diesen

135 Dass das Diptychon von Halberstadt ein Erzeugnis einer westlichen Werkstatt (Ravenna?) war, legt zumindest der Vergleich mit dem Felix-Diptychon (von 428; VOLBACH, Nr. 2) und dem Diptychon von Novara (VOLBACH, Nr. 64) nahe; ebenso die stilistische Nähe zum Missorium des Theodosius (von 388). Vgl. OLOVSDOTTER (2005) 8; ENGEMANN (1999) 158-168; MEISCHNER (1996) 404; VOLBACH 2(1952) 32 und STEENBOCK (1965) $67 \mathrm{f}$. CAMERONs Annahme, wonach es sich hierbei um ein oströmisches Diptychon handeln soll, wurde von ENGEMANN überzeugend widerlegt; die traditionelle Klassifizierung als westlich nach DELBRUECK (1929) 91 wird auch durch die Betrachtung der Fragmente der ottonischen Inschrift auf dem Antiphonar bestätigt. Vgl. FUHRMANN (2009) 10-12.

136 Für gewöhnlich würde die Münzprägung, die oftmals das Herrscherkolleg abbildete, heranzuziehen sein, wenn nicht gerade unter Honorius ein solches Motiv eine Rarität darstellen würde. Ein direkter Vergleich bietet sich lediglich mit RIC 10, 1207, welches die Kaiser Arcadius (rechts sitzend, größer dargestellt) und Honorius (links, kleiner) als Konsuln von 396 zeigt, an. Die Datierung in das Jahr 414 präferieren aus diesem Grund auch BÜHL (2001); ENGEMANN (1999) 159 u. 165f. und CAMERON (1998) 385 - 387. DELBRUECK (1929) 92 plädiert hingegen für das Jahr 417. Gegen CAMERON, der eine Vielzahl an Beispielen anführt, in denen jeweils der Kaiser, der das 15. Lebensjahr noch nicht vollendet hatte, kleiner dargestellt wurde, wendet sich BÜHL (2001) $197 \mathrm{f}$. Möglich ist so auch das Jahr 417, in welchem Theodosius II. sechzehn Jahre alt war, nicht siebzehn Jahre, wie CAMERON (1998) 386389 meint.

137 Die weibliche Gestalt, welche hinter den Augusti steht, wird oftmals als Galla Placidia, angesprochen, die sich zwar 414 noch im Gefolge der Westgoten aufhielt, doch über deren Rückgabe bereits Verhandlungen geführt wurden; vgl. Olymp. fr. 22; fr. 24; fr. 26 (Blockley); so die Deutung nach ENGEMANN (1999) 158, 164f. u. 166f.; vormals bereits DELBRUECK (1929) 92, der hieraus allerdings schlussfolgerte, dass eine Entstehung des Diptychons nach 416, der Rückkehr der Galla Placidia, in Betracht zu ziehen sei. CAMERON (1998) 389 sieht, entsprechend seiner Annahme, hierin Aelia Pulcheria, bezweifelt aber auch nicht, dass es sich hierbei um eine hohe Dame des Kaiserhauses handeln muss. Zu Galla Placidia in den Jahren 413 bis 417 und dem Interesse des weströmischen Hofs, ihre Rückgabe zu erwirken vgl. u. a. SALISBURY (2015) 87-11; SIVAN (2011) 24-29 u. 37-59; LÜTKENHAUS (1998) 72-75; SCHARF (1996a) 5-25; O’FLYNN (1983) 66 oder OOST (1968) 118-120.

138 Auch hier ist der Größenunterschied deutlich kenntlich gemacht worden.

139 Vgl. Hierzu auch DELBRUECK (1929) 52. 
sichtbar in der Mitte der Senatsaristokratie verortet. Für einen Heermeister, der keine natürliche, durch eine edle Abstammung begründete Verbindung zu den Kreisen der Senatsaristokratie für sich beanspruchen konnte, stellte das aristokratische Geleit ein wichtiges Repräsentationselement dar, welches seine gesellschaftliche Spitzenposition unterstrich. Schon Stilicho beanspruchte für sich zweimal das Konsulat und erkannte die Bedeutung dieser höchsten Würdestellung. Constantius übernahm die Ehre des ordentlichen Konsulats insgesamt dreimal. Die konsularische Iteration ${ }^{140}$ war hierbei geradezu notwendig, um sich gewissermaßen aus dem Nichts ${ }^{141}$ an die Spitze der Rangfolge des ordo senatorius zu katapultieren.

Um die Akzeptanz der stadtrömischen Senatsaristokratie zu erlangen, war es aber ebenso notwendig, sich die aristokratischen Normen und Werte anzueignen, um damit die eigene nobilitas unter Beweis zu stellen. Letztlich strebte der magister militum vor der stadtrömischen Senatsaristokratie die Führungsrolle an, die er - um mit der Terminologie Löhkens zu sprechen - gleich dem Kaiser nur als „Superaristokrat unter Aristokraten“142 wahrnehmen konnte. Angesichts der wenig schmeichelhaften Beschreibung, die Olympiodor von Constantius abgibt, erforderte es gewiss einiges an Arbeit und Energie, das Bild des obersten Heermeisters dem „besseren Teil der Menschheit“ anzugleichen:

[...], ein Mann mit hervorquellenden Augen, langem Hals und breitem Kopf, der ständig über dem Hals des Pferdes, auf dem er ritt, gebeugt lag, [...]. Aber bei Banketten und Festen war er so ausgelassen und umgänglich, dass er sogar mit den Gauklern ${ }^{143}$, die häufig an seinem Tisch auftraten, in Wettbewerb trat. ${ }^{144}$

Ein solcher Mann musste in den feinen Kreisen der stadtrömischen Senatsaristokratie deplatziert wirken. Zu Beginn seines Aufstiegs war Fl. Constantius alles andere als der „Superaristokrat unter Aristokraten“. Ein Dichter vom Format Claudians, der Con-

140 Vgl. hierzu SGUAITAMATTI (2012) 63-66.

141 Der magister militum zählte zwar als vir inlustris zur obersten Rangklasse, war aber dadurch den Reichspräfekten, den Stadtpräfekten oder den obersten Hofbeamten (u. a. mag. off., QSP, CSL, CRP, sowie der com. dom.) prinzipiell nur gleichgestellt und nicht übergeordnet; zum Rangsystem vgl. REBENICH (2008) 153-176, hier 157 f.; NOETHLICHS (1998b) 33-35 und LÖHKEN (1982) $1 \mathrm{f}$.

142 LÖHKEN (1982) 56.

143 Bereits Ammianus Marcellinus (Amm. 14,6,12-17 u. 28,4,14) kritisiert, dass sich die Senatoren in unwürdiger Weise an ihrer Tafel mit Schauspielern umgaben. Zum wenig schmeichelhaften Sittengemälde Ammians in dessen Rom-Exkursen vgl. u. a. VERGIN (2013) 241-252 oder zusammenfassend NÄF (1995) 58f. und STRAUB (ND 1964) 202f.; grundlegend KOHNS (1975) 485-491 und PACK (1953) $181-189$.

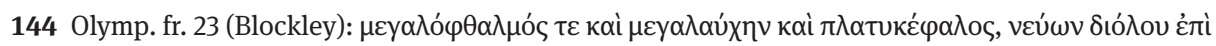

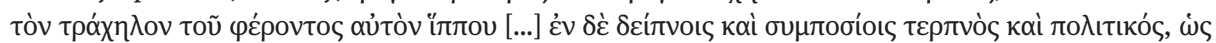

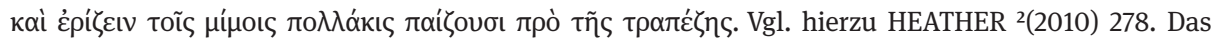
unwürdige Bild, welche Olymiodor hier von Constantius (III.) zeichnet, hat vermutlich mit der ablehnenden Haltung des Ostens gegenüber seiner Kaisererhebung zu tun. Konstantinopel betrachtete Constantius (III.) sicher als illegitim und unwürdig. 
stantius zu Diensten stand und ein für die stadtrömische Senatsaristokratie passförmiges Bild kreierte, fehlt uns hier.

Umso wichtiger sind die archäologisch fassbaren Zeugnisse. Neben dem bereits angeführten Konsulardiptychon aus dem Domschatz von Halberstadt ist ein Fragment ${ }^{145}$ eines weiteren Diptychons, welches Fl. Constantius zugeordnet werden kann, ${ }^{146}$ anzuführen. Nach rechts gewandt an eine Säule gelehnt steht die Muse Erato ${ }^{147}$ mit Chiton und Himation bekleidet. In der linken Hand hält sie eine Schriftrolle. Ihr zur Seite ein nackter Eros auf der Weltkugel, mit der Rechten eine Fackel nach unten haltend und mit der Linken der Muse einen Palmzweig entgegenstreckend. Hinter ihm steht die Büste eines jungen Dichters. ${ }^{148}$ Es muss gar nicht darüber spekuliert werden, ob Fl. Constantius auf der nicht bekannten Haupttafel möglicherweise selbst dargestellt wurde. ${ }^{149}$ Das Dichter-Musen-Diptychon von Monza ${ }^{150}$ wird für eben dieses bildliche Gesamtarrangement, welches auf der einen Tafel einen Dichter bzw. Philosophen und auf der anderen eine Muse zeigt, als Vergleichsstück dienen dürfen. Unwahrscheinlich und überdies auch unnötig erscheint es, dass Constantius hier selbst als Dichter oder Philosoph in Erscheinung trat. Als Mann von Bildung ließ ihn allein schon die gewählte Darstellung erscheinen. Entsprechend des Dichter-Musen-Diptychons von Monza präsentiert sich auch hier der geehrte Konsul als ein Liebhaber beider Facetten der hohen Gelehrsamkeit, dem sowohl die ernsthafte literarische Beschäftigung mit der Philosophie und Wissenschaft als auch die Schönheit der Lyrik und Musik nicht fremd war. Wie Claudian die Bildung des Stilicho vor der Senatsaristokratie pries, ${ }^{151}$ waren solche Bilder bestens geeignet, Constantius den hoch gebildeten senatorischen Kreisen ${ }^{152}$ anzuempfehlen.

145 DELBRUECK (1929) Nr. 36 und VOLBACH ${ }^{2}$ (1952) Nr. 34. Die entsprechende Diptychontafel gilt seit dem Zweiten Weltkrieg als verschollen.

146 Die fragmentarisch erhaltene tabula ansata gibt die Zeilen [...] Q(ue) PATR(icius) ET SECVNDO [consul ordinarius] zu erkennen, was es erlaubt, das Diptychons mit dem zweiten Konsulat des Constantius 417 in Verbindung zu bringen. Vgl. ENGEMANN (1998) 116 mit Taf. 8c. Es handelt sich hierbei um die rechte Tafel, welche die Inschrift der linken Haupttafel, die den Namen getragen hatte (vgl. CIL 13, 3674), fortführt. Ausführlich zum Diptychon vgl. SHELTON (1983) 7-23. Die Zuweisung an Fl. Constantius erfolgte bereits durch DELBRUECK (1929) 156.

147 'Ерат⿳́, die „liebliche“ Muse der Lyrik (i. B. der Liebesdichtung), des Gesangs und des Tanzes; möglicherweise mit dem Werben um Galla Placidia zu verbinden; die mit Fl. Constantius 417 die Ehe einging.

148 Zur knappen Beschreibung vgl. VOLBACH ${ }^{2}(1952) 42$.

149 Diese Vermutung, wonach sich hier Constantius selbst als Dichter oder Philosoph darstellen ließ, weist zu Recht SHELTON (1983) 20 als unwahrscheinlich zurück; ihr folgt hierin ENGEMANN (1999) 161. 150 VOLBACH $^{2}(1952)$ Nr. 68.

151 Claud. Cos. Stil. 2,66 ff.: als Erzieher des Honorius und Claud. Cos. Stil. 2,124ff. u. 168 ff.: Künste und Wissenschaft sowie Rhetorik und Geschichtsbildung; jedoch wirft ihm Hieronymus nach seinem Sturz eine mangelhafte Bildung vor; Hieron. ep. 123,17.

152 Sid. ep. 8,2,2: [...] nam iam remotis gradibus dignitatum, per quas solebat ultimo a quoque summus quisque discerni, solum erit posthac nobilitatis indicium litteras nosse. Hierzu vgl. GOLTZ (2020) 128f.; HESS (2019) 1; REBENICH (2008) 153; NÄF (1995) 137 u. 285f.; HARRIES (1994) 239; ferner GERTH (2013) 
Formal abgesichert und legitimiert war die Machtstellung des Constantius dennoch nicht. Das Dilemma, mit welchem bereits Stilicho zu kämpfen hatte, bestand fort. Ein wichtiger Schritt, diese nach wie vor informelle Machtstellung formal mit einer ebenso außerordentlichen Ehrenstellung abzusichern, war die Verleihung des Patriziustitels. ${ }^{153}$ Hierdurch wurde der zivilen Führungsrolle des Constantius erstmals eine Bezeichnung gegeben. Der Titel zeigte zum einem das besondere Nahverhältnis des Constantius zum Kaiser an und setzte seinen Inhaber symbolisch mit den Verwandten des Kaisers gleich, ${ }^{154}$ zum anderen verdeutlichte der Titel den Vorrang vor den übrigen Amts- und Würdenträger des ordo senatorius. ${ }^{155}$ Die wesentlichen Grundzüge des Patriziats, wie es Constantius verstanden wissen wollte und einsetzte, hat bereits Lütkenhaus versucht darzulegen. ${ }^{156}$ Vor allem im Schisma von 418/419 157 tritt Constantius als patricius vor die im Kirchenstreit tief gespaltene stadtrömische Senatsaristokratie und fungiert als wichtige Entscheidungsinstanz. Von Bedeutung ist hier vor allem die Kommunikation zwischen dem Stadtpräfekten Aurelius Anicius Symmachus ${ }^{158}$ und Constantius. Besonders aufschlussreich ist hierbei auch die Anredeformel, mit der Symmachus den patricius anschrieb:

[...] DOMINO SEMPER ILLVSTRI ET CVNCTA MAGNIFICO, MERITOQUE SVBLIMI AC PRAECELSO PATRONO CONSTANTIO SYMMACHVS PRAEF. VRB. ${ }^{159}$

Neben der geradezu ausufernden Huldigung fällt vor allem die Titulatur praecelsus patronus - sehr hoher Patron - auf, welche das Verhältnis zwischen dem Stadtpräfekten und dem patricius näher bestimmt. Als unwahrscheinlich darf gelten, dass der

157-223; MATHISEN (1988) 45-52. Zu den senatorischen Bildungsidealen und der Bildung als Distinktionsmerkmal der stadtrömischen Senatsaristokratie vgl. Kap. 9.1.

153 Die Verleihung des Patriziustitels für 415 lässt sich auf Grundlage von Prosp. Tiro s. a. 415 annehmen; das erste fassbare Gesetz, welches sich an den patricius Constantius richtet (CTh. 15,14,14), datiert auf den 1. März 416. DEMANDT (1970) Sp. 630 f. datiert die Ernennung auf den Winter 414/15. Vgl. auch HEIL (1966) 30 und ENSSLIN (1931) 496.

154 Gerade für Fl. Constantius, der zumindest zu Beginn seines Aufstiegs anders als Stilicho nicht über ein besonders Vertrauens- bzw. Nahverhältnis zum Kaiser verfügte, war dies nicht unwichtig. Vgl. O’FLYNN (1983) 65f. u. 107; DEMANDT (1970) Sp. 632 und ENSSLIN (1931) 497 f.: „Dieser patricius ist der nächste am Thron“. Zum Patriziat unter Konstantin d. Gr. vgl. HEIL (1966) bes. 36 f. und ENSSLIN (1934) 361-376. Stilicho führte den Patriziustitel nicht; seine besondere Nähe zum Kaiserhaus fand seine Entsprechung in der Titulatur des parens principum.

155 Es handelt sich hierbei wohl eher nicht um ein fest umrissenes Amt mit konkreten Befugnissen; so noch O’FLYNN (1983) 66; ENSSLIN (1931) 497 ff. und bes. PICOTTI (1928) 3-80; sondern um eine Ehrenstellung, die maximale Dignität verlieh. Vgl. ANDERS (2010) 126f.; MACGEORGE (2002) 5; BARNWELL (1992) 44-47; MATHISEN (1991) 173-190; ders. (1986) 35-49 und DEMANDT (1970) Sp. $631 \mathrm{f}$. 156 LÜTKENHAUS (1998) 143-149.

157 Zum Verlauf vgl. DUNN (2015) 1-13; DIEFENBACH (2007) 242-249; LÜTKENHAUS (1998) 136-143; WIRBELAUER (1994) 388 - 437 bes. 410 - 415 und ausführlich CHANTRAINE (1988) $79-94$.

158 PLRE 2, 219f. (Aurelius Anicius Symmachus 6).

159 Coll. Av. 29,1 (21. Mai 419); zu Coll. Av. 32,6 (Ende Mai) = CSEL 35,1,78f. mit selbiger Anredeformel vgl. LÜTKENHAUS (1998) 147 oder O’FLYNN (1983) 67. 
Stadtpräfekt Aurelius Anicius Symmachus in einem Klientenverhältnis ${ }^{160}$ zum magister militum Constantius stand. Überdies liegt hier keine Privatkorrespondenz vor, sondern ein offizielles Dienstschreiben aus dem Büro des praefectus Urbi. ${ }^{161}$ Somit trägt die gesamte Titulatur einen amtlichen Charakter und definiert das Verhältnis zwischen beiden Amtsträgern. Die Bezeichnung des Constantius als patronus kann in diesem Fall nur so verstanden werden, dass sich hierdurch der Stadtpräfekt unter die höhere auctoritas des patricius stellt. Damit wurde Constantius zum patronus des Amtsbereichs des Stadtpräfekten, der Stadt Rom und des Senats. Hierdurch war der patricius zwischen Kaiser und praefectus Urbi als neue Instanz zwischengeschaltet worden. ${ }^{162}$ Dementsprechend wird er mit der Anrede dominus ebenso in Nähe des Kaisers gerückt. ${ }^{163}$ Die Rechtmäßigkeit seiner außergewöhnlichen Stellung betont eigens die Wendung meritoque sublimis - rechtmäßig emporragend.

Die gewaltsamen Ausschreitungen in der Stadt, an welchen senatorische Kreise offenbar eine Mitschuld trugen, ${ }^{164}$ die Einmischung Galla Placidias ${ }^{165}$ und die unklare

160 Es trifft zwar zu, dass auch Stilicho als Patron vor Angehörigen des ordo senatorius auftrat (so Patroinus) und Melania und Pinian von Serena protegiert wurden; die hochrangigen Vertreter der Senatsaristokratie, die selbst Patrone waren, begaben sich wohl eher nicht in ein Patron-/Klientenverhältnis zum obersten Heermeister - konnten aber in amicitia zu diesem treten (so Quintus Aurelius Symmachus zu Stilicho oder Patroclus, der Bischof von Arles, zu Constantius). Vgl. KRAUSE (1987) 12f. u. 57. Zur schwierigen Abgrenzung zwischen amicitia und patrocinium vgl. KRAUSE (1987) 5f.; ferner PEACHIN (2011) 412-419 und besonders EPP (1999) 7-16 u. 130 - 175.

161 Das Bonifatius-Eulalius-Dossier (Coll. Av. 14-37) aus dem Archiv des Stadtpräfekten ist zusammen mit dem Damasus-Ursinus-Dossier (Coll. Av. 1-13) überliefert in der Collectio Avellana; in der Mitte des 6. Jhs. in das Kirchenrecht aufgenommen und im Streit zwischen Laurentius und Symmachus um den Bischofsstuhl von Rom (498/499) herangezogen. Vgl. WIRBELAUER (1994) 407 mit Anm. 80 und ders. (1993) 134-138 und CHANTRAINE (1988) 80f. Edition CSEL 35 GÜNTHER (1895). Zum Schriftverkehr aus juristischer Sicht aktuell nun auch LIEBS (2015) 146-165, bes. $158 \mathrm{ff}$.

162 Vgl. LÜTKENHAUS (1998) 149. Der PVR war eigentlich nur dem Kaiser rechenschaftspflichtig; vgl. KRAUSE (2014) 159.

163 PICOTTI (1928) 64 geht davon aus das die Anrede als dominus Constantius aufgrund seines Patriziustitels zustand. Dies ist insofern möglich, als dass Constantius mit dem Titel des patricius symbolisch den Verwandten des Kaisers gleichgestellt war und überdies anlässlich seines zweiten Konsulatsantritts am 1. Januar 417 mit der Halbschwester des Kaisers, Galla Placidia, vermählt wurde. Zu der Titulatur/Anredeform patricius noster oder patricius Honorii vgl. LÜTKENHAUS (1998) 149 oder PICOTTI (1928) 43.

164 Coll. Av. 29,4f.; offenbar gestanden die Sklaven, die gegen die Anhänger des Eulalius ausgeschritten waren, die Beteiligung ihrer Herren; gemäß der Lex Iulia maiestatis war die Aussage eines Sklaven, die sich gegen seinen dominus richtete, unter diesen besonderen Umständen zulässig (Ulp. Dig. 48,4,7). Vgl. LÜTKENHAUS (1998) 147 mit Anm. 69.

165 Zur Positionierung der Galla Placidia und ihrer Nähe zur stadtrömischen Senatsaristokratie vgl. SALISBURY (2015) 125-128; SIVAN (2011) 72-78; LÜTKENHAUS (1998) 141-143 u. 148-150; CHANTRAINE (1988) 87 f. und OOST (1968) 159 u. 167. Die von OOST geäußerte Annahme, wonach Galla Placidia sich auf der Seite ihres Gatten positioniert haben soll, wurde bereits von CHANTRAINE widerlegt. In der Collectio Avellana sind zwei Briefe der Galla Placidia erhalten; Coll. Av. 25 (ad Aurelium) und Coll. Av. 28 (ad Augustinum et al.). Vgl. hierzu aktuell auch DUNN (2015) 6f. 
Haltung des Kaisers ${ }^{166}$ hatten Symmachus wohl dazu veranlasst, sich an den patricius Constantius zu wenden. Symmachus musste befürchten, am Ende mit dem Vorwurf konfrontiert zu sein, die falsche Partei ${ }^{167}$ bestraft oder bevorzugt zu haben. In solch einer heiklen Situation war es gewiss sinnvoll, sich abzusichern. Jedoch unterließ es Constantius, Anweisungen zu geben, und verwies lediglich auf die Beschlüsse des Kaisers. Erst als Bonifatius als Bischof von Rom am 3. April 419 vom Kaiser bestätigt wurde, ${ }^{168}$ hatte Symmachus Klarheit. Durch diesen Sachverhalt werden gleich zwei entscheidende Punkte ersichtlich, die in der Forschungsdiskussion immer wieder fälschlich ins Gegenteil verkehrt wurden. Zum einen wäre hier der Auffassung Lütkenhaus entgegenzutreten, wonach der Patriziustitel, insbesondere in der Anrede patricius noster, welche

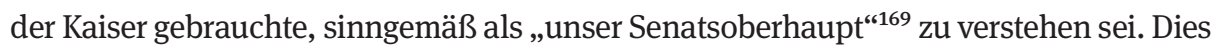
würde implizieren, dass Honorius den Constantius als Oberhaupt des Senats mit umfassenden Befugnissen eingesetzt hätte. Doch dies liegt offensichtlich im Fall des Schismas von 418/419 nicht vor, denn als weisungsbefugt sieht sich Constantius selbst nicht an. Zum anderen kann nicht die Rede davon sein, dass Constantius in irgendeiner Weise beabsichtigt hätte, in dieser Angelegenheit seine Kompetenzen aus eigenem Antrieb heraus zu erweitern, wie dies Jones ${ }^{170}$ dem Heermeister unterstellen wollte.

Gleichwohl bedarf es nur einer kleinen, aber nicht unbedeutenden Modifikation der Hypothese von Lütkenhaus. An der allgemeinen Führungsrolle und dem beherrschenden Einfluss des Constantius im gesellschaftlichen und staatlichen Gefüge des Westens wird insgesamt nicht zu rütteln sein. Doch ob Constantius den Titel des patricius erst für sich instrumentalisierten musste, um den Senat, die stadtrömischen Senatsaristokratie und die Dinge in Rom bestimmen zu können, bleibt ernsthaft zu bezweifeln. ${ }^{171}$ Der entscheidende Impuls, den patricius Constantius als übergeordnet meritoque sublimis ${ }^{172}$ - anzuerkennen und als Oberhaupt in die Pflicht zu nehmen, ging letzten Endes von der stadtrömischen Senatsaristokratie selbst aus. Constantius wurde von den Senatoren Roms und dem Stadtpräfekten nicht nur gewollt, sondern auch

166 Zur Haltung des Kaisers, welche wechselhaft war und im Verlauf des Konflikts von Eulalius zu Bonifatius wechselte vgl. DUNN (2015) 1-13, bes. 4- 7 (i. B. zur Korrespondenz zwischen Honorius und dem PVR); LÜTKENHAUS (1998) 140 - 142 und CHANTRAINE (1988) 86f.

167 DIEFENBACH vermutet, dass Symmachus im Gegensatz zu der Mehrheit seiner Standesgenossen eher mit Eulalius sympathisierte; vgl. DIEFENBACH (2007) 243-245. Die Bevorzugung des Eulalius durch den Stadtpräfekten geht aus dem Bericht an den Kaiser vom 29. Dezember 418 (Coll. Av. 14,4-7) sowie der Inhaftierung und Abmahnung der abtrünnigen Presbyter (Coll. Av. 14,6) hervor; so bereits auch CHANTRAINE (1988) 82f. und PIETRI (1976) 457f. LÜTKENHAUS lässt dies unberücksichtigt.

168 Coll. Av. 33: Anweisung, dem Bonifatius den Zugang zur Stadt zu gewähren, nachdem sich Eulalius durch die Gewaltakte zum Osterfest selbst disqualifiziert hatte. In Coll. Av. 29,2 an Constantius geht Symmachus offenbar noch davon aus, dass Eulalius die Rückkehr nach Rom gestattet worden war. Vgl. LÜTKENHAUS (1998) 141.

169 LÜTKENHAUS (1998) 149, ferner ebd. 119 u. 132.

170 JONES (1964) $343 \mathrm{f}$.

171 So auch ANDERS (2010) 129.

172 Coll. Av. 29,1 u. 32,1. 
gebraucht. Die administrativen Probleme, mit welchen Symmachus konfrontiert war und die ihn veranlasst hatten, sich an den patricius zu wenden, waren symptomatisch für die Herrschaft des Honorius. Zu nennen ist hier die Entscheidungsschwäche des Kaisers, die gepaart mit gravierenden Kommunikationsschwierigkeiten zwischen dem ravennatischen Hof und dem Stadtpräfekten zu ernsten administrativen Problemen führte. Constantius konnte die kaiserliche Entscheidung forcieren und die Entscheidungsfindung damit beschleunigen. Ebenso konnte er als Mittler zwischen Hof und Senat bzw. dem Stadtpräfekten fungieren und kommunikative Schwierigkeiten überbrücken. Der magister militum et patricius machte sich somit gerade durch die Defizite seines Kaisers unentbehrlich für das reibungslose Funktionieren der administrativen Organe.

Die außerordentlichen Ehrungen, die Constantius im Jahr 420 erhielt, spiegeln seine enorme Bedeutung und Unentbehrlichkeit für das Funktionieren des römischen Staats wider. Zusammen mit dem dritten Konsulat erhielt Constantius ein Ehrenmonument, welches ihn als reparator rei publicae und parens invictissimorum principum ${ }^{173}$ feierte. Als Dedikant tritt Aurelius Anicius Symmachus in der Funktion des praefectus Urbi auf. Trotz der heiklen Situation im Schisma von 418/419 konnte sich Symmachus im Amt halten. Höchstwahrscheinlich besaß er die Unterstützung des Constantius, wofür er diesem nun im Namen des Kaisers (vice sacra iudicans) ${ }^{174}$ in der Stadt Rom, vermutlich auf dem Trajansforum, ${ }^{175}$ ein Denkmal setzen ließ. Nicht nur der gallische Aristokrat Rutilius Claudius Namatianus erkannte in der Wiedererrichtung des Gemeinwesens die große Leistung des Constantius. Auch dem Senat und der stadtrömischen Senatsaristokratie entgingen die beachtlichen Erfolge des Heermeisters nicht. Die überragende Machtstellung des Constantius als „väterlicher“ Beschützer und Lenker des Kaisers, fand nicht nur unter der gallischen, sondern auch unter der stadtrömischen Senatsaristokratie ihre Anerkennung. Allerdings stand die Entscheidungsgewalt des Constantius formal noch immer unter der des Kaisers, was bei den Amtsträgern der kai-

173 CIL 6, 1719 (ILS 801): REPARATORI REI PVBLICAE [et] / PARENTI INVICTISSIMO[rum] / PRINCIPVM [Fl(avio)] CO[n]S[tan]T[io] / V(iro) C(larissimo) ET INLVSTRI COMITI [et] / MAGISTRO VTRIVSQ(ue) [militiae] / PATRICIO ET TERTIO C[ons(uli)] / ORDINARIO [...]; aktuelle Lesung nach LSA 1423 (U. GEHN). Vgl. ferner NIQUET (2000) 84f. und O’FLYNN (1983) 67. Die Statuenbasis mit der Inschrift gilt heute als verschollen, war aber noch dem Ancorianer CYRIACUS (1424) zugänglich und wurde von diesem festgehalten. Vgl. MOMMSEN, CIL 3, 1, p. 22f. Vgl. auch CIL 6, 1720, welches ein zweites Ehrenmonument für Constantius bezeugt, jedoch nur unvollständig überliefert ist.

174 CIL 6, 1719 (ILS 801): [...] / VICE SACRA IVDICANS / DEDICAVIT.; es fehlt das S.P.Q.R. - die Erwähnung von Senat und Volk von Rom - die hier nicht als Dedikanten genannt sind, sondern der PVR als Vertreter des Kaisers. Zum titularen Zusatz des PVR iudex sacrarum cognitionum oder vice sacra iudicans, der diesen als kaiserlichen Magistrat ausweist, vgl. EICH (2005) $360 \mathrm{f} . ;$ NIQUET (2000) 131f.; KASER/HACKL ${ }^{2}$ (1996) 535f. und MOMMSEN (ND 1961) 270 [1899].

175 Dagegen nimmt NIQUET (2000) 23 f. u. 72 eine Ehrung auf dem Forum Romanum an. In diesem Fall hätten aber der Senat und das Volk von Rom über die Aufstellung verfügen müssen, wie dies an zahlreichen Beispielen, die NIQUET selbst vor Augen hatte, belegt ist; z. B. CIL 6, 1730 u. 1731: Stilicho; CIL 6, 41389: Aëtius oder CIL 6, 41398: Petronius Maximus; vgl. die ergänzte Dedikationsformel nach PANCIERA (1996) 294. 
serlichen Administration $\mathrm{zu}$ hierarchischen Problemen und Unsicherheiten führen konnte.

Letztlich konnte nur die Erhebung des Constantius (III.) zum Mitkaiser ${ }^{176}$ dieses Problem lösen. Insofern war die Kaisererhebung $421^{177}$ ein konsequenter Schritt. Dass Honorius hierbei nicht ganz freiwillig ${ }^{178}$ zum auctor imperii des Constantius wurde, ist durchaus nachvollziehbar, war doch zu befürchten, dass er sich hierdurch nun vollends überflüssig machen würde. Gleichwohl sorgte Honorius mit seiner Führungsschwäche selbst dafür, dass es für notwendig erachtet wurde, ${ }^{179}$ ihm Constantius als Mitkaiser zur Seite zu stellen. Auch mochte die Erkrankung des Kaisers, die ihm zwei Jahre später, im Alter von 38 Jahren, den Tod brachte, eine Rolle gespielt haben. ${ }^{180}$ Mit Ausnahme des unwahrscheinlichen Falls, dass hier eine direkte Willenserklärung des Honorius vorlag, musste die Aufforderung hierzu aus einem breiten Konsens ${ }^{181}$ der entscheidenden Führungsgruppen hervorgegangen sein. Auf alle Fälle konnte Constantius die Kaiserwürde nicht selbst einfordern. Sie musste ihm angetragen werden. Zunächst ist hier an das direkte Umfeld des Kaisers zu denken, eben jene höfischen Funktionsträger, die einen exklusiven Zugang zum Herrscher ${ }^{182}$ hatten und damit leicht Gehör bei diesem fanden. Ebenso vorstellbar ist, dass die hohen Zivilbeamten der Reichsadministration, die ohnedies ihre Ernennung sicherlich dem Heermeister verdankten, für die Kaisererhebung des Constantius eintraten. Gerade für die Reichspräfekten, einschließlich des praefectus Urbi, bedeutete dies eine deutliche Entlastung. Sie mussten fortan nicht mehr

176 Im Herrscherkolleg nahm Constantius III. den dritten Rang ein (im Osten zu Lebzeiten nicht anerkannt; erst nach 426). Zur Hierarchisierung im Kaiserkolleg vgl. KOLB (2001) 102-09.

177 Das genaue Datum überliefert Theoph. a. m. 5913; die Spanne der Regierungszeit vom 8. Februar bis 2. September 421 passt in etwa zu der von Olympiodor (Olymp. fr. 33,1) angegebenen siebenmonatigen Herrschaft. Zu den übrigen Quellen, die z.T. fehlerhafte Angaben machen vgl. LÜTKENHAUS (1998) 156 mit Anm. 92.

178 Olymp. fr. 33,1 (Blockley). Vgl. LÜTKENHAUS (1998) 156 mit Anm. 93.

179 Solche Bestrebungen verfolgten bereits Allobich mit Konstantin III. und Jovius mit Attalus, die dem Honorius als Mitkaiser zur Seite gestellt werden sollten. Vgl. PFEILSCHIFTER (2013) 347; HEATHER ²(2010) 299 oder LÜTKENHAUS (1998) 28.

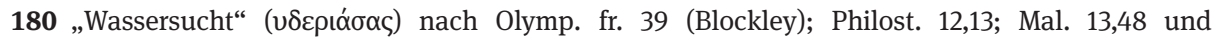
Zon. 13,21,17; diese stellt zwar eine topische Todesart für schlechte Kaiser dar, ist aber gewiss in diesem Fall mit einer realen Erkrankung des Honorius zu verbinden.Vgl. MEIER/PATZOLD ${ }^{3}$ (2013) 99; zur Kritik an der theodosianischen Dynastie als „tönernes Geschlecht“ (Philost. 12,13), auch im Hinblick auf dessen schwache gesundheitliche Konstitution (so auch Theodosius I. und Arcadius), vgl. BLECKMANN (2008) 21-23 u. 30-35. Die „Wassersucht“ bezeichnet letztlich aber nur ein erkennbares Symptom der eigentlichen Krankheit - die abnorme Wassereinlagerung im Körper (Ödem). Im Gespräch sind eine von väterlicher Seite vererbte Herzinsuffizienz oder Diabetes. Für Diabetes sprechen sich u. a. NÄF (2013) 103 mit Anm. 143 und LÜTKENHAUS (1998) 158 aus.

181 Dieser Konsens fand in der Herrscherakklamation, an welcher die entscheidenden Führungsgruppen im Heer, am Hof und im Senat beteiligt waren, seinen unmittelbaren Ausdruck. Vgl. KOLB (2001) 91-102 und MARTIN (1997) 47-62, bes. 52f.

182 Hierzu würden besonders der praepositus und primicerius sacri cubiculi im unmittelbaren Umfeld des Kaisers und die führenden Hofminister zählen. Über die Besetzung dieser wichtigen Posten lassen sich jedoch keine Aussagen treffen. 
befürchten, die kaiserliche Majestät zu verletzen, wenn sie sich an Constantius wandten. Welche Rolle die stadtrömische Senatsaristokratie oder der Senat hierbei wahrgenommen hat, lässt sich anhand der Quellen nicht beurteilen. Die Besetzung der höchsten senatorischen Zivilämter mit zwei namhaften Vertretern der senatorischen Häuser Roms, Fl. Iunius Quartus Palladius als $\mathrm{PPO}^{183}$ und Petronius Maximus als PVR ${ }^{184}$, deutet aber darauf hin, dass die Kaisererhebung des Constantius auch unter der stadtrömischen Senatsaristokratie und im Senat Zustimmung fand.

Das Ehrenmonument auf dem Trajansforum ${ }^{185}$, welches Petronius Maximus auf Eingebung des Senats sogleich von den invictissimi principes Honorius, Theodosius II. und Constantius III. ${ }^{186}$ bewilligt bekam, dürfte dies bestätigen. Der kaiserlichen Titulatur wurde hierbei der besonderer Zusatz censores remuneratoresque virtutum beigefügt. ${ }^{187}$ Im Aufgreifen der censura ${ }^{188}$ wird insbesondere der lectio senatus und des regimen morum gedacht. Der Senat ${ }^{189}$ erwartete offenbar, dass das um Constantius erweiterte Herrscherkolleg sich fortan stärker um die Curie und die Senatoren kümmern werde. Der plötzliche Tod ${ }^{190}$ des Constantius schon am 2. September 421, gerade einmal sieben Monate nach seiner Inthronisierung, beendete jedoch sein Wirken als Kaiser. Wie

183 Hier schon im fünften Jahr; PLRE 2, $822 \mathrm{ff}$. (Palladius 19; PPO seit). Palladius hatte unter Honorius und Constantius Karriere am Hof gemacht und 416 sogar zusammen mit Theodosius II. das Konsulat bekleidet. Vgl. CIL 6, 41383; die Inschrift wurde auf dem Aventin gefunden und gehörte aller Wahrscheinlichkeit nach zu einer Ehrenstatue, die in einer senatorischen domus aufgestellt war. Die Ämterlaufbahn ist beachtlich und führt sogar die Quästur und Prätur an. Am Hof war dieser tribunus et notarius sowie nachfolgend comes sacrarum largitionum (vor 416).

184 Petronius Maximus erhielt dieses Amt im verhältnismäßig jungen Alter von etwa 25 Jahren. Da in einem so jungen Alter die Amtsvergabe eher als besondere Ehrenbezeugung und weniger als Machtverleihung anzusehen ist, scheint dahinter in erster Linie das Umwerben von Teilen der stadtrömischen Senatsaristokratie, womöglich der gens Anicia, zu stehen.

185 CIL 6, 1749 (ILS 809; vgl. ILS 826). Vgl. NÄF (2013) 101; NIQUET (2000) 157; LÜTKENHAUS (1998) $164 \mathrm{f}$. und CHASTAGNOL 1962, 281f. Der Anfang der Inschrift lautet: DDD. NNN. INVICTISSIMI PRINCIPES HONORIVS THEODOSIVS ET CONSTANTIVS CENSORES REMVNERATORESQVE VIRTVTVM PETRONIO MAXIMO V. C. PRAEF. VRB., AD PETITIONE $(m)$ SENATVS AMPLISSIMI POPVLIQ. ROMANI STATVAM, MERITORVM PERENNE MONVMENTVM IN FORO VLPIO CONSTITVI IVSSERVNT [...]; Lesung nach HEINEN (2000) 274.

186 Die Reihenfolge der Nennung der Augusti spiegelt deren auctoritas wider; NÄF (2013) 101 gibt die falsche Reihenfolge an.

187 Vgl. auch LÜTKENHAUS (1998) 164.

188 Die Verbindung der Kaiserwürde mit den Aufgaben eines censor ist so auch noch bei Sidonius, der seinen panegyricus auf Majorian vor Augen hat, angelegt.Vgl. Sid. carm. 3,7-10: [...] hic nostrum tutatur, crede, pudorem, hoc censore etiam displicuisse placet.

189 Selbstverständlich geht der Text auf die Senatsaristokratie (bzw. den Senat: ad peditionem senatus) zurück, so dass hier in erster Linie das Herrscherbild vom senatorischen Denken bestimmt ist. Da aber vorausgesetzt werden kann, dass die Inschrift vom Kaiser so bewilligt wurde, wird sie der Selbstauffassung der Herrscher und dem offiziell am Hof propagierten Herrscherbild nicht entgegenstanden haben.

190 Lediglich Theoph. a. m. 5913 nennt Mord; bei allen übrigen Autoren klingt nichts dergleichen an, so dass die communis opinio eher von einer natürlichen Todesursache ausgeht; dagegen SCHARF (1996b) 26 -31, bes. 30 f. spekulierend über eine Täterschaft der Galla Placidia. 
sich das Verhältnis zwischen ihm und der stadtrömischen Senatsaristokratie und dem Senat entwickelt hätte, wäre gewiss höchst interessant gewesen. Doch durch seinen Tod wird dies Frage obsolet. Es muss offenbleiben, ob Constantius die Rechte des Senats und der Senatsaristokratie gestärkt hätte, wie dies beispielsweise mit den Gesetzen von 423 geschehen ist, ${ }^{191}$ oder doch eher die Souveränität des Senats beschnitten und die kaiserliche Zentralgewalt gegenüber dem Senatorenstand stärker zur Geltung gebracht hätte.

In den zehn Jahren, in denen Constantius die Politik im Westen maßgeblich beherrschte, findet sich einiges, was an Stilicho erinnert. Dies betrifft im Besonderen die zentrale Machtstellung des magister militum, die enge Zusammenarbeit mit der stadtrömischen Senatsaristokratie und die Anpassung an die senatorischen Standeskonventionen. In vielen Punkten führt aber Constantius die Entwicklung weiter und ist hierbei auch erfolgreicher als Stilicho. Die militärischen Erfolge waren die Voraussetzung, dass Constantius als reparator rei publicae auftreten konnte. Dies erhöhte die Akzeptanz gegenüber der Machtstellung des magister militum ungemein. Hierbei war es kaum noch von Bedeutung, ob dieser auch tatsächlich das Vertrauen des Kaisers besaß. Wichtig ist hier die Feststellung, dass die Akkumulation von Befugnissen nicht nur von Constantius allein ausging, sondern auch von den senatorischen Amtsträgern, die dem Heermeister die Entscheidungsgewalt antrugen, gewünscht wurde. Honorius konnte dem nur wenig entgegensetzen. Constantius wurde gebraucht, letzten Endes auch als Kaiser.

\subsection{Aëtius - im Schatten der stadtrömischen Senatsaristokratie?}

Nach dem Ableben des Constantius folgten erbitterte Machtkämpfe am Hof. ${ }^{192}$ Nachdem Honorius am 15. August 423 verstorben war, kam es zur Usurpation und zum Bürgerkrieg, aus welchem die theodosianische Dynastie als Sieger hervorging. Obgleich Aëtius zu den Verlierern des Bürgerkriegs - sogar zu den ,Verrätern' an der theodosianischen Dynastie - gehörte, ${ }^{193}$ gelang es ihm, Straffreiheit und den Posten eines comes rei militaris ${ }^{194}$ in Gallien zu erlangen. ${ }^{195}$ Die zentrale Heermeisterstellung

191 CTh. 1,6,11; CTh. 2,1,12; CTh. 4,10,2 und CTh. 9,6,4. Vgl. NÄF (2013) 102; LÜTKENHAUS (1998) 173; GIGLIO (1990) 202-206 und VINCENTI (1992) 67-76.

192 Olymp. fr. 38 (Blockley).

193 Zur Rolle in der Usurpation des Johannes vgl. STICKLER (2002) 33f. Die Spekulationen bei ZECCHINI (1983) 124, wonach Aëtius unter Constantius zurückgestellt wurde und sich nun unter Johannes die Möglichkeit eröffnete, aufzusteigen und abermals „stilichonische Ziele“ (u. a. Offenheit gegenüber den ,Barbaren‘ und ein gemäßigter Katholizismus) zu verfolgen, wurde von LÜTKENHAUS (1998) 163 mit Anm. 111 und STICKLER (2002) 33f. vollkommen zu Recht zurückgewiesen. Vgl. auch SEIBEL (2006) $132 \mathrm{f}$.

194 CIL 6, 41389. Vgl. STICKLER (2002) 40 mit Anm. 191 und die ausführliche Untersuchung bei DEMANDT (1970) Sp. $662 \mathrm{ff}$. 
ging aber an den bis dahin unbekannten Fl. Felix. ${ }^{196} 428$ wurde er mit dem ordentlichen Konsulat ${ }^{197}$ geehrt und hatte auch den Patriziustitel ${ }^{198}$ inne. Es ist zwar nicht gänzlich auszuschließen, dass es sich hier um einen Vertrauten ${ }^{199}$ der Galla Placidia handelte. Die Dominanz des Ostens ${ }^{200}$ in den Jahren zwischen 425 und 430 legt aber eher nahe, dass Konstantinopel über die Besetzung dieses wichtigen Postens entschied und Felix als Mann des oströmischen Kaiserhofs ${ }^{201}$ anzusehen ist. Sollte dies zutreffen, wäre davon auszugehen, dass es um das Verhältnis zwischen dem neun ,starken Mann' und der stadtrömischen Senatsaristokratie nicht gerade gut stand. Fl. Felix könnte als höchster Vertreter der oströmischen ,Protektion' wahrgenommen worden sein. Die gewaltsame Beseitigung von zwei hohen Geistlichen im Folgejahr, des stadtrömischen Diakons Titus ${ }^{202}$ und des Bischofs Patroclus von Arles ${ }^{203}$, sowie

195 Vgl. Greg. Tur. Franc. 2,8; Philost. 12,14 und Chron. Gall. 102 (s. a. 425). Als politisches Druckmittel dienten Aëtius die noch für Johannes angeworbenen hunnischen Truppen.

196 PLRE 2, $461 \mathrm{f}$. (Fl. Constantius Felix 14; jedoch mit falscher Namensnennung „Constantius“); diese falsche Namensnennung wird so jüngst auch noch von SALISBURY (2015) 162f.; WIJNENDAELE (2015) 68 und FIELDS (2015) 41 übernommen. Vgl. KUHOFF (2012) 65 mit Anm. 51 und CAMERON (2007) 191 mit Anm. 3. Auf dem Felix-Diptychon (ILS 1298) einschließlich der verlorenen zweiten Tafel (GORI (1759)) ist der Name so nicht überliefert. Der Namen „Constantius“ basiert auf der Lesung der Stifterinschrift des Apsismosaiks von S. Giovanni in Laterano (ILS 1293), die von PANVINIO vorgeschlagen wurde. Gegen diese Lesung argumentierte bereits DESSAU, ILS 1293; heute zumeist gelesen: Fl. Felix v.c. magister utriusque militiae, patricius et cons. ord. et Padusia eius inl. femina, [...].; vgl. DESSAU (1892) 287 = ILS 1293. 197 Erhalten ist das Konsulardiptychon; vgl. DELBRUECK (1929) Nr. 3 und VOLBACH ${ }^{2}(1952)$ Nr. 2.

198 CIL 6, 41393 (ILS 1293); die nicht erhaltene zweite Tafel des Felix-Diptychons.

$199 \mathrm{Zu}$ dieser Annahme vgl. COULON (2000) 94-96; OOST (1968) 170 mit Anm. 2 und SCHMIDT (1899) 449-462, hier 449 mit Anm. 3. Diese Vermutung wird begründet mit der Gleichsetzung des Namens Spadusia (PLRE 2, 1024) mit Padusia (PLRE 2, 816), der Gemahlin des Flavius Felix. So nennt Olymp. fr. 38 (Blockley) eine Spadusia als Vertraute der Galla Placidia, die u. a. OOST mit Padusia, der Gattin des Flavius Felix, identifizieren will. Hieraus ergebe sich nicht nur, dass Flavius Felix zu den Vertrauten der Galla Placidia zu zählen sei, sondern auch vor 425 bereits im Westen war. PLRE 2, 1024 gibt aber richtig zu bemerken: „The identity of Spadusa with Padusia (wife of the MVM Felix 14) cannot be excluded, although it is only an hypothesis.“

200 Vgl. hierzu auch MCEVOY (2010) 175-178 und STICKLER (2002) 35-48.

201 Hierhin tendieren HUGHES 2012, 78; STICKLER (2002) 38; ZECCHINI (1983) 142 und SIRAGO (1961) 265f. Für die Nähe zum oströmischen Kaiserhof sprechen u. a. auch die auf dem Felix-Diptychon wiedergegebene Frisur, die mit glatt anliegenden Stirnhaar eher an die „östliche Staatsfrisur“ erinnert; im Unterschied zur westlichen Mode, die vollere bzw. aufgetürmte Stirnwellen bevorzugt (vgl. z.B. das Diptychon von Halberstadt oder von Novara). Vgl. hierzu DELBRUECK (1933) 44.

202 Prosp. Tiro 1292 (s. a. 426).

203 Ebd.; Patroclus von Arles wurde von Fl. Constantius 412 als amicus et familiaris (Prosp. Tiro 1247, s. a. 412) eingesetzt und nahm in kirchlichen Angelegenheiten sowohl in Spanien als auch in Gallien eine Führungsposition ein; hinzu kommt eine Abstammung aus einem senatsaristokratischen Geschlecht Galliens, was diese Mordtat zu einem Frevel an einem kirchlichen Würdenträger und gallischen Aristokraten werden lässt. Zu Patroclus und die Gallienpolitik des Constantius vgl. aktuell MARCOS (2013) 145166; ferner LÜTKENHAUS (1998) 121-129; MATHISEN (1989) 48-74 oder PIETRI (1976) 1006-1021. 
die kompromisslose Haltung gegenüber ,Häretikern ${ }^{\text {‘204 }}$ und sicherlich auch ,Heiden‘, sendeten gewiss keine positiven Signale an die stadtrömische und auch gallische Senatsaristokratie. ${ }^{205}$ Dagegen musste Aëtius für die stadtrömische Senatsaristokratie der bevorzugte Kandidat gewesen sein. Mütterlicherseits entstammte er sogar der italischen Aristokratie. ${ }^{206}$ Als Vertreter der gemäßigten und durchaus senatsfreundlichen Politik des Usurpators Johannes ${ }^{207}$ empfahl sich Aëtius. Überdies war er über jeden Verdacht erhaben, nur ein ,Diener` Konstantinopels zu sein. Seine Rückkehr an den Hof wird so sicherlich nicht wenige Unterstützer im Kreis der senatorischen Häuser Roms gefunden haben.

In den entscheidenden Jahren zwischen 425 und 430, in denen sich der politische Umsturz anbahnte, aus welchem Aëtius als der neue ,starke Mann` hervorgehen sollte, finden sich ausgesprochen namhafte Vertreter der stadtrömischen Aristokratie auf den höchsten Posten der Zivilverwaltung. So amtierten unter anderen Fl. Anicius Auchenius Bassus $^{208}$ (426), Rufius Antonius Agrypnius Volusianus ${ }^{209}$ (428/429) und Macrobius Ambrosius Theodosius ${ }^{210}$ (430) als praefectus praetorio Italiae. Zumindest die beiden Erstgenannten werden auch unter der Führung des Aëtius noch bedeutende Ämter und Würden zuteil. Volusianus wird 436/437 mit der ehrenvollen Aufgabe betraut, die Brautwerbung für Valentinian III. in Konstantinopel vorzutragen. ${ }^{211}$ In dieser wichtigen Funktion musste er nicht nur das volle Vertrauen seines Kaisers und der Kaiserinmutter

204 Der Verdacht der Häresie mochte möglicherweise ein vorgeschobener Grund gewesen sein, mit welchem der Mord zweier Geistlicher gerechtfertigt wurde. Auch im Konflikt mit Bonifatius wurden möglicherweise dessen liberale Haltung gegenüber den Donatisten und dessen Ehe mit einer gotischen Arianerin (Aug. ep. 220,4) angeführt, um ihn seines Amtes zu entheben. Zur verschärften Religionsgesetzgebung nach dem Sturz des Usurpators Johannes vgl. Kap. 4.2; hier wären des Weiteren zu nennen: CTh. 16,7,7; CTh. 16,8,28 und CTh. 16,10,13 (alle 426) und die Gesetze aus der Osthälfte CTh. 16,5,65 (428) und CTh. 16,8,29 (429).

205 Vgl. hier vor allem ZECCHINI (1983) 142-144; deutlich zurückhaltender STICKLER (2002) $40 \mathrm{f}$.

206 Iord. Get. 176 und Greg. Tur. Franc. 2,8: mater Itala, nobilis ac locuplex faemina. Vgl. COULON (2000) 43 und STICKLER (2002) 21f.; nachfolgend auch ders. (2015) Absatz 4 mit Anm. 5: „... hätte auf diese Weise neben seiner Einbindung in das militärische Milieu auch über einen direkten Zugang zu den zivilen Eliten des Westreiches verfügt.“ (Publications de l'École française de Rome: http://books.openedition.org/efr/ 2813; abgerufen am 07.01.2016).

207 Vgl. Kap. 4.2.

208 PLRE 2, $220 \mathrm{f}$. (Bassus 8); dieser war bereits 425 als CRP am Hof präsent; hier bereits zusammen mit Aëtius unter dem Usurpator. Zu seiner Verbindung zu den Aniciern vgl. CAMERON (2012) 140 - 143.

209 PLRE 2, 1182f. (Volusianus 6); auch dieser kann nach einer fast fünfzehnjährigen Laufbahn im hohen Staatsdienst als einflussreicher Mann am Hof angesehen werden.

210 Theodosius 8 (PLRE 2, 1101); CAMERON (1966) 25- 38 identifiziert Macrobius mit dem in CTh. 12,6,33 erwähnten PPO des Jahres 430, was zwar nicht unumstritten ist, doch mehrheitlich befürwortet wurde; zuvor MAZZARINO (1937/1938) 255-258.Vgl. u. a. RÜCKER (2012) 52 oder FRATEANTONIO (2007) 360 - 377, bes. 361. Seine Herkunft ist umstritten, auch wenn in der Forschung immer wieder Nordafrika (proconsul Africae von 410) angeführt wird, stand Theodosius der stadtrömischen Senatsaristokratie besonders nahe; noch sein Sohn Flavius Macrobius Plotinus Eustathius (PLRE 2, 436) wird zwischen 457 und 472 als PVR amtieren.

211 Vgl. Vit. Mel. 50 u. 52. 
besessen haben, sondern auch das des Aëtius. Hinsichtlich des Fl. Anicius Auchenius Bassus und Teilen der gens Anicia wird die Zusammenarbeit mit Aëtius noch deutlicher. So erhält nicht nur Bassus ein zweites Mal 435 die Prätorianerpräfektur und wird 431 zum Konsul ernannt, auch die Anicier Petronius Maximus ${ }^{212}$ und Anicius Acilius Glabrio Faustus $^{213}$ kommen zum Zug und werden sich sogar über mehrere Jahre hindurch in dieser hohen Position abwechseln. Es ist daher keineswegs abwegig anzunehmen, dass Angehörige dieser angesehenen Häuser Roms den Aufstieg des Aëtius unterstützten.

Vor allem die Ermordung des Felix im Jahr 430, ${ }^{214}$ bedurfte einer bereiten Unterstützung. ${ }^{215}$ Um nicht blutbefleckt als Mörder auf die Stellung des Felix aufzurücken, musste Aëtius um Akzeptanz für diese Tat werben. Prosper Tiro ${ }^{216}$ nennt so ein Mordkomplott des Felix, welchem Aëtius lediglich zum Selbstschutz zuvorgekommen sein soll. Dies war sicherlich die offizielle Version. Ein seltsamer, bislang kaum beachteter Punkt, stellt die Auflistung der Opfer dar, die auch ein Mann der Kirche, einen Diakon Namens Grunitus, nennt. Grunitus wird am ehesten als enger Vertrauter des Felix anzusehen sein. Sollte ausgerechnet diesem als geistlichem Führer ${ }^{217}$ und Berater des Felix der harte religionspolitische Kurs des Heermeisters angelastet worden sein, so könnte dies in der Tat seine Ermordung erklären. Diese Annahme hat einiges für sich. Denn falls die Ermordung des Grunitus gezielt erfolgte, zeigt dies, dass mitunter auch religionspolitische Erwägungen beim Machtwechsel 430 eine Rolle gespielt haben müssen. Als potentielle Befürworter der Tat kommen somit besonders die Präfekten Volusianus und

212 PLRE 2, 749 (Maximus 22). Sollte Petronius Maximus neben seiner bis hierhin schon beachtlichen Ämterlaufbahn auch noch als praeceptor (CIL 6, 41398) dem jungen Valentinian gedient haben, so wird er hervorragende Möglichkeiten der Einflussnahme auf den Kaiser und die Kaiserrinmutter besessen haben. 213 PLRE 2, $452-454$ (Faustus 8)

214 Hyd. Lem. 94 (s. a. 430); ferner Marcell. Com. s. a. 430 (ohne weitere Angaben) und Prosp. Tiro 1303 (s. a. 430) mit Angaben, dass Felix zusammen mit seiner Gemahlin Padusia und einem Diakon mit dem Namen Grunitus ermordet wurde; ähnlich auch Ioh. Ant. fr. 201,3 (= Prisk. fr. 30,1 (Blockley)). Agnell. lib. Pontif. 31 gibt an, dass sich der Mord im Mai 430 auf den Stufen der Basilica Ursiana in Ravenna ereignete: In diebus eius occisus est Felix patricius ad gradus ecclesiae Ursianae mense Mai.Vgl. HUGHES (2012) 78f.; STICKLER (2002) 48f.; ferner auch SIRAGO (1961) 285.

215 Entgegen STICKLER (2002) 50: „Problematisch war für Aëtius, daß im höfischen Milieu Ravennas zumindest für uns erkennbar - über keine starke Unterstützungsgruppe verfügte“; dem ist zwar prinzipiell zuzustimmen, da sich alles darüber hinaus auf Vermutungen stützen muss, doch gerade der verhältnismäßig reibungslose Ablauf des Führungswechsels am Hof setzt doch eine durchaus fähige Unterstützergruppe voraus; zumal es sich Aëtius schon unmittelbar danach erlauben kann, Ravenna fernzubleiben.

216 Prosp. 1303 (Tiro s. a. 430): Aetius Felicem cum uxore Padusia et Grunito diacono, cum eos insidiari sibi praesensisset, interimit; ähnlich auch Ioh. Ant. fr. 201,3 (= Prisk. fr. 30,1 (Blockley)).

217 Die feste Glaubenshaltung und strenge Religiosität des Felix und der Padusia bezeugt die Stifterinschrift des Apsismosaiks von S. Giovanni in Laterano (ILS 1293), welche sogar explizit darauf verweist, dass hierdurch ein Gelübde erfüllt wurde ([...] voti compotes de proprio fecerunt [...]). Das Zurateziehen eines niederen Geistlichen, etwa eines Diakons oder Presbyters, stellte in hohen gesellschaftlichen Kreisen keine Seltenheit dar; so stand z. B. Melania d. Ä. unter dem Einfluss des Mönchs Rufinus von Aquileia, Melania d. J. und Pinian vertrauten Gerontius und Anicia Demetria wandte sich einem Presbyter Namens Tigrinus zu. 
Macrobius Ambrosius Theodosius infrage, die sich zum Heidentum bekannten ${ }^{218}$ und allein schon deswegen eine liberalere Haltung des Hofes in der Religionsgesetzgebung bevorzugen mussten. Doch auch die christliche gens Anicia hatte ein berechtigtes Interesse, dem harten religionspolitischen Kurs Einhalt zu gebieten. Anicia Demetria, Anicia Iuliana und Anicia Faltonia Proba ${ }^{219}$ standen Pelagius ${ }^{220}$ verdächtig nahe. Dies konnte für die Anicier zum Problem werden.

Aëtius erfüllte die aus senatorischen Kreisen in ihn gesetzten Erwartungen. Nicht allein nur der Flut an restriktiven Religionsgesetzen wurde Einhalt geboten, ${ }^{221}$ auch die Rehabilitierung des älteren Virius Nicomachus Flavianus, der vor über 35 Jahren auf der Seite des Usurpator Eugenius gekämpft hatte und gestorben war, wurde 431 endlich ermöglicht. ${ }^{222}$ Mit einer Ehrenstatue auf dem Trajansforum ${ }^{223}$ wurde dieser durch seinen Enkel Appius Nicomachus Dexter geehrt. Überdies wurde dessen Sohn, Virius Nicomachus Flavianus d. J., für 431/432 zum Prätorianerpräfekten ernannt. Grunewald ${ }^{224}$ spricht nicht unbegründet von einer kurzen Phase der Konsolidierung der paganen Aristokratie in Rom, die sich mit dem Aufstieg des Aëtius verbindet. Bereits Stein und Twyman $^{225}$ sahen hierin ein wichtiges Indiz für die politischen Allianz zwischen Aëtius und Teilen der stadtrömischen Senatsaristokratie. Die Zusammenarbeit wurde beidseitig gesucht und beruhte zu einem gewissen Grad auf einer gegenseitigen Abhängigkeit. Die stadtrömische Senatsaristokratie und auch der Senat profitieren letztlich da-

218 Zum Heidentum des Volusianus und Macrobius, wohl dem Autor der Saturnalien, vgl. VON HAEHLING (1978) 319-323; zu Macrobius DÖPP (1978) und CAMERON (1966).

219 PLRE 2, 351 f. (Demetria), PLRE 1, 468 (Iuliana 2) und PLRE 1, 731 f. (Proba 3); ferner vgl. DISSELKAMP (1997) 62, 73f. u. 91. Zur Verbindung senatorischer Kreise mit den nordafrikanischen Donatisten (z. B. Melania d. J.) vgl. OVERBECK (1973) 50-52.

220 Pelag. ep. ad Demetr.; vgl. auch Aug. ep. 180 und Hieron. ep. 130,1. Vgl. u. a. BROWN (2017) 303-309; ders., (1970) 56-72; KURDOCK (2007) 190 - 224; LAURENCE (2002) 131-163; ferner auch THIER (1999) 5 f. u. 58 f. und grundlegend DE PLINVAL (1943). Zur senatorischen Unterstützung des Pelagius vgl. allgemein BROWN (1970).

221 In der überlieferten Gesetzgebung finden sich zwar kein Gesetz, welches eine Erleichterung darstellt oder die vorher erlassenen Gesetze revidiert; jedoch ist ein Abbruch der noch zwischen 425 und 429 sehr intensiv vorangetriebenen Religionsgesetzgebung zu verzeichnen. Im Osten wird dagegen die Gesetzgebung gegen ,Häretiker', ,Heiden` und Andersgläubige unvermindert fortgeführt: vgl. CTh. 16,10,25 (435), CJ. 1,5,6 (435), Nov. Theod. 3 (438:), CJ. 1,1,3 (448), CJ. 1,11,7 (451), CJ. 1,1,4 (452) und CJ. 1,7,6 (455).

222 Vgl. Kap. 3.1; zur Rehabilitierung/Ehrung vgl. Kap. 8.1.

223 CIL 6, 1783 (ILS 2948). Vgl. zur Inschrift NIQUET (2000) 82f. oder WYTZES (1977) 149f. mit Anhang 6; ausführlicher HEDRICK (2000) und GRÜNEWALD (1992) 462-487.

224 GRÜNEWALD (1992) 486f. Die Vermutung, dass dies mit Unterstützung des Aëtius erfolgte, äußerte bereits SOLARI (1936) 357-360, hier 359. Vgl. nachfolgend auch STICKLER (2002) 290f. und HEDRICK (2000) 223f. Dagegen nahm OOST (1968) 231 an, dass Galla Placidia die Rehabilitierung veranlasst habe, um wiederum gegen Aëtius in senatorischen Kreisen Unterstützung zu sammeln. CAMERON (2011) $204 \mathrm{f}$. meinte sogar, die Familie Flavians könnte selbst die Initiative ergriffen haben. OOST und CAMERON bleiben dabei jedoch die Beantwortung der Frage schuldig, weswegen nun gerade 431 die Rehabilitierung erfolgte, und nicht bereits früher.

225 TWYMAN (1970) 482f. und STEIN (1959) 340f. Vgl. ferner COULON (2000) 110f. und zur älteren Forschungsmeinung WEBER (1989) $480 \mathrm{ff}$. mit Anm. 119. 
von, dass der ,starke Mann' nicht auch gleichermaßen stark legitimiert war und in ihren Kreisen fortwährend um Akzeptanz werben musste. Wie bereits Stilicho und Constantius arbeitet so auch Aëtius eng mit einzelnen Vertretern der senatorischen Häuser Roms zusammen und versuchte, den Senat für seine politischen Ziele einzuspannen. Die Rehabilitation des älteren Nicomachus im Jahr 431 stellte dabei nur den Auftakt dar. Dem folgten die feierliche Veröffentlichung des Codex Theodosianus im Dezember 438, die Errichtung einer Ehrenstatue für Aëtius ${ }^{226}$ zwischen 438/439 und 442 und die zwei Panegyrici des Merobaudes ${ }^{227}$, die 437 und 446 gehalten, einem Rechenschaftsbericht zumindest recht nahekamen.

Die Veröffentlichung des Codex Theodosianus ${ }^{228}$ war ein hoheitliches Recht beider Kaiser und erfolgte - wie sich dies darstellt - ohne Zutun des Aëtius. Dennoch richtete der Senat insgesamt 43 Akklamationsrufe an den Heermeister:

Aeti, aveas! [Dictum XV.]. Ter consulem te! [Dictum XIII.] Excubiis tuis salvi et securi sumus! [Dictum XII.] Excubiis tuis, laboribus tuis! [Dictum XV.]. ${ }^{229}$

Gegenüber dem amtierenden Konsul und praefectus praetorio Anicius Acilius Glabrio Faustus, ${ }^{230}$ in dessen Anwesen ad palmam ${ }^{231}$ die Veröffentlichung des Codex Theodosianus erfolgte, steht Aëtius, was die Zahl der Akklamationsrufe angeht, zwar zurück. Und auch dem Stadtpräfekten Fl. Paulus ${ }^{232}$ ist er nachgeordnet. Doch allein seine Nennung, die im Gegensatz zu den beiden Erstgenannten in Abwesenheit ${ }^{233}$ erfolgte, ist bemerkenswert. Ein drittes Konsulat fordert der Senat für den Heermeister. Mit dem Nachdruck von insgesamt 27 Wiederholungen werden die Wachsamkeit und die Mühen des Aëtius gewürdigt, durch welche die anwesenden Senatoren und das gesamte Imperium wohlbehalten und geschützt seien. Aëtius wird gerade durch die

226 CIL 6, 41389. Sicher als terminus post quem gilt das zweite Konsulat des Aëtius im Jahr 437, welches die Inschrift anführt; des Weiteren wird auf die inschriftlich erwähnte Vernichtung der Burgunder 436 und Niederwerfung der Goten 438 verwiesen; die Nichterwähnung des seit 442 in einem Friedensvertrag „gelösten“ Vandalen-Problems legt hingegen nahe, dass die Ehrung früher erfolgte; als gesicherter terminus ante quem gilt das Jahr 446, das dritte Konsulat des Aëtius, welches noch keine Erwähnung findet. $\mathrm{Zu}$ den verschiedenen Datierungsansätzen vgl. CIL 6, 41389 (G. Alföldy); ferner STICKLER (2002) 257. 227 Zur Datierung vgl. CLOVER (1971) 1-78, bes. 41.

228 Zur Entstehungsgeschichte des Codex Theodosianus vgl. u. a. KROPPENBERG (2007) 112-126; MATTHEWS (2000); zusammenfassend PFEILSCHIFTER (2014) 145-147; HEATHER 2(2010) 153-163 oder MARTIN ${ }^{2}(1990) 107 \mathrm{f}$.

229 CTh. gest. in sen. 5f. Vgl. MCEVOY (2013a) 258f.; HEATHER ²(2010) 158-163; NÄF (1995) 30f. und BURIAN (1980) 17-43, hier 34.

230 PLRE 2, 452-454 (Faustus 8).

231 Hierzu Kap. 8.4.

232 PLRE 2, 854 (Paulus 31).

233 Entgegen der Vermutung MCEVOY (2013a) 259. 
gewählte Formulierung an die Kaiser herangerückt. ${ }^{234}$ Im Unterschied zu den Akklamationen für Faustus und Paulus ${ }^{235}$ wird hier individuell der Leistungen des Aëtius gedacht. Bereits McEvoy mutmaßte, dass hier die Unterstützer des Aëtius im Senat am Werk waren. ${ }^{236}$

Das durch diese vier Zeilen gesetzte Zeichen ist gleich in zweifacher Hinsicht von großer politischer Bedeutung für Aëtius. Zum einen zwang die Akklamation den Senat zu einer Konformität, die alle Senatoren zumindest nominell zu Befürwortern des Aëtius und seiner Verdienste werden ließ. Zum anderen dokumentierte dieser Vorgang insbesondere vor dem Kaiser noch einmal in aller Deutlichkeit die starke Position des Aëtius. Der securitas-Begriff, der nachfolgend bezüglich der Ehreninschrift CIL 6, 41389 noch zu besprechen sein wird, erhält in den Gesta Senatus Urbis Romae eine besondere Konnotation. Im Zusammenhang mit dem römischen Recht kann securitas auch die Rechtssicherheit ${ }^{237}$ im Speziellen meinen. In diesem Fall bleibt sie aber genauso wenig auf diese ${ }^{238}$ wie auf die militärische Sicherheit, die wohl hinsichtlich des Heermeisters die erste Assoziation darstellt, beschränkt. Die Akklamation des Senats erhebt Aëtius neben den Augusti zum Garanten der salus und securitas. ${ }^{239}$ Wenn hierauf salus und securitas mit dem obersten Heermeister Aëtius und seinem Einsatz für das Reich in Verbindung gebracht werden und eben nicht in gleicher Weise mit dem Codex Theodosianus, ist dies doch recht bezeichnend für die Einstellung der Senatoren gegenüber der aus Konstantinopel überbrachten Gesetzessammlung. ${ }^{240}$

234 Seine Entsprechung findet dies beispielsweise in CIL 6, 2086 (act. Arv. a. 213); zum Text vgl. DIETZ (1980) 333; BURIAN (1980) 33 und PALMER (1978) 1085-1120, hier 1105; ähnlich auch SHA. Comm. 18,14f. Vgl. BALDWIN (1984) 43.

235 Faustus: Fauste, aveas! [Dictum XVII] Bis consulem te! [Dictum XV] (2x). Paulus: Paule, aveas! [Dictum XII] Consulem te! [Dictum XI]. Die übrigen Zurufe beziehen sich auf Wünsche gegenüber dem Gesetz und seiner Publikation; mit Übersetzung und Erläuterung vgl. HEATHER 2(2010) 159.

236 MCEVOY (2013a) 259; wobei die persönliche Anwesenheit des Aëtius m. E. nicht wahrscheinlich ist, da dies in der Durchführung der Sitzung hierarchische Probleme aufgeworfen hätte. Überdies geht auch STICKLER (2002) 286 davon aus, dass Aëtius erst ab 439 häufiger in Italien präsent war.

237 Vgl. u. a. NÖRR (1969) 106; BLEICKEN (1966) 251f. u. 267 oder AMELOTTI (1958) 4.

238 Vgl. hierzu KNEPPE (1994) 268 mit Anm. 281 bezüglich Cass. Dio 56,41,4 (Augustus).

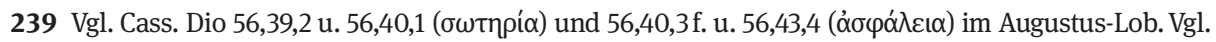
KNEPPE (1994) 267f. Bezüglich der lateinischen Tradition vgl. BRENK (1999a) 122-131.

240 Der Codex Theodosianus selbst wird an keiner Stelle direkt mit einer Wertung bedacht; das Lob bezieht sich stets auf die Kaiser direkt und entspricht dem zu erwartenden Herrscherlob. Direkt bezogen auf die Kaiser als Gesetzgeber heißt es: Per vos arma, per vos iura [Dictum XX.]. Dispositioni vestrae gratias agimus [Dictum XXIII.]. Constitutionum ambiguum removistis [Dictum XXIII.]. Pii imperatores sic consulunt [Dictum XXVI.]. Hieran anschließend sogleich die Forderungen/Bitten des Senats: i. B. Hinweise zur Verbreitung (u. a. in den Reichsämtern), zur Lesbarkeit, zum Schutz vor Verfälschungen (durch Kommentare/Ergänzungen oder Bittschriften) und zum Schutz der Grundbesitzer. Vgl. HEATHER 2(2010) 159. Allgemeinen zur Problematik vgl. HAHN (2011) 206f. u. 289f. (i. B. zur Religionsgesetzgebung); umfassend KAISER (2007); ferner WIEMER (2006) 11f.; MATTHEWS (2000) 292f. und ERRINGTON (1997b) $21 \mathrm{ff}$. und JONES (1964) 366-410 u. 1052f. Auch die Kaiser sahen dieses Problem. Vgl. CTh. 16,10,19 (Const. Sim. 12); CTh. 16,10,9; CTh. 16,10,10 und besonders Nov. Theod. 3,8f. sowie Coll. Avell. 13,7.Vgl. HAHN (2011) 289 und KREUZ (2008) 199ff. mit Anm. 294. 
Für die Rolle und Stellung des Aëtius lässt sich die 1937 aufgefundene Ehreninschrift CIL 6, $41389^{241}$ heranziehen. Der ausführlichen Betrachtung, die zuletzt Stickler und Delmaire ${ }^{242}$ der Inschrift angedeihen ließen, sind durchaus einige Punkte hinzuzufügen. Zunächst ist noch einmal besonders darauf hinzuweisen, dass es sich hierbei um eine vom Senat und Volk von Rom vergebene Ehrung handelt, die nominell auf Geheiß der Augusti erfolgt ist:
[6] [...] HVIC
SENATVS POPVLVSQVE ROMANVS OB ITALIAE SECVRITATEM,
$[\ldots]$
[10] IVSSV PRINCIPVM DD NN THEODOSI ET PLACIDI [Valenti]- [n]IANI PP. AVGG. IN ATRIO LIBERTATIS, [...]
[12] [...] ST[atuam aure/aere?]- AM CONLOCAVIT [...]. ${ }^{243}$

Die Initiative ging vom Senat aus und nicht vom Kaiser. Nicht allein nur der Aufstellungsort - das Atrium Libertatis - legt dies nahe, sondern auch der Text selbst. Die zum Teil antiquiert anmutende Terminologie und die ungeheuerliche Erhöhung des Aëtius lassen nur den Schluss zu, dass weder Valentinian III. noch Galla Placidia imstande waren, hierauf Einfluss zu nehmen. So werden die Augusti zwar nicht gänzlich in der Inschrift übergangen. Jedoch bleibt der Verweis auf die Herrscher auf das Notwendigste ${ }^{244}$ beschränkt. Im Vergleich zu den öffentlichen Ehrungen des Stilicho auf dem Forum Romanum ${ }^{245}$ wird dies besonders deutlich. Die Nähe zum Kaiserhaus und seine Treue zur theodosianischen Dynastie werden als machtpolitisch entscheidende Qualifikationsmerkmale Stilichos mit Nachdruck artikuliert - nicht so bei Aëtius.

Als Beschützer der securitas Italiae war Aëtius der Garant sowohl für die Unversehrtheit senatorischen Besitzes als auch für die Aufrechterhaltung der gesellschaftlichen Ordnung und damit der privilegierten Stellung der Senatoren, des Senats und Roms. Die securitas bezieht sich nicht allein auf die bloße Grenzsicherung, die durch die militärischen Siege des Aëtius sichergestellt wurde, sondern auch auf die innere Si-

241 Die erste Veröffentlichung der Inschrift erfolgte durch ihren Ausgräber BARTOLI (1948) 267-273; nachfolgend DEGRASSI (1946-1948) 33-44; AE 1950,30 und letztlich CIL 6, 41389 (G. Alföldy); eine deutschsprachige Übersetzung liefert SCHUMACHER (1994) 212f. Eine Zusammenfassung der Forschungsgeschichte bietet STICKLER (2002) 255-260. Vgl. ferner auch SPERA (2012) 133-141.

242 STICKLER (2002) 256-273; nachfolgend DELMAIRE (2008) 291-294.

243 Lesung nach CIL 6, 41389 (Alföldy); in Großbuchstaben unter Einhaltung der Zeilenvorgabe, jedoch zur Erleichterung der Lektüre ohne die von ALFÖLDY angegebenen Unterpunkte.

244 Etwas zurückhaltender noch STICKLER (2002) 272: „[...] angesichts des bisher Gesagten ist ihre Rolle dennoch eher zweitrangig.“

245 Dies betrifft CIL 6, 1730 und CIL 6, 1731. 
cherheit und Stabilität $t^{246}$. Die innenpolitische Dimension wird dabei eigens hervorgehoben, indem betont wurde, dass Aëtius ein eingeschworener Feind der Denunzianten sei und als Garant der Freiheit und Rächer der Ehre gelte:

[13] [...] MORVM PROBO, OPVM REFVGO, DELATO-

RVM VT HOSTIVM INIMICISSIMO, VINDICI LIBERTATIS,

PVDORIS VLTO( $($ ).

Die securitas wird am Ende der Inschrift noch einmal deutlich in Verbindung mit libertas gebracht. Entgegen der bereits in der frühen Kaiserzeit einsetzenden Tendenz, anstelle der libertas die securitas hochzuhalten oder beide gleichzuschalten, ${ }^{247}$ werden hier beide Begriffe nebeneinandergestellt, ohne dass diese ihr Eigengewicht einbüßen. Noch in den Gesta Senatus Urbis Romae wird Aëtius nur mit dem Begriff securitas assoziiert. ${ }^{248}$ Doch jetzt verkörpert Aëtius darüber hinaus auch die libertas und zwar als vindex libertatis. Der Heermeister nimmt hierdurch vor dem Senat und Volk von Rom kaiserliche Qualitäten ${ }^{249}$ an. Da ausgerechnet das Atrium Libertatis zum Aufstellungsplatz des Ehrenmonuments bestimmt wurde, fällt der libertas mehr Gewicht zu. Für den Senat und die stadtrömische Senatsaristokratie war die libertas besonders als spezifisch aristokratische Freiheit - von überaus hohem Wert. ${ }^{250}$ Sie garantiert als solche die politische Handlungsfreiheit, die Dignität und nicht zuletzt auch die gesellschaftliche Führungsrolle der Senatsaristokratie und des Senats. So wird der vindex libertatis - namentlich Fl. Aëtius - zum Schutzherrn der freiheitlichen Rechte und Privilegien des Senats und der Senatsaristokratie.

Darüber hinaus wird der magister militum et patricius Aëtius in den elitären Kreis der pars melior humani generis aufgenommen. So wird Aëtius als treuer Verteidiger des mos maiorum und vortrefflicher Staatsmann apostrophiert. ${ }^{251}$ Der Inschrift zufolge las-

246 Zur innenpolitischen Dimension des Begriffes securitas vgl. STICKLER (2002) 267-269; für die Zeit der frühen und hohen Kaiserzeit vgl. KNEPPE (1994) 217-277; INSTINSKY (1952a) bes. 21ff. und HARTMANN (1921) Sp. 1000 - 1003.

247 Die Schwierigkeit, libertas mit securitas bzw. der Kaiserherrschaft in Einklang zu bringen, klingt deutlich in Tac. Agr. 3,1 an; zum Problem vgl. ROMAN (2014) 91f.; NORENA (2011) 130: „securitas is conjoined to libertas“; BLEICKEN (1966) 267: „Man kann sogar sagen, daß die securitas die libertas als zentralen Begriff der Ideologie ablöst. “Ferner vgl. ders. (1975) 511f.; KUNKEL (1969) 68-93, bes. 91 f.; ders. (1958) 302-352, hier 344-346; ausführlich WIRSZUBSKI (1950).

248 Gerade im Zusammenhang mit der kaiserlichen Gesetzesgebung tritt libertas deutlich hinter securitas zurück. Vgl. BLEICKEN (1975) 511f. Zum Vergleich zwischen CIL 6, 41389 und CTh. gest. in sen. $5 \mathrm{f}$. vgl. DELMAIRE (2008) 293.

249 Res gest. div. Aug. 1: [...] per quem rem publicam a dominatione factionis oppressam in libertatem vindicavit. Vgl. DELMAIRE (2008) 292; STICKLER (2002) 267 u. 269 f. und ausführlich ZECCHINI (1985) 124142; ferner TIERSCH (2015) 27-50, bes. 45-48; WELWEI (2004) 217 ff. und SCHEER (1971) 182-188.

250 Vgl. RAAFLAUB (1974) 158f.; ferner zur libertas senatus vgl. WIRSZUBSKI (1950) 160 - 166.

251 Zur Zusammengehörigkeit von moralischer Integrität (gemäß des mos maiorum) und politischen bzw. auch militärischen Leistungen vgl. STICKLER (2002) 270f. und NIQUET (2000) 151f. Auch im 
sen sich die Eigenschaften labor, fortitudo, pietas, clementia, modestia, iustitia und das Ideal der res publica ${ }^{252}$ mit der Person des Aëtius verbinden. Zumindest indirekt durch den anspruchsvollen Sprachgebrauch der Inschrift und seine antiquiert anmutende Formulierung ${ }^{253}$ erscheint der Geehrte überdies als ein Mann hoher Bildung. Dies alles wies Aëtius als hoch präsentablen Vertreter der pars melior humani generis aus und stilisierte ihn sozusagen zu einem vivum exemplum der von senatorischer Seite hochgehaltenen Tugenden.

Dabei erhält auch diese Aussage der Inschrift einmal mehr besonderen Nachdruck durch den gewählten Aufstellungsort. Die inhaltlichen Assoziationen der Inschrift mit dem Atrium Libertatis bleibt nicht auf die Wortassoziation vindex libertatis/libertas beschränkt. Dieser Ort ${ }^{254}$ war vordergründig dem Erhalt des mos maiorum verpflichtet und symbolisierte überdies das Bildungsideal der Senatsaristokratie. So wachten die Censoren $^{255}$ einst im Atrium Libertatis über die Sitten des römischen Volks (regimen morum $)^{256}$ und auch die erste öffentliche Bibliothek Roms fand hier ihren Platz. ${ }^{257}$ Die

panegyricus des Merobaudes auf Aëtius werden die militärischen Qualitäten (Merob. pros. frg. I A 21-24) den charakterlichen Vorzügen (frg. I B 9-13) zur Seite gestellt.

252 Die Werte labor, fortitudo und pietas sind vor allem den Zeilen 7-9 zu entnehmen, die auf die militärischen Leistungen abheben (labor/fortitudo) und betonen, dass dies zum Schutz Italiens (pietas; speziell als Treue/Hingabe gegenüber Italien und seinen Bewohnern) erfolgte. Die Werte clementia, modestia und iustitia werden in den Zeilen 13-15 thematisiert. Den Leitgedanken der res publica - dem Wohl des Gemeinwesens Vorrang vor dem Privatleben einzuräumen - trägt die Inschrift, die öffentlich Aëtius für seine dem Gemeinwesen erbrachten Leistungen Dank abstattet, insgesamt Rechnung.

253 Neben Wendungen wie vindici libertatis, pudoris ultor(i) (Z.14f.) oder dona militaria (Z. 5f.), die eher im senatorischen Traditionsbewusstsein als im zeitgemäßen Sprachgebrauch und realpolitischen Tagesgeschäft seine Anwendung fanden, steht die Inschrift der panegyrischen Dichtung des Merobaudes recht nahe; vgl. OLAJOS (1971) 469-472. Möglicherweise entsprach die Inschrift auch metrischen Vorgaben: secundo/consuli ordinario (Z 4f.) - trochäische Klausel; vgl. STICKLER (2002) 260 Anm. 1369.

254 Eine wichtige Grundlage für die Lokalisierung des Atrium Libertatis für die Zeit der Republik ist Cic. Ad Att. 4,16,14 und Suet. Galb. 19. Vgl. Überblickshalber KALAS (2015) 153-157 STICKLER (2002) 261f.; BAUER (1996) 12f.; ausführlich hinsichtlich der älteren Forschung, aber nicht auf neusten Stand, WELIN (1953) 180-197. Umstritten ist die genaue Lokalisierung des Baus: vgl. PURCELL (1993) 125-155 (Tabularium); CASTAGNOLI (1946) 282ff. (Caesarforum, später Trajansforum); ihm folgen u. a. COARELLI (1993a); ZANKER (1970) 522f.; LUGLI (1964); dagegen BAUER (1996) 12-14 (Curia Iulia/Atrium Minervae). Ein weiteres Problem betrifft die Baukontinuität: BAUER (1996) 14 spricht sich diesbezüglich für eine Rückführung vom Trajansforum aus; LUGLI (1964) 815 diskutierte dies bereits; allerdings vertreten einige Forscher, u. a. BONNEFOND (1979) 610, auch eine Kontinuität von der Republik bis zur Spätantike. Aktuell vgl. KALAS (2015) 153-155 und SPERA (2012) 133-141 (im Wesentlichen BAUER folgend).

255 Der letzte namentlich bekannte Censor ist Fl. Dalmatius (PLRE 1, $240 \mathrm{f}$. (Dalmatius 6); Athan. C. Ar. 65,1ff.), der Halbbruder Konstantin d. Gr., der dieses Amt jedoch wohl mehr der Ehre halber führte. 256 Liv. 43,16,13: censores [...] in atrium Libertatis escenderunt et obsignatis tabellis [...]. Vgl. ebenso Liv. 45,15,5 und ferner auch Liv. 39,41,4: zur Bewerbung des Cato als „Sittenhüter“. Eine vollständige Auflistung der Quellen bietet LUGLI (1965) 79-83, Nr. 436-465; ders. (1964) 807-815, hier 808-811 und CASTAGNOLI (1946) 276-291.

257 Im Jahr 39 v.Chr. gründet C. Asinius Pollio hier die erste öffentliche Bibliothek; so auch noch festgehalten in Isid. Orig. 6,5. Vgl. Suet. Iul. 44,4 u. Aug. 29; Plin. Nat. 7,115 u. 35,10. Unter Trajan wurde das Atrium Libertatis in die Nordwestapsis der Basilica Ulpia überführt (gemäß der Forma Urbis Romae 29b: 
Errichtung der Ehrenstatue des Aëtius in Atrio Libertatis lässt den Heermeister an einer Geschichte partizipieren, die bis auf die Censoren der römischen Republik zurückverweist und deren Bemühen um den Erhalt des mos maiorum kommemoriert. Entsprechend des historischen Vorbilds der Censoren konnte Aëtius vor Senat und Volk von Rom als Hüter der Sitten (censor morum) ${ }^{258}$ gelten. Der Patriziat, den Aëtius seit 435 führte, ${ }^{259}$ konnte mittels republikanischer Termini genauer definiert werden. Nicht mehr nur das besondere Nahverhältnis zum Kaiser, welches im Fall des Aëtius ohnehin problematisch war, sondern auch die Aufsicht über die moralisch-sittliche Integrität des ordo senatorius wurde offenbar auf den patricius übertragen.

Wie dies bereits Stickler richtig feststellte, „war der Senat keineswegs die bloße Manövriermasse in den Händen der Machthaber“260. Die Ehrung des Aëtius durch den Senat zeigt dies nur zu gut, denn am Ende konnte der Senat hierbei seine Interessen sehr gut zur Geltung bringen. Der ,starke Mann` lässt sich gerade durch die außergewöhnlich hohen Ehrenbezeugungen als Garant der securitas, libertas und des mos maiorum vom Senat in die Pflicht nehmen. Die hier erfolgte Ehrung trägt so auch den Charakter eines ,Koalitionsvertrags‘, auf deren Grundlage die Zusammenarbeit zwischen Aëtius und dem Senat zustande kommen konnte. ${ }^{261}$ Um 440 wusste der Senat offensichtlich genau um seinen politischen Wert. CIL 6, 41389 bleibt in diesem Punkt das, als was es bereits Bartoli ${ }^{262}$ auswies: ein bemerkenswertes Zeugnis für die politische Lebenskraft des spätrömischen Senats.

Der Horizont der Senatoren Roms beschränkte sich hierbei aber nicht allein nur auf den Senat und die Urbs aeterna. Diese Feststellung ist wichtig, um nicht den Senat nur als Organ städtischer Administration - als „organo dell'amministrazione cittadina“263 _ zu verstehen. Die in CIL 6, 41389 angeführte securitas Italiae wurde jedenfalls in Gallien erkämpft und belegt sehr wohl, dass das große Ganze - das Imperium Romanum - nicht vergessen wurde. Entsprechend gibt Merobaudes im panegyricus auf Aëtius für das Jahr 446 einen Bericht zur Gesamtlage des Imperiums. Natürlich erfolgte dies vorrangig, um die Leistungen des obersten Feldherrn angemessen zu würdigen. Doch auch strittige Aspekte, wie die Hunnen-Politik ${ }^{264}$ und die Vandalen-Frage ${ }^{265}$, erhielten hier eine

[L]IBERTA[tis]). Vgl. BAUER (1996) 12-14; LUGLI (1964) 809f. und CASTAGNOLI (1946) 284-287. Zur Funktionsvielfalt des Atrium Libertatis vgl. COARELLI (1993a) 133-135; LUGLI (1964) 811 und CASTAGNOLI (1946) 280-287.

258 Bereits Fl. Constanitus in CIL 6, 1749 (ILS 809): censor remuneratorque virtutum (alledings als Kaiser).

259 Fast. Merseb. s. a. 435.

260 STICKLER (2002) 272.

261 Ähnlich auch STICKLER (2002) 271: „sie formuliert eine Geschäftsgrundlage“.

262 BARTOLI (1948) 271-273.

263 DE FRANCISCI (1946/1947) 279; ähnlich STROHEKER (ND 1970) 62 und SUNDWALL (1915) 152; vgl. auch STICKLER (2002) 275.

264 Merob. Pan. 2,1-4: Danuvii cum pace redit Tanainque furore exuit et nigro candentes aethere terras Marte suo caruisse iubet; dedit otia ferro Caucasus et saevi condemnant proelia reges. Vgl. HEATHER 2(2010) 333f. und STICKLER (2002) $117 \mathrm{f}$. 
Rechtfertigung. Zunächst wird dabei der Eindruck erweckt, dass Hesperium regnum und damit der Geltungsbereich des Senats erstrecke sich vom Kaukasus bis zum Atlasgebirge. Aëtius selbst sei die alles ordnende Gewalt, die den Mächten des Chaos trotzte. An einem Schreckensszenario, in welchen sinistre Kreaturen der Unterwelt den Ton angeben, wird die Bedeutung des Aëtius als Retter gemessen. Gegen das Wüten Bellonas und Enyos $^{266}$ führt der Heermeister den Frieden herbei. ${ }^{267}$ Seit dem Jahr 442 bestand ein Friedensvertrag zwischen Rom und den Vandalen. ${ }^{268}$ Bereits im sogenannten Vertrag von Margus ${ }^{269}$ waren 434 die Interessensphären zwischen Westrom und den Hunnen abgesteckt worden.

Das Wort Friede hatte in den Ohren der versammelten Väter gewiss einen sehr ambivalenten Klang. Obwohl der Raub ihrer nordafrikanischen Besitztümer ${ }^{270}$ die großen stadtrömischen Familien, die Anicii ${ }^{271}$, Decii ${ }^{272}$ oder die Caeionii-Rufii ${ }^{273}$, nicht in die Armut trieb, war der Verlust schmerzhaft. Ein schneller Sieg oder ein stabiler Friede, doch keinesfalls ein langer Krieg mit ungewissem Ausgang, standen zur Debatte. Das Scheitern römischer Kriegsbemühungen ${ }^{274}$ zwang am Ende zum Frieden. Von diesem

265 Merob. Pan. 2,39f. u. 190 -195. Vgl. mit Übersetzung HEATHER ²(2010) 338-341.

266 Beide werden oftmals auch gleichgesetzt als Göttin des wütenden Krieges und der rücksichtslosen Vernichtung (Plut. Sull. 9,2); bei Claudian (Claud. Ruf. 1,89 und Claud. Eutr. 2,95-173) noch positiv konnotiert, führen sie den Sturz des Rufinus und Eutropius herbei. Vgl. SCHINDLER (2009) 180.

267 Merob. Pan. 2,39f. u. 190-195.

268 Vgl. auch Merob. Carm. 1,5-10 und Pan. 2, 24-29 (vgl. Prok. BV. 1,4,12-14; zum Friedensvertrag vgl. HEATHER ${ }^{2}$ (2010) 341f.; STICKLER (2002) 239f.; SCHULZ (1993) 92-95 oder CLOVER (1973) 104-117, bes. 107 f.; zum Text vgl. CLOVER (1971) $20 \mathrm{f}$. u. $51 \mathrm{ff}$.

269 Prisk. fr. 2 (Blockley); der Vertrag hat zwar Theodosius II. auf der einen und Attila und Bleda auf der anderen Seite als Hauptvertragspartner, durch die Anwesenheit des Aëtius wurden aber auch weströmische Belange verhandelt - i. B. die Konzessionierung der pannonischen Provinzen. Vgl. STICKLER (2002) 114f.; SCHULZ (1993) 94f. u. 111-122, bes. 112 mit Anm. 11 und VÁRADY (1969) 290 ff.

270 Zur Lage in Nordafrika im Vorfeld der Vandalen-Invasion vgl. DIESNER (1966) 31- 34 und COURTOIS (1955) 65-67. Aktuell vgl. u. a. WIJNENDAELE (2015) 74-78; BÖRM (2013) 67-72 oder HEATHER ²(2010) 306-317 mit Karte 10.

271 Die gens Anicia stammte ursprünglich aus Africa (Amm. 27,11,1) und besaß vor allem in der Africa Procunsularis ausgedehnte Besitzungen. Zur Verbundenheit der Anicier mit Nordafrika vgl. BRANDT (2014b) 97-108, hier 99f.; ferner WICKHAM (2005) 163; LANCON (2001) 64f. und bes. OVERBECK (1973) 23-30 u. 40. Vergleichbares trifft auch auf die Aradii zu. Vgl. PANCIERA (1986) 547-572.

272 Dies betrifft vor allem Fl. Albinus 10 (PLRE 2, 53), wohl mit Albinus 7 gleichzusetzen. Vgl. WEBER (1989) 493-497 (gleichgesetzt mit Albinus 7); MATTHEWS (1975) 360 und OVERBECK 1973, 22.

273 Die Verbindung der Caeionii-Rufii bzw. der gens Valeria zu nordafrikanischen Besitzungen (nahe Thagaste) ist u. a. durch Vit. Mel. Lat. XXI belegt; ferner bezeugen die im Haus der Valerier aufgefundenen Patronatstafeln CIL 6, 1684-1689 eine aufs engste mit Africa verbundene Ämterlaufbahn (u. a. praeses Byzacenae). Rufius Antonius Agrypnius Volusianus war bereits in sehr jungen Jahren Prokonsul in Africa (CIL 8, 25990) und unterhielt noch später, wie die Korrespondenz mit Augustinus (z. B. Aug. ep. 136) belegt, enge Kontakte. Vergleichbares trifft auch auf die gens Paulae zu; vgl. MATTHEWS (1975) 27f.; OVERBECK (1973) $41 \mathrm{f}$.

274 Prosp. Tiro 1344 (s. a. 441); Cassiod. Chron. a. 441 und Theoph. a. m. 5941. Die oströmischen Truppen, die sich zwecks der geplanten Invasion Nordafrikas auf Sizilien aufhielten und die Bewohner auch noch 
Frieden konnten die Senatoren Roms erhoffen, dass sich Geiserich langfristig in römische Strukturen einbinden ließ ${ }^{275}$ und hierdurch die senatorischen Besitzstände in Nordafrika ${ }^{276}$ geschützt blieben und für ihre Besitzer wieder zugänglich werden würden. Der vom Heermeister arrangierte Friede ${ }^{277}$ sollte am Hof und im Senat Zustimmung finden. Entscheidend für den Senat war hierbei auch, dass zumindest formal das Supremat der römischen Herrschaft ${ }^{278}$ weiter Gültigkeit besaß. ${ }^{279}$ Die kaiserliche Regierung war im Folgenden bemüht, für die ökonomisch stark in Mitleidenschaft gezogenen senatorischen Großgrundbesitzer Abhilfe zu schaffen. Dass diesbezüglich zahlreiche Gesetze erlassen wurden, die bis in die 450er-Jahre reichen, ${ }^{280}$ verdeutlicht, wie schwer die Senatsaristokratie durch den Verlust der Gebiete in Africa getroffen war. Die Steuerausfälle ${ }^{281}$ nahmen mittlerweile aber auch für den Fiskus kritische Ausmaße an, so dass

um ihre letzte Habe gebracht hatten, wurden 441 abgezogen. Vgl. HEATHER ${ }^{2}$ (2010) 338; STICKLER (2002) 238 und CLOVER (1966) 80-83.

275 In den letzten Jahren erfuhren Geiserich und das Diktum von der ,barbarischen Fremdherrschaft" (Vict. Vita hist. pers. 2,6: barbara dominatio) eine gewisse Revision; sein Bemühen um die Integration in römische Strukturen wird jüngst stärker hervorgehoben. Vgl. BÖRM (2013) 69f. u. 77 f.; HEATHER ${ }^{2}$ (2010) 455f.; ANDERS (2010) 189f. oder DEMANDT (2008b) 271-289, hier 282f.; WIRTH (1986) geht sogar so weit in Geiserich einen Sachwalter der theodosianischen Dynastie zu sehen.

276 Zum Fortbestand senatorischen Besitzes vgl. OVERBECK (1973) 58-62. Die Enteignungen bis 439 löschten sicherlich nicht den kompletten senatorischen Besitz aus. Gegen flächendeckende Verwüstung (Vict. Vit. Hist. pers. 1,2-4) und Enteignung senatorischen Besitzes spricht vor allem der archäologische Befund; vgl. CHRISTIE (2011) 1-3. U. a. Der Sarkophag von Lamta (wohl aus Italien importiert); vgl. WARLAND (2009) 293f. und BÉJAOUI (2009). Die prachtvolle Villa von Sidi Ghrib überstand das 5. Jh. und wurde erst im frühen 6. Jh. durch einen Brand zerstört; vgl. ENNABLI (2009) 234f. Zahlreiche einschlägige Beispiele sind dem hier angeführten Katalog des Badischen Landesmuseums Karlsruhe, Das Königreich der Vandalen (2009) zu entnehmen.

277 Das Aëtius der Architekt dieses Friedens war unterstreichen vor allem STICKLER (2002) 239f. und ZECCHINI (1983) 179f. Formal galt aber einzig Valentinian III. als Vertragspartner (im amicitia-Verhältnis); die amicitia betonend SCHULZ (1993) 92-95; EPP (1999) 176-233, bes. 194ff. Mit seinem Tod 455 konnte Geiserich den Vertrag von 442 als hinfällig betrachten.

278 Vgl. hier auch Merob. Carm. 1,5-10: ipse micans tecti medium cum coniuge princeps lucida ceu summi possi astra poli, terrarum veneranda salus: pro praeside nostro amissas subito flet novus exul opes; cui natura dedit, victoria reddidit orbem claraque longinquos praebuit aula toros.; eine Übersetzung bietet HEATHER 2(2010) 340 f.; vgl. hierzu MCEVOY (2013a) 269f.; CLOVER (1971) 16-18.

279 Zur untergeordneten Stellung Geiserichs gegenüber dem Kaiser vgl. ANDERS (2010) 453f.; CASTRITIUS (2007) 103f.; STICKLER (2002) 239; WOLFRAM (1990) 245; DEMOUGEOT (1979) 513; CLOVER (1966) 90 und DIESNER (1964) $183 \mathrm{f}$.

280 Nov. Val. 12 (443): Aussetzen der Steuer für betroffene Grundbesitzer; Nov. Val. 12,1-4: Regelung von Krediten; Nov. Val. 34,2 (451): Steuererlass für fünf Jahre; ferner Nov. Val. 1,2 (440/441?): Steuererleichterung für Sizilien; Nov. Val. 13 (21.6.445): für die Provinz Mauretania Sitifensis; vgl. HEATHER 2(2010) 342344; BARNISH (1986) 170 - 195, hier 176 oder JONES (1964) $462 \mathrm{f}$.

281 Unter Honorius wird das jährliche Steueraufkommen auf etwa 2,5 Millionen Solidi (STEIN) oder 350.000 Pf. Gold (ILUK) geschätzt (bei intaktem Reichsgebiet bis etwa 407); die Zahlen variieren stark und sind abhängig von den Schätzungen STEINs und ILUKs; vgl. STEIN (1928) 508-511 und ILUK (1985) 79103, hier 96 ff.; ersteren folgt NOETHLICHS (1998a) 1-31, hier 10 f.; letzteren folgt DEMANDT ²(2007) 285. Diese Zahlen können allenfalls als Orientierung dienen, bleiben jedoch problematisch. Ohne absolute 
es auf lange Sicht zwischen der Senatsaristokratie und dem Staat zwangsläufig zu einem harten Ringen um die verbliebenen Ressourcen kommen musste.

In Zuge dessen wurden bereits 441 sämtliche steuerliche Privilegien gestrichen. ${ }^{282}$ Statt von Vergünstigungen zu profitieren, war nunmehr diversen neuen Verpflichtungen nachzukommen. Der Bau und die Instandsetzung von Militärstraßen, die Waffenfabrikation und das Hochziehen der Mauern sowie die Versorgung des Heeres waren zu erledigen. ${ }^{283}$ Die Befreiung der senatorischen Grundbesitzer von der munera sordida ${ }^{284}$ war damit aufgehoben. Überdies wurden der Senatsaristokratie eine weitere Zahlungserhöhung aufgebürdet. So sollten, wie bereits unter Honorius, 30 Solidi als aurum tironicum $^{285}$ jährlich für den Unterhalt eines Soldaten gezahlt werden. Jedoch erfolgte nun eine Abstufung, welche die Begüterten - eben die Senatoren - zu einer Zahlung von 90 Solidi verpflichtete. ${ }^{286}$ Hinzu kam eine neue Abgabe auf An- und Verkäufe, das siliquaticum. ${ }^{287}$ All dies sollte der Bündelung der Kräfte dienen. Aëtius, der für viele dieser

Zahlen anzugeben, lässt sich erwarten, dass sich die Staatseinnahmen durch den Verlust der wichtigsten Provinzen Nordafrikas der schwierigen Lage in Spanien und den Verlust Britanniens um mehr als 50\% reduziert haben dürften; Nov. Val. 13 (445) veranschlagt für die verbliebenen Gebiete in Nordafrika so nur noch 1/8 des vorigen Steuersatzes, was einen Verlust von etwa 106.200 Solidi (HEATHER) bedeutete; vgl. HEATHER 2(2010) 346 und NOETHLICHS (1998a) 10f. Zum drastischen Rückgang der Steuereinnahmen vgl. HENNING (1999) 261 f.; ELTON (1996) 126f.; DIESNER (1989) 7-22, hier 13f.; KRAUSE (1987) 328 - 330; STEIN (1959) 342f.; ders. (1928) 509-511. Signifikant ist auch die Reduzierung des Solidi-Feingehalts von 99\% auf knapp 96\% Gold. Vgl. RIC 10 (1994) 5f. Zur Bedeutung der reichen nordafrikanischen Provinzen für den Ausgleich des Staatshaushaltes vgl. HEATHER 2(2010) 317-327; ferner OVERBECK (1973) 46f. 282 Nov. Val. 10,3 (20.02.441; hier vollständig): Haec enim superioris aetatis principes et divorum parentum nostrorum liberalitas inlustribus titulis redundantis opulentia saeculi minore aliorum possessorum pernicie conferebant: quod quamvis et tunc iniustum, tamen inter initia lenius videbatur; sub difficultate autem praesentis temporis non modo rei ipsius natura iniquum, sed et inpossibile paucis ac tenuioribus constat, qui multiplicato suae alienaeque functionis onere depressi procumbent penitus, nisi aliquando idoneorum societate respirent. Eine Übersetzung bietet HEATHER ${ }^{2}$ (2010) 345. Die Beschneidung von Finanzprivilegien beinhalten auch die Gesetze Nov. Val. 4 (440): Rücknahme aller bestehenden Sonderregelungen Steuerbefreiung bzw. Minderung; Nov. Val. 7,1 u. 7,2 (440 u. 442): gegen die Praxis der palatini beim Eintreiben der Steuern einen Prozentsatz für sich einzubehalten; Nov. Val. 6,3 (444): Aufhebung früherer Steuervergünstigungen. $\mathrm{Zu}$ denken ist hierbei an die Vergünstigungen in Nov. Val. 1,1 (438: Steuernachlass für Italien und Nordafrika) oder Nov. Val. 1,2 (440/441?: Nachlass für Sizilien); ferner CTh. 7,30,30 (413); CTh. 7,26,14 (412); CTh. 10,18,1 (412) und CTh. 7,27,13 (403) vgl. DELMAIRE (1977) 311-331, hier 319.

283 Vgl. Nov. Val. 10,3 und Nov. Val. 4 (440). Vgl. HEATHER ${ }^{2}(2010) 344$.

284 Zur munera sordida vgl. DRECOLL (1997) 261-263; SCHLINKERT (1996a) 125-127 und KRAUSE (1987) 319f.; vgl. ferner allgemein zu den munera senatoria jetzt auch LA ROCCA/OPPEDISANO (2016) 26-31. 285 CTh. 7,13,20 (410); zum aurum tironicum vgl. KARAGIANNOPOULOS (1958) 119-123, bes. 122.; zur Diskussion bezüglich der Organisation vgl. BRANDT (1988) 73-77 und ZUCKERMAN (1998) 79-139, bes. $125 \mathrm{f}$.

286 Nov. Val. 6,3 (14.7.444); hierzu auch Nov. Val. 13,3 (445). Vgl. auch NOETHLICHS (1998a) $11 \mathrm{mit}$ Anm. 29.

287 Nov. Val. 15 (Ende 444/445: De Siliquarum Exactionibus). Vgl. ANDERS (2010) 379; HENDY (1985) 627; BRANDES (2002) 24 u. 301; HENNING (1999) 261; HERZ (1988) 349; SCHNEIDER (1981) 100; JONES (1964) 205 u. 435 mit Anm. 60; zu Recht darauf verweisend, dass diese Steuer ob der mangelnden Kontrollmöglichkeiten weitgehend ineffektiv blieb. 
Erlasse sicherlich verantwortlich war, musste hierbei besonders auf eine konstruktive Zusammenarbeit mit dem praefectus praetorio Italiae ${ }^{288}$ setzen.

Zwei Amtsinhaber fallen hierbei besonders ins Auge: Petronius Maximus (PPO 439441) ${ }^{289}$ und Flavius Albinus (PPO 443-449) ${ }^{290}$. In ihnen zwei politische Antagonisten zu sehen, die in fiskalischen Fragen gegensätzliche Positionen vertraten, ist keineswegs eine neu geäußerte Vermutung. Bereits Zecchini ${ }^{291}$ wollte dies erkannt haben. So glaubte er, in Albinus einen Gegner des Aëtius zu erkennen, wohingegen Petronius Maximus ein Parteigänger des Heermeisters gewesen sein soll. Entscheidender ist aber wohl eher, wie die beiden Präfekten zueinanderstanden. Denn dass keiner der beiden die Feindschaft des Aëtius oder auch des Kaisers auf sich zog, belegt ihre ausgesprochen lange Amtszeit. ${ }^{292}$ Nichtsdestotrotz sind sie offensichtlich die Protagonisten zweier vollkommen konträr laufender politischer Programme. Dies wird ersichtlich, wenn die steuerlichen Gesetze in die richtige chronologische Reihenfolge gebracht und den entsprechenden Adressaten im Amt des praefectus praetorio zugeordnet werden:

maximale Ausschöpfung:

Nov. Val. 4 (440): ad Maximum.

Nov. Val. 7,1 (440): ad Maximum. ${ }^{293}$

Nov. Val. 10 (441): ad Maximum.

Nov. Val. 7,2 (442): ad Paterius.

Nov. Val. 2,3 (443): ad Albinum.

Nov. Val. 6,3 (444): ad Isidorum. ${ }^{294}$

Nov. Val. 15 (444/445): ad ...295 finanzielle Entlastung:

Nov. Val. 1,1 (438): ad Maximum.

Nov. Val. 1,2 (440/441?): ad Maximum.

Nov. Val. 12 (443): ad Albinum.

Nov. Val. 13 (445): ad Albinum.

Nov. Val. 34 (451): ad Firminum. ${ }^{296}$

Die Übersicht verdeutlicht zunächst den vorgenommenen politischen Kurswechsel sowohl 440 als auch 442. Im Zuge der Kriegsvorbereitungen erwies sich vor allem

288 Zur erweiterten Befugnis des PPO; der letzte entscheidende Erlass Nov. Val. 1,3 (5.3.450).

289 PLRE 2, 749 (Maximus 22).

290 PLRE 2, 53 (Albinus 10); wohl identisch mit Caecina Decius Aginatius Albinus (Albinus 7).

291 ZECCHINI (1983) 244ff.; zuvor bereits ders. (1981) $125 \mathrm{ff}$. und ders. (1980) $70 \mathrm{ff}$.

292 So auch STICKLER (2002) 298 und WEBER (1998) 491; entgegen ZECCHINI (1983) 246.

293 Nov. Val. 7,1 - wie auch folgend Nov. Val. 7,2 - betrifft vor allem die palatini und die Finanzverwaltung des CSL. Vgl. hierzu auch Kap. 3.3.

294 Gemeint ist vermutlich der CSL Isidorus 4 (PLRE 2, 628); hier bezüglich des aurum tironicum.

295 Hier fehlt der Adressat; da es sich aber um die Einführung des siliquaticum handelt und mit Nov. Val. 7,2 (442) - erneut bestätigt in Nov. Val. 7,3 (447) - die palatini wieder unter dem comes sacrarum largitionum standen, wird möglicherweise dieser in Nov. Val. 15 (444/5) mit der Steuererhebung beauftragt worden sein.

296 PLRE 2, 471 (Firminus 2); als PPO 449- 452 und patricius ist er nach Petronius Maximus und Albinus einer der am längsten amtierenden Prätorianerpräfekten und somit wohl ein Mann, der eng mit Aëtius zusammenarbeitete; da es sich bei Firminus vermutlich um einen Vertreter der gallischen Aristokratie handelt, soll dieser hier nicht weiter behandelt werden. Ob sich durch seine Ernennung eine wie auch immer geartete Zurückstufung der stadtrömischen Senatsaristokratie abzeichnet (so TWYMAN und ZECCHINI), bleibt zu bezweifeln; vgl. STICKLER (2002) 298f. mit Anm. 1549; schwierig ZECCHINI (1983) 251 mit Anm. 35 und TWYMAN (1970) $486 f$. 
Petronius Maximus in der Stellung des praefectus praetorio als hilfreich, die Senatsaristokratie finanziell stärker in die Pflicht zu nehmen. Vorher gewährte Steuervergünstigungen, die für Italien, Nordafrika und Sizilien ${ }^{297}$ galten, fielen 441 durch Nov. Val. 10 weg. Petronius Maximus wird in diesem Zusammenhang am ehesten als Vertreter eben jener Senatoren zu verstehen sein, die nach dem Fall Karthagos 439 die rasche Rückgewinnung des verlorenen Gebiets ganz oben auf die politische Agenda setzten. ${ }^{298}$ Die Pläne scheitern jedoch. Die oströmischen Truppen wurden zurückbeordert $^{299}$ und trotz weiterer Bemühungen im Jahr 441, die Kriegslasten allein zu stemmen, sah sich der Westen außerstande, den Feldzug zu führen. Die politische Ratlosigkeit lässt sich gut erkennen. Petronius Maximus scheidet 441 aus dem Amt, nachdem im Februar noch Nov. Val. $10^{300}$ auf den Weg gebracht wurde. Bis zum Amtsantritt des Albinus Mitte 443 lösen sich im schnellen Wechsel Anicius Acilius Glabrio Faustus (Aug. 442) ${ }^{301}$, Fl. Paterius (Sep. 442) ) $^{302}$ und Quadratianus (Mai 443) (303 $^{303}$ ab, was wohl einer Phase der politischen Umorientierung entsprach.

An dieser Stelle steht der von Merobaudes gepriesene Frieden von 442, der wohl zu Recht als radikaler politischer Kurswechsel anzusehen ist. Die Politik, die Petronius Maximus mitgetragen hatte, war gescheitert. Dieser durfte sich ehrenvoll als designierter Konsul für das Jahr 443 aus dem Amt zurückziehen. ${ }^{304}$ Erst mit Albinus schien dann wieder ein passender Amtsträger gefunden worden zu sein. Einiges spricht dafür, dass der neue Mann im Amt den vormals auf Krieg ausgerichteten Kurs und vor allem die starke finanzielle Belastung der Senatsaristokratie nicht mitgetragen hatte. Eine zugegebenermaßen sehr isolierte Nachricht Prosper Tiros zum Jahr $440^{305}$ berichtet von ei-

297 Nov. Val. 1,1 (438: für Italien und Nordafrika) und Nov. Val. 1,2 (440/441?: für Sizilien).

298 Bezeichnenderweise eskaliert der Konflikt zwischen Rom und den Vandalen auch unter der Herrschaft des Petronius Maximus. Vgl. Kap. 4.3.

299 Anlass hierfür bot vermutlich die Einfälle der Hunnen unter Attila in Thrakien ab 441. Vgl. zusammenfassend BÖRM (2013) 81-89; STICKLER (2007a) 67f. und ders. (2002) 115f.; ausführlich u. a. ALTHEIM (1975) 289-292; WIRTH (1967) 41-69, bes. 50 ff.; mit abweichender Chronologie vgl. SCHARF (1996c) 48-58.

300 Auffällig ist, dass Nov. Val. 10 - das am schärfsten formulierte Gesetz - noch vor der schiffbaren Saison herausgegeben wurde, was möglicherweise dafür sprechen könnte, dass für 441 noch immer ein Feldzug ins Auge gefasst wurde. Nov. Val.1,2 (440/441?), welches nicht genau zu datieren ist, trägt mit der Steuerentlastung für Sizilien vielleicht dem Umstand Rechnung, dass noch immer ein weströmisches Heer in dieser Region zu versorgen war.

301 PLRE 2, 452-454 (Faustus 8).

302 PLRE 2, 836 (Paterius 3); das an ihn gerichtete Gesetz Nov. Val. 7,2 (27.9.442) hebt die Weisungsbefugnis des PPO über die palatini wieder auf; was vermutlich mit dem Ende des ganz auf die Wehrkraftsteigerung ausgerichteten finanzpolitischen Kurses zu tun haben dürfte.

303 PLRE 2, 931 (Quadratianus 1); vermutlich mit Petronius Perpenna Quadratianus Quadratianus 2 identisch.

304 In der Tat finden wir ihn nach 442 nicht mehr in einem politisch wichtigen Amt; als weitere Ehrung wird ihm 445 allerdings noch der Patriziustitel zuerkannt.

305 Prosp. Tiro 1341 (s. a. 440): Defuncto Xysto episcopo XL amplius diebus Romana ecclesia sine antistite fuit, mirabili pace atque patientia praesentiam diaconi Leonis expectans, quem tunc inter Aetium et Albinum 
nem Zerwürfnis zwischen Aëtius und Albinus. Am naheliegendsten erscheint es, als Gegenstand des Streits Nov. Val. 4 anzusehen. Am 24. Januar erlassen war es das erste Gesetz, welches die Privilegien der Senatsaristokratie beschnitt und einen berechtigten Grund zum Protest bot. Sollte sich Albinus auf diese Weise bereits in den Jahren 440/441 in einer eher oppositionellen Haltung politisch profiliert haben, war er nach dem Frieden von 442 die bestmögliche Wahl, wenn es darum ging, den politischen Richtungswechsel authentisch und mit Nachdruck zu vertreten.

Dass hierbei nun die senatorischen Besitzstände durch gleich drei an Albinus adressierte Gesetze erneut eine Begünstigung erfuhren, entsprach gewiss ganz der finanzpolitischen Haltung des neuen praefectus praetorio. Natürlich begünstigten diese in erster Linie nicht etwa Italien, sondern die nordafrikanischen Provinzen und die aus den verlorenen Gebieten geflohenen Landbesitzer. Dies hatte immerhin schon Weber ${ }^{306}$ veranlasst, in Albinus einen Patron dieser Provinzen zu sehen, der ernsthaft bemüht war, die Verhältnisse dort so gut wie möglich in Ordnung zu bringen. Dies entsprach aber auch dem ökonomischen Interesse der stadtrömischen Senatsaristokratie, deren außeritalischen Besitzungen vor allem in Nordafrika ${ }^{307}$ lagen. Letzten Endes wird sich beides wohl gut ergänzt haben. Ein Mann, der sowohl für die nordafrikanischen Provinzialen eintrat als auch die Interessen der stadtrömischen Senatsaristokratie wahrte und beiderseitiges Vertrauen genoss, war nach 442 die denkbar beste Wahl.

Damit wurden jedoch jegliche Bemühungen der Jahre 440/441, die verbliebenen Ressourcen für den Staat zu bündeln, letztlich konterkariert. ${ }^{308} \mathrm{Im}$ Zweifelsfall wusste die stadtrömische Senatsaristokratie ihre ökonomischen Interessen zu wahren. Vielleicht etwas zu verfrüht gibt in diesem Zusammenhang Krause lakonisch zu bemerken:

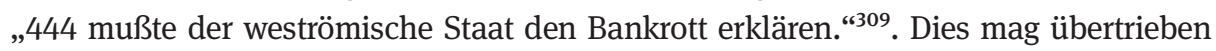
wirken, doch feststeht, dass der Staat weiter verarmte, während die reichsten der Senatoren ihren opulenten Besitzstand sich bewahren konnten. Salvian von Massilia bemerkte in seinem um 450 verfassten Werk De gubernatione Dei hierzu:

\footnotetext{
amicitias redintegrantem Galliae detinebant [...]; demnach im Sommer 440, etwa zwischen dem 19. August (Tod Sixtus III.) und dem 29. September (Wahl Leos). Vgl. hierzu aktuell auch MCEVOY (2013a) 285f.; SIVAN (2011) 146; ferner WESSEL (2008) 36f.

306 WEBER (1989) 496f.; hierin folgt ihm auch STICKLER (2002) 298.

307 So i. B. die Anicier und Caeioner-Rufier und Valerier.

308 So auch HENNING (1999) 261; die effektive Durchsetzung dieser Gesetze zogen bereits TWYMAN (1970) 481 und STEIN (1959) 342 in Zweifel.

309 KRAUSE (1987) 330; sich dabei auf den Wortlaut von Nov. Val. 6,3 (444) und Nov. Val. 15 (444/445) beziehend. Etwas nach hinten datiert und vorsichtiger formuliert MAIER (1968) 146: „Am Ende der Herrschaft Valentinians III. war der weströmische Staat praktisch bankrott.“ Vgl. ANDERS (2010) 379 (nach der Plünderung Roms 455); HENNING (1999) 264 (unter Avitus). Das Jahr 444 wird i. B. in der englischsprachigen Literatur angegeben; vgl. z. B. WACHER (ND 2002) 119 [1987] oder FRIELL/WILLIAMS (2005) 72.
} 
Da damals jene Magistraten arm waren, erhielten sie einen wohlhabenden Staat, jetzt aber lässt eine wohlhabende Amtsgewalt den Staat verarmen! ${ }^{310}$

In Anbetracht schwindender Ressourcen musste die Frage, Rom und Italien oder der ,Rest', zunehmend eine stärkere Rolle gespielt haben. Die stadtrömische Senatsaristokratie stand so der gallischen und selbst der oberitalischen Aristokratie bald genauso konkurrierend gegenüber wie der kaiserlichen Zentralgewalt, wenn es um die eigene Existenzsicherung ging. Dies wird aber erst nach 455 ganz zur Ausprägung kommen, wofür auf die von Anders, Henning und Schäfer ${ }^{311}$ durchgeführten Untersuchungen verwiesen werden kann.

Abschließend bleibt festzuhalten, dass die Entscheidungen und Ereignisse, die direkt oder indirekt mit der Person des Flavius Aëtius zu verbinden sind, in vielen Fällen zur weiteren politischen und gesellschaftlichen Destabilisierung des Westens beigetragen haben. Durch die bürgerkriegsähnlichen Umstände, die seinen Aufstieg begleiteten, ${ }^{312}$ wurde Nordafrika für Geiserich zur leichten Beute. Auf lange Sicht gelang es zwar dem Heermeister, den Einfluss des Kaisers und des „inneren Hofs“‘313 zurückzudrängen, was ihm die nahezu alles beherrschende Stellung sicherte. Doch hierzu musste er sich in starke Abhängigkeit zur stadtrömischen Senatsaristokratie begeben. Der eignen Machtbasis verpflichtet ließen sich die notwendigen Maßnahmen kaum konsequent durchsetzen. Die Senatsaristokratie Roms definierte so letzten Endes in erheblichem Maß den Handlungsspielraum des Aëtius.

\subsection{Zusammenfassung: Kaiser, Usurpatoren und Heermeister}

Kapitel III bis V befassten sich vor allem mit der politischen Bedeutung des Senats und der stadtrömischen Senatsaristokratie. Im Besonderen wurde nach der politischen Partizipation gefragt. Dabei wurden vor allem die Kaiser, Usurpatoren und Heermeister in den Blick genommen.

Mit dem Kapitel zur theodosianischen Dynastie gelang es zunächst, dem Herrscherprofil der Kaiser Honorius und Valentinian III. deutlicher als dies bisher in der

310 Salv. gub. 1,11: Itaque tunc illi pauperes magistratus opulentam rempublicam habebant, nunc autem dives potestas pauperem facit esse rempublicam. Vgl. auch Salv. gub. 6,43.; allgemein zur Sozialkritik im Werk Salvians vgl. BADEWIEN (1980).

311 ANDERS (2010) 283f. und HENNING (1999) 123 u. 163f.; zum Interessenkonflikt mit der oberitalischen bzw. ligurischen Senatsaristokratie im 5./6. Jh. vgl. SCHÄFER (1991). Zur Konkurrenz zwischen Gallien und Italien vor 454/455 vgl. ZECCHINI (1983) 239 und TWYMAN (1970) 484-487; wobei aufzupassen ist, dass man dem nicht zu viel Gewicht beimisst. Vgl. STICKLER (2002) 298 mit Anm. 1549. Hierzu auch Kap. 2.2.

312 Hierzu jetzt auch WIJNENDAELE (2015) $56 \mathrm{ff}$.

313 Dies betrifft vor allem das direkte Umfeld des Kaisers, welches sich nur schwer durch den Heermeister beherrschen ließ. Vgl. STICKLER (2002) 299f. Das Ringen um die Finanzverwaltung in den 440erJahren ist signifikant hierfür. Vgl. STICKLER (2002) 291-296 und TWYMAN (1970) 488ff. 
Forschung geschehen ist, Kontur zu verleihen. Die Untersuchung zum zweiten Rombesuch des Theodosius hat zwar dessen Historizität nicht zweifelsfrei beweisen können. Die Überlegungen zu Auftreten und Erscheinungsbild des Theodosius waren aber dennoch höchst aufschlussreich. Sie ließen zum Ausgang des 4. Jhs. noch einmal einen Herrscher erkennen, der militärisch siegreich vor Rom, den Senatoren und dem Klerus den consensus universorum befehlen konnte. Nach 394 sollte es im Grunde keinen Kaiser mehr geben, der es vermochte, dermaßen machtvoll Rom, dem Senat und seinen senatorischen Häusern gegenüberzutreten. Dabei verschob sich in der Folgezeit das politische Gewicht deutlich zugunsten der senatorischen Häuser und des Senats. Da es den Erben Theodosius' d. Gr. nie gelang, eine persönliche Bindung zum Heer aufzubauen, blieb als einzige soziale Gruppe, an der sich die Kaiser sowohl identifikatorisch als auch distinktiv ausrichten konnten, die Senatsaristokratie übrig. Daraus resultierte ein stark dem senatorischen Habitus und Werten verpflichtetes Herrscherverständnis. Darüber hinaus dürfte zum einen der Konflikt mit Konstantinopel in den Jahren bis 408 sowie die Dominanz Theodosius' II. ab 425 dazu geführt haben, dass sich das weströmische Kaisertum wieder verstärkt auf den politischen Wert Roms besann. Zum anderen zwang der Kontrollverlust über weite Teile des Westens und des daraus resultierenden Steuereinbruchs sowie die sich verkleinernde Rekrutierungsbasis der Administration den Kaiser und seine Regierung in eine starke Abhängigkeit zur italischen und stadtrömischen Senatsaristokratie. Die Kaiser konnten so die Wünsche der stadtrömischen Senatsaristokratie kaum ablehnen. Hierbei ließ sich die besondere Sorge (cura) der Kaiser für Rom nicht nur der Gesetzgebung entnehmen, sondern konnte auch an der verhältnismäßig großen Zahl an kaiserlichen Baumaßnahmen belegt werden.

In gewisser Weise traf dies auch auf die Usurpatoren der ersten Hälfte des 5. Jhs. zu, zumindest auf jene, die die Herrschaft in Italien antraten. Zwar ließ sich im engeren Sinne nur Priscus Attalus auch als „Senatskaiser“ auffassen. Bei den beiden anderen relevanten Usurpationen, der des Johannes Primicerius und der des Petronius Maximus, schien vor allem der Kaiserhof die Machtbasis dargestellt zu haben. Da aber die hohen Hofämter nun wieder häufiger von Angehörigen der stadtrömischen Senatsaristokratie bekleidet wurden und höchstwahrscheinlich auch der Senat für die Investitur und Herrscherlegitimation zumindest formal bemüht wurde, sind alle drei Usurpationen letztlich als zivil-senatorisch aufzufassen. Mitunter gab dabei die Regierung eines Attalus, Johannes und Petronius Maximus einiges Potenzial zu erkennen. Der Wille, eine selbstbestimmte Regierungstätigkeit zu entfalten und die Probleme des Reichs ernsthaft anzugehen, ließ sie zu mehr werden. Sie waren jedenfalls nicht nur ,Marionetten eines mächtigen Militärs. Entsprechend konfliktgeladen konnte das Verhältnis zwischen dem führenden Militär und dem erhobenen Herrscher sein. Im Fall aller drei Usurpationen dürften das mangelnde Nahverhältnis zum Heer und die fehlende Treuebindung ausschlaggebend für ihr Scheitern gewesen sein. Dass sich zweimal Konstantinopel und die theodosianische Dynastie behaupten konnten, hatte am Ende erheblich damit zu tun, dass sich die politischen Bündnisse und die primär zivile Machtbasis der Usurpatoren letztlich nicht als krisenbeständig erwiesen. Zwar ließ sich am Hof oder im Senat eine Mehrheit finden, welche die Herrschaft antragen konnte, doch musste dies nicht be- 
deuten, dass sich der Herrscher auch tatsächlich auf eine breite Basis von Unterstützern verlassen konnte.

Bezüglich des Senats als meinungsbildendes Gremium der Senatsaristokratie wurde dies besonders deutlich. Der Senat konnte sich zwar für einen Herrscher aussprechen, doch an dieses votum waren die senatorischen Häuser nicht zwingend gebunden. So zerfiel nicht selten die stadtrömische Senatsaristokratie, obwohl der Usurpator über die Stimmen der Senatoren verfügte oder sogar selbst aus dem Kreis der Senatoren Roms stammte, in ein Lager von Befürwortern bzw. Unterstützern und ein Lager von Gegnern. Es zeigte sich somit, dass der Senat als meinungsbildendes Gremium nicht mehr in der Lage war, die Senatsaristokratie in seiner Gesamtheit zu vertreten, schon gar nicht die des Westens, aber auch nicht die Italiens oder Roms. Hierdurch waren die Möglichkeiten des Senats, eine stabile Akzeptanz- und Machtbasis für die Usurpatoren zu schaffen, stark begrenzt.

Dennoch wurde der Senat auch von den Heermeistern umworben und je nach Stellenwert, den das Erbe Roms und (pseudo-)republikanische Traditionsbilder für die heermeisterliche Politik hatten, politisch eingebunden. Hier präsentierte sich der Heermeister nicht mehr nur als fähiger Feldherr an der Spitze des Heeres, sondern beanspruchte nun auch eine führende Rolle im Kreis der Senatsaristokratie und vor dem Senat. Dies ließ ihn in seiner Repräsentation zum ,Mann zweier Welten' werden. Die Heermeister erhielten hierdurch die Möglichkeit, sich durch den Senat beauftragen zu lassen und so faktisch auch eine Politik am Kaiser und dem Hof vorbei zu betreiben. Eben diese Politik, die die Heermeister seit Stilicho betrieben, sorgte dafür, dass der Senat nicht nur an Bedeutung, sondern auch an Selbstbewusstsein gewann. Der ,starke Mann' im Westen, der oberste Heermeister, konnte hier weit weniger stark auftreten als dies seine hohe Stellung und Machtfülle vielleicht nahelegen würde. Tatsächlich war er seiner Unterstützerschaft stark verpflichtet und musste seine Politik dementsprechend an senatorischen Interessen ausrichten. Verstärkt bauten die Heermeister so auch auf Amtsträger, die sich aus dem Kreis der stadtrömischen Senatsaristokratie rekrutierten. So fiel auf, dass gerade in senatsaristokratischen Kreisen die Akzeptanz gegenüber dem Regime des Heermeisters stark war und zu einer engen Zusammenarbeit geführt hatte. Die Notwendigkeit, einen ,starken Mann“ in Person des obersten Heermeisters zu haben, wurde durchaus erkannt. Dies musste umso mehr gelten, als die Kaiser Honorius und Valentinian III. offensichtlich nicht dazu imstande waren, dieser ,starke Mann` zu seien. Dementsprechend ließ sich beobachten, dass dem Heermeister seitens der senatorischen Amtsträger und des Senats eher noch mehr Verantwortlichkeiten angetragen wurden. Damit trugen am Ende auch die stadtrömische Senatsaristokratie und der Senat entscheidend dazu bei, dass der magister militum (et patricius) im 5. Jh. zu jener nahezu alles beherrschenden Zentralgestalt aufsteigen konnte. 